ARGONNE NATIONAL LABORATORY

9700 South Cass Avenue

Argonne, Illinois 60439

A SYMBOLIC DERIVATIVE-TAKER FOR A SPECIAL-PURPOSE LANGUAGE

FOR LEAST-SQUARES FITS

by

Marian Gabriel

Applied Mathematics Division

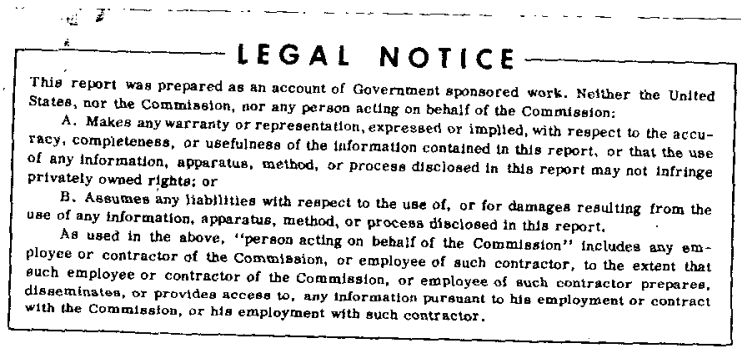

February 1970 


\section{DISCLAIMER}

This report was prepared as an account of work sponsored by an agency of the United States Government. Neither the United States Government nor any agency Thereof, nor any of their employees, makes any warranty, express or implied, or assumes any legal liability or responsibility for the accuracy, completeness, or usefulness of any information, apparatus, product, or process disclosed, or represents that its use would not infringe privately owned rights. Reference herein to any specific commercial product, process, or service by trade name, trademark, manufacturer, or otherwise does not necessarily constitute or imply its endorsement, recommendation, or favoring by the United States Government or any agency thereof. The views and opinions of authors expressed herein do not necessarily state or reflect those of the United States Government or any agency thereof. 


\section{DISCLAIMER}

Portions of this document may be illegible in electronic image products. Images are produced from the best available original document. 
$\bullet$ 
ABSTRACT。 . . . . . . . . . . . . . . . . . . 5

I. BASIC CONSIDERATIONS。 . . . . . . . . . . . . 5

II. THE SCANNING ROUTINES . . . . . . . . . . . . . 6

III. TRIPLE-HANDLING ROUTINES. . . . . . . . . . . . . 8

IV. DERIVATIVE-TAKING ROUTINES . . . . . . . . . . . . . 11

V. SIMPLIFICATION. . . . . . . . . . . . . 12

VI. CONCLUSIONS . . . . . . . . . . . . . . . . . . 13 APPENDIXES

A. Specia1-purpose Language for Least-squares Fits . . . . 14

B. Flow Charts for the Derivative-taker. . . . . . . 25

C. Listing of DERV . . . . . . . . . . . . . 56

D. Listings of Cataloged Procedures VMMCLG and VMMLG . . . . 69

E. Sample Function and Its Derivatives . . . . . . . . 71 ACKNOWLEDGMENT. . . . . . . . . . . . . . . . . . . 72 REFERENCES. . . . . . . . . . . . . . . . . 72 


\section{LIST OF FIGURES}

No。

Title

$\underline{\text { Page }}$

1. Production for $A^{* * B}$. . . . . . . . . . . . . . 9

2. Redefinition of Pointers after a Triple Is Dropped. . . . . . 9

3. Sorting of Triples by SC Value. . . . . . . . . . . . 10

4. Replacement of Constants in the Expression for the Derivative. 11

BI. Flow Chart 1, ANALYS. . . . . . . . . . . . . . 25

B2. Flow Chart 2, GTNAM . . . . . . . . . . . . . . 28

B3. Flow Chart 3, BACKUS. . . . . . . . . . . . . . . . 31

B4。 Flow Chart 4, MKTRPL。................... 36

B5。 Flow Chart 5, STPTRS。.................... 37

B6. Flow Chart 6, SHRINK. . . . . . . . . . . . . . 38

B7. Flow Chart 7, SORT. . . . . . . . . . . . . . 40

B8. Flow Chart 8, STORE .................... 41

B9. Flow Chart 9, REP . . . . . . . . . . . . . . 42

B10. Flow Chart 10, DRV Outline. . . . . . . . . . . . 44

B11. Flow Chart 11, DRV $(\mathrm{ST}, \mathrm{X})$. . . . . . . . . . . . 45

B12。 Flow Chart 12, RPLCNS (STR). . . . . . . . . . . 47

B13. Flow Chart 13, SIMP Outline ............... 49

B14. Flow Chart 14, SIMP . . . . . . . . . . . . . 50

B15. Flow Chart 15, CKOPN. . . . . . . . . . . . . . 54

\section{LIST OF TABLES}

No.

I. Operation of ANALYS (First Scan) on a Sample String . . . . . . 6

II. Operation of ANALYS (Second Scan) to a Sample String. . . . . 6

III. Arrays ELT and SIG for a Sample String. . . . . . . . . . . 7

IV。. Array BNF for A**B。 . . . . . . . . . . . . . . . 7

Vo Formation of the Production for $\mathrm{A} * *^{\mathrm{B}}$. . . . . . . . . . . 8

A.I. Symbolic Parameters and Default Values for VMMCLG and VMMLG . . 17 


\section{A SYMBOLIC DERIVATIVE-TAKER FOR A SPECIAL-PURPOSE LANGUAGE FOR LEAST-SQUARES FITS}

by

Marian Gabriel

\section{ABSTRACT}

This report describes a computer program for performing symbolic differentiation of FORTRAN formulas. The process by which formulas are analyzed, their analytic derivatives found, and the resulting derivative expressions simplified is described in detail。 A program listing and a sample output are included.

\section{BASIC CONSIDERATIONS}

This report describes a program that analyzes functions, defined by FORTRAN formulas, and produces FORTRAN expressions for their derivatives. The program was written to be a part of a special-purpose language for doing least-squares fits.l The curve-fitting program used Davidon's method, ${ }^{2}$ which requires partial derivatives of the function to be fitted, and thus the user had to supply FORTRAN expressions for these derivatives. Finding them for a complicated function is, at best, a nuisance. At worst, it is a common source of errors. It seemed desirable, therefore, to add a symbolic derivative-taker to the language. Within this language, the derivative-taker may be called by using the statement $D P N A M E=D E R V$, where PNAME is the name of a fitting parameter. (See Appendix A for a full description of the language.)

During the entire process of writing this special-purpose language, the emphasis has been on producing, as quickly as possible, reasonable programs that would be easy to use. No significant effort was directed toward making either the translators or the generated code maximally efficient. In writing the derivative-taker, the methods and language used were those that happened to be available. The programming was done in $\mathrm{PL} / \mathrm{I}$; text-scanning was done by the method given by Sheridan. 3

Since Sheridan's methods for handling user-defined functions and arrays are oriented more to assembly language than to $\mathrm{PL} / \mathrm{I}$, these two types of functions were excluded from the derivative-taker capabilities. These restrictions may be removed in the future.

This description of the derivative-taking program is divided into the following sections: scanning routines, triple-handling routines, derivativetaking routines, and simplification routines. Only a small part of the program, and of the description, is concerned with actually evaluating the derivative according to the rules of calculus. Most of the work lies in analyzing the structure of the FORTRAN formula so that these rules may be applied。 


\section{THE SCANNING ROUTINES}

The function whose derivative is required is passed to the derivativetaker by a statement of the form $D=D E R V(F C N, X)$. Here $F C N$ is a string of at most 1320 characters; $\mathrm{X}$ is a string of at most 6 characters.

First, DERV must separate this string into an array of names, constants, and operators, and indicate the hierarchy of the operations. Two routines, ANALYS and GTNAM, make a list of names, constants, and operators. The first of these, ANALYS, sets up arrays of bits to describe the characters of the string. ANALYS scans the string twice. On the first scan one of the three bits OPP (I), ALP(I), and NUM(I) is set to ' $I$ ' (or "true" or "on"), depending on whether the Ith character is an operator, a letter, or a digit or decimal point, respectively. The other two bits for the particular I are set to ' 0 '. For instance, for the string $5.2 \mathrm{E}+06 * \operatorname{EXP}((\mathrm{X} / \mathrm{Y}) * * 2$. $)+\mathrm{XI}$, Table I gives the values of OPP, ALP, and NUM for each character.

TABLE I. Operation of ANALYS (First Scan) on a Sample String

\begin{tabular}{rlllllllllllllllllllllllll}
\hline $\mathrm{I}$ & 1 & 2 & 3 & 4 & 5 & 6 & 7 & 8 & 9 & 10 & 11 & 12 & 13 & 14 & 15 & 16 & 17 & 18 & 19 & 20 & 21 & 22 & 23 & 24 & 25 \\
\hline CHARACTER & 5 &. & 2 & $\mathrm{E}$ & + & 0 & 6 & $*$ & $\mathrm{E}$ & $\mathrm{X}$ & $\mathrm{P}$ & ( & ( & $\mathrm{X}$ & $/$ & $\mathrm{Y}$ & ) & $*$ & $*$ & 2 &. & ) & + & $\mathrm{X}$ & 1 \\
OPP & 0 & 0 & 0 & 0 & 1 & 0 & 0 & 1 & 0 & 0 & 0 & 1 & 1 & 0 & 1 & 0 & 1 & 1 & 1 & 0 & 0 & 1 & 1 & 0 & 0 \\
ALP & 0 & 0 & 0 & 1 & 0 & 0 & 0 & 0 & 1 & 1 & 1 & 0 & 0 & 1 & 0 & 1 & 0 & 0 & 0 & 0 & 0 & 0 & 0 & 1 & 0 \\
NUM & 1 & 1 & 1 & 0 & 0 & 1 & 1 & 0 & 0 & 0 & 0 & 0 & 0 & 0 & 0 & 0 & 0 & 0 & 0 & 1 & 1 & 0 & 0 & 0 & 1 \\
\hline
\end{tabular}

On the second scan, one of the bits OP(I), $\operatorname{VAR}(\mathrm{I})$, or CONST(I) is set to ' 1 ' to indicate whether the $I^{\text {th }}$ character is an operator, part of the name of either a variable or a library function, or part of a number. This is done by examining the first character of the string following each operator. If the character is a letter, the string is a name; otherwise, it is a number. Table II gives the results of applying these rules to the sample string above. Here the characters ' $E+$ ' are treated as part of the number. Figure B1 of Appendix B describes ANALYS in flow chart form.

TABLE II. Operation of ANALYS (Second Scan) to a Sample String

\begin{tabular}{rlllllllllllllllllllllllllll}
\hline $\mathrm{I}$ & 1 & 2 & 3 & 4 & 5 & 6 & 7 & 8 & 9 & 10 & 11 & 12 & 13 & 14 & 15 & 16 & 17 & 18 & 19 & 20 & 21 & 22 & 23 & 24 & 25 \\
\hline CHARACTER & 5 &. & 2 & $\mathrm{E}$ & + & 0 & 6 & $*$ & $\mathrm{E}$ & $\mathrm{X}$ & $\mathrm{P}$ & ( & ( & $\mathrm{X}$ & $/$ & $\mathrm{Y}$ & ) & $*$ & $*$ & 2 &. & ) & + & $\mathrm{X}$ & 1 \\
$\mathrm{OP}$ & 0 & 0 & 0 & 0 & 0 & 0 & 0 & 1 & 0 & 0 & 0 & 1 & 1 & 0 & 1 & 0 & 1 & 1 & 1 & 0 & 0 & 1 & 1 & 0 & 0 \\
VAR & 0 & 0 & 0 & 0 & 0 & 0 & 0 & 0 & 1 & 1 & 1 & 0 & 0 & 1 & 0 & 1 & 0 & 0 & 0 & 0 & 0 & 0 & 0 & 1 & 1 \\
CONST & 1 & 1 & 1 & 1 & 1 & 1 & 1 & 0 & 0 & 0 & 0 & 0 & 0 & 0 & 0 & 0 & 0 & 0 & 0 & 1 & 1 & 0 & 0 & 0 & 0 \\
\hline
\end{tabular}

GTNAM assigns a name to each constant in the string S (FCN with blanks removed) and expresses $S$ as an array ELT, where each member of ELT is a name, an operator, or a name representing a constant. GTNAM also stores the constants in an array CONS and defines an array, SIG, of bits by setting SIG(I) to ' $I$ ' if ELT(I) is a name or a left parenthesis and to ' 0 ' otherwise. For the string above, the members of ELT and SIG would be as shown in Table III. The array CONS would have two elements, 5.2E+06 and 2. Figure B2 shows the flow chart for GTNAM. 
TABLE III. Arrays ELT and SIG for a Sample String

\begin{tabular}{rcccccccccccccc}
\hline $\mathrm{I}$ & 1 & 2 & 3 & 4 & 5 & 6 & 7 & 8 & 9 & 10 & 11 & 12 & 13 & 14 \\
\hline $\operatorname{ELT}(\mathrm{I})$ & $\mathrm{C} \$ 1$ & $*$ & $\operatorname{EXP}$ & ( & ( & $\mathrm{X}$ & $/$ & $\mathrm{Y}$ & ) & $* *$ & $\mathrm{C} \$ 2$ & ) & + & $\mathrm{X} 1$ \\
$\mathrm{SIG}(\mathrm{I})$ & 1 & 0 & 1 & 1 & 1 & 1 & 0 & 1 & 0 & 0 & 1 & 0 & 0 & 1 \\
\hline
\end{tabular}

BACKUS, the final routine in this section, creates the Backus normal form, which indicates the priority of operations in the string. The routine uses the method described by Sheridan. ${ }^{3}$ The Backus normal form indicates the "separation" between two operands by adding extra parentheses and operations. For instance, in a FORTRAN expression, the additions are performed last. Therefore, the operator ' + ' "strongly separates" two variables, and A+B becomes

$$
+(*(* *(\# A)))+(*(* *(\# B))) \text { ('\#' represents the action of a function). }
$$

In contrast, '**' indicates a "weak separation." The Backus normal form of $A * * B$ is

$$
+(*(* *(\# A) * *(\# B))) \text { 。 }
$$

For convenience in programming the next sections, the program BACKUS returns a two-dimensional array BNF with two columns. For a given I, either

(a) $\operatorname{BNF}(I, 1)$ is null and $\left.\operatorname{BNF}(I, 2)={ }^{\prime}\right)^{\prime}$ ',

or

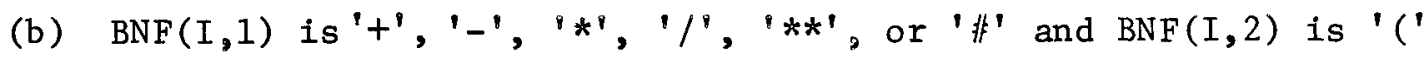
or a name.

The array $\mathrm{BNF}$ created by BACKUS for the string $\mathrm{A}^{* * B} \mathrm{~B}$ is shown in $\mathrm{Tab} l \mathrm{e}$ IV.

TABLE IV。 Array BNF for $A * * B$

\begin{tabular}{rcccccccccc}
\hline $\mathrm{I}, \mathrm{J}$ & 1,1 & 1,2 & 2,1 & 2,2 & 3,1 & 3,2 & 4,1 & 4,2 & 5,1 \\
\hline $\mathrm{BNF}(\mathrm{I}, \mathrm{J})$ & + & ( & $*$ & ( & $* *$ & ( & $\#$ & $\mathrm{~A}$ & $\mathrm{nul}$ \\
\hline $\mathrm{I}, \mathrm{J}$ & 7,1 & 7,2 & 8,1 & 8,2 & 9,1 & 9,2 & 10,1 & 10,2 \\
\hline $\mathrm{BNF}(\mathrm{I}, \mathrm{J})$ & $\#$ & B & nu11 & ) & nul1 & ) & nu1l & ) \\
\hline
\end{tabular}

Further details of BACKUS are given in Fig. B3。 


\section{TRIPLE-HANDLING ROUTINES}

Once $B N F$ has been established for the string, a number is assigned to each nonnul1 operation $(B N F(I, 1)$ ) and to the operand (BNF(I,2)) following it. This number depends on the number of left and right parentheses preceding the operation in the sequence of operations in the string. These numbers are calculated by counting left and right parentheses and constructing a list of triples, called a production, where each triple contains a number, an operation, and an operand. When all the numbers have been assigned, the triples corresponding to extraneous operations in the Backus normal form are dropped, and the remaining triples are listed in order of increasing number.

$\mathrm{PL} / \mathrm{I}$ 1ist-processing facilities are used extensively in this section. Each triple is represented by a based structure TRPL that contains the number, SC; the operation, DI; the operand, PSI; and a bit string SV. TRIPL also contains two pointers (UP and DOWN) to define its position in the production.

The first routine in this section, MKTRPL, allocates a triple for each nonnull $B N F(I, 1)$, sets $S V$ to ' $O$ ', and defines $S C$, DI, and PSI by the following method. Let $\mathrm{N}, \mathrm{A}$, and $\mathrm{C}$ be integers, and let $\mathrm{K}$ be a sequence of integers. As the Backus normal form is scanned from left to right, $N$ gives the total number of left parentheses that have occurred, A gives the difference between the number of left parentheses and the number of right parentheses, $C$ gives the hierarchy of the current operation, and $\mathrm{K}$ is a list of the previous values of $C$. Initially, $N=1$, both $A$ and $C$ are zero, and $K$ has no elements. For each I, SC, DI, PSI, then, N, A, C, and $\mathrm{K}$ are defined inductively by $\operatorname{BNF}(I, 1)$ and $\operatorname{BNF}(I, 2)$ according to the following rules:

1. If $\operatorname{BNF}(I, 2)$ is a left parenthesis, $S C=C, D I=B N F(I, 1)$, and PSI $=\mathrm{N}$. Now $\mathrm{K}$ becomes $\mathrm{K} \cup\{\mathrm{C}\} ; \mathrm{C}$ is set to $\mathrm{N}$; and $\mathrm{N}$ and $\mathrm{A}$ are each increased by 1 .

2. If $\operatorname{BNF}(I, 2)$ is a name, $S C=C, D I=\operatorname{BNF}(I, 1)$, and $\operatorname{PSI}=\operatorname{BNF}(I, 2)$. Then $\mathrm{K}, \mathrm{C}, \mathrm{N}$, and $\mathrm{A}$ all remain the same.

3. If $\operatorname{BNF}(I, 2)$ is a right parenthesis, $B N F(I, 1)$ is null, and TRPL is not allocated. $K$ becomes $K-\left\{C_{n}\right\}$, where $C_{n}$ is the last $C$ value added to $K$. $C$ becomes $C_{n}$, and $A$ is decreased by 1 . N remains fixed. Table $V$ illustrates the formation of the production for $A * * B$.

TABLE V. Formation of the Production for $A * * B$

( $\mathrm{SC}, \mathrm{DI}, \mathrm{PSI}, \mathrm{N}, \mathrm{C}, \mathrm{A}$, and $\mathrm{K}$ values are determined by the BNF values in the preceding column; " $\Lambda$ " indicates no value.)

\begin{tabular}{cccccccccccc}
\hline $\mathrm{BNF}(\mathrm{I}, 1)$ & $\mathrm{BNF}(\mathrm{I}, 2)$ & +( & $*($ & $* *($ & $\# \mathrm{~A}$ & ) & $* *($ & $\# \mathrm{~B}$ & ) & ) & $\Lambda$ \\
\hline SC & $\Lambda$ & 0 & 1 & 2 & 3 & $\Lambda$ & 2 & 4 & $\Lambda$ & $\Lambda$ & $\Lambda$ \\
DI & $\Lambda$ & + & $*$ & $* *$ & $\#$ & $\Lambda$ & $* *$ & $\#$ & $\Lambda$ & $\Lambda$ & $\Lambda$ \\
PSI & $\Lambda$ & 1 & 2 & 3 & $\mathrm{~A}$ & $\Lambda$ & 4 & $\mathrm{~B}$ & $\Lambda$ & $\Lambda$ & $\Lambda$ \\
N & 1 & 2 & 3 & 4 & 4 & 4 & 5 & 5 & 5 & 5 & 5 \\
$\mathrm{C}$ & 0 & 1 & 2 & 3 & 3 & 2 & 4 & 4 & 2 & 1 & 0 \\
$\mathrm{~A}$ & 0 & 1 & 2 & 3 & 3 & 2 & 3 & 3 & 2 & 1 & 0 \\
$\mathrm{~K}$ & $\Lambda$ & $(0)$ & $(0,1)$ & $(0,1,2)$ & $(0,1,2)$ & $(0,1)$ & $(0,1,2)$ & $(0,1,2)$ & $(0,1)$ & $(0)$ & $\Lambda$ \\
\hline
\end{tabular}


MKTRPL also calls STPTRS to set UP and DOWN. UP is set to null for the first triple and points to the preceding triple for all others. DOWN is null for the last triple and points to the succeeding triple for all others. Another pointer, HEAD, points to the first triple in the list; TAIL points to the last. For example, at the end of MKTRPL, the production for $A * * B$ would look as shown in Fig. 1. Since all values of SV are ' 0 ', they are omitted from the diagram. Figures $B 4$ and $B 5$ describe MKTRPL.

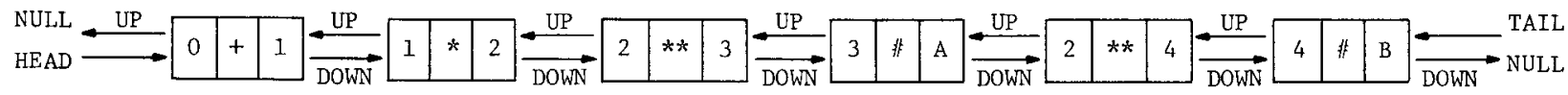
\begin{tabular}{|l|l|l|}
\hline$S C$ & DI & PSI \\
\hline
\end{tabular}

Fig. 1. Production for $A * * B$

The next routine, SHRINK, scans the list, starting with the triple at TAIL, and drops any triple whose SC value appears only once in the production, unless the DI value of the triple is ' - '. When a triple is dropped, its PSI value replaces the PSI of the triple immediately preceding it.

Two pointers, PT1 and PT2, are used to scan the list. PT1 moves from triple to triple, starting with TAIL and ending with HEAD. If PT1 $\rightarrow \mathrm{SV}^{*}$ is ' 1 ', PT1 is replaced by UP, so that PT1 now points to the preceding triple. Otherwise, PT2 moves from PT1 to HEAD.

If PT1 $\rightarrow \mathrm{SV}$ is ' 0 ', then the production is searched for SC values equal to PT1 $\rightarrow$ SC. This is done by making PT2 progress through the production, beginning with PTl and ending with HEAD.

For each value of PT2, a comparison of PT2 $\rightarrow$ SC is made with PT1 $\rightarrow$ SC; if they are equal, both $\mathrm{PT} 2 \rightarrow \mathrm{SV}$ and $\mathrm{PT} 1 \rightarrow \mathrm{SV}$ are set to ' 1 '. If no PT2 $\rightarrow \mathrm{SC}$ equals PT1 $\rightarrow$ SC, the entire triple addressed by PT1 is dropped unless PT1 $\rightarrow$ DI is ' 1 '. When a triple is dropped, the pointers UP and DOWN are redefined so that the list structure is preserved (see Fig. 2). Here the middle triple is to be dropped. The dotted lines represent the new values of the pointers UP and DOWN. SHRINK is described in Fig. B6.

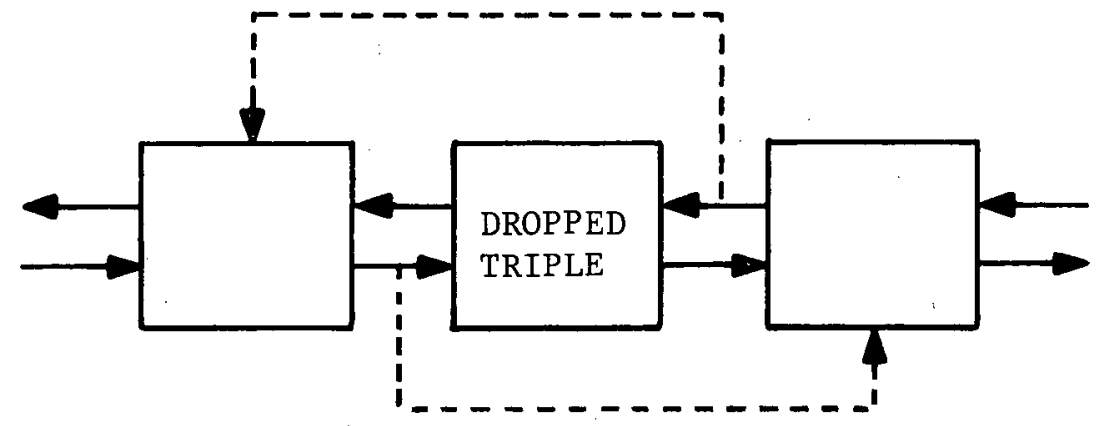

Fig. 2. Redefinition of Pointers after a Triple Is Dropped

*The notation 'PTI $\rightarrow$ SV' denotes the SV of the triple to which PTl points. 
Next, SORT arranges the triples in order of increasing SC. This sorting method depends on the fact that when a given SC value first appears in the list, it is greater than any SC preceding it. Thus, additional triples with the same SC can simply be placed behind the first one.

Always HEAD has an $S C$ value of 0 . The production is searched for other triples with $\mathrm{SC}=0$, which are placed immediately behind HEAD in the order in which they occur in the production. After all the triples with a particular SC have been resequenced, the process is repeated for the next SC value that is found. Figure 3 illustrates this process; the dotted lines give the triples after the resequencing. The triples have not actually been relocated in core, but their UP and DOWN pointer values have been redefined. Figure B7 shows this process in greater detail.

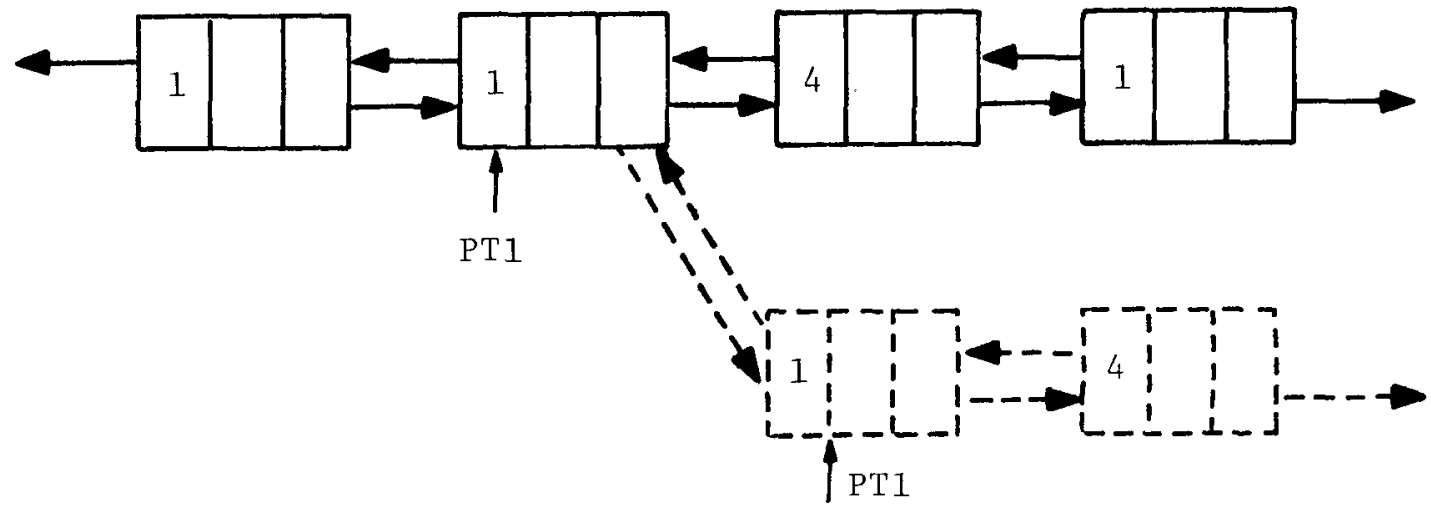

Fig. 3. Sorting of Triples by SC Value (PTl is the search pointer)

At this point, the reduced production may be organized as a list of segments, where a segment is the list of all triples with the same SC value. The operations in a segment are all performed at the same time in the evaluation of the string. Because the $\mathrm{PL} / \mathrm{T}$ list-processing facilities were not available when these derivative-taking routines were written, the following arrays are constructed for the segments. The segments are numbered in order of increasing SC, and $S(I)$ is defined as the $S C$ value of the $I_{\text {th }}$ segment. LS (I) gives the number of triples in the $I_{\text {th }}$ segment; OPR $(I, J)$, for $J=1$, ..., LS(I), gives the value of DI; and $\operatorname{OPND}(I, J)$ gives the values of PSI. Before core storage for these arrays is allocated, a procedure COUNT is called to find the number of segments and the maximum segment length. Once the arrays are allocated, a routine STORE assigns values to the array elements and releases the storage used by the triples (see Fig. B8).

A segment is now represented as a number $S(I)$ and arrays of operations $\operatorname{OPR}(I, J)$ and operands $\operatorname{OPND}(I, J)$. The $S(I)$ value is sufficient to identify a segment.

Last, CKRF defines an array RFX of bits such that RFX(I) is ' $I$ ' if for some $J, \operatorname{OPND}(I, J)=X$ or $\operatorname{OPND}(I, J)$ equals some segment $S(K)$ such that $\operatorname{RFX}(K)$ is ' 1 '. Otherwise $\operatorname{RFX}(I)$ is ' 0 '. This routine detects segments that have no references to $X$, and therefore do not need to be further analyzed. 


\section{DERIVATIVE-TAKING ROUTINES}

Three routines are used for the actual derivative taking: REP, which represents a variable or segment as a character string; DRV, which gives the derivative of a segment; and RPLCNS, which replaces the symbols C\$I by the actual constants. Both DRV and REP are recursive procedures. REP is straightforward, and can be understood from its flow chart (see Fig. B9) and its listing in Appendix $C$.

DRV solves the following problems. The routine examines sequences of the form <operand> <operator> <operand> and expresses the derivative of each such string in terms of the derivatives of the operands. Each operand that is not a name is further decomposed into a similar sequence. If an operand is a name, it is compared to $X$; then if the operand name is $X$, its derivative is set to 1.0 , and otherwise the derivative is set to 0.0 .

When a formula is evaluated, the first operations performed are in the segment $N$ with the largest $S(I)$ value. Within a segment, operations other than exponentiation are performed from left to right; exponentiation is performed from right to left.

In DRV this order is exactly reversed. Derivatives are taken starting with the first segment. If a segment contains no references to $X$ (i.e., $\operatorname{RFX}(I)$ is ' $0^{\prime}$ ), no analysis is done, and the string ' $0.0^{\prime}$ is returned for the derivative. Within a segment the rightmost operation, except for '**', is examined first. Each time DRV operates on a segment, the segment length is reduced by 1 . In a segment of length 1 , the operand $(\operatorname{OPND}(I, 1)$ ) replaces the segment in the next call of DRV. When the operation is ' $* *$ ', the operands $\operatorname{OPND}(I, 1)$ and $\operatorname{OPND}(I, 2)$ are examined first, and the first operand and operation are dropped first.

When the operation is '非 (the operation of a function), provision is made only for a FORTRAN library function with one argument, that is, a segment of length 2. A routine FNDFCN searches the list of these functions and returns the appropriate derivatives. See Figs. B10 and B11 for the details of DRV.

DRV returns a character string that gives the FORTRAN expression for the derivative, but with the constants represented as $C \$ I$, where $I$ is a positive integer. RPLCNS replaces these names by the actual constants. The replacement is done by scanning the string for the first occurrence of the characters ' $C \$$ '. When they are found, the string is divided into three sections: STRA is the part of the string before the C\$I. C\$I is the second section, and STRB is the part after the C\$I. C\$I is then replaced by the entry designated by CONS(I) (see Fig. 4). The process is repeated until

\begin{tabular}{|c|c|c|c|}
\hline Befor & STRA & $C \$ I$ & STRB \\
\hline
\end{tabular}

After RPLCNS

\begin{tabular}{|l|l|l|}
\hline STRA & CONS (I) & STRB \\
\hline
\end{tabular}

Fig. 4. Replacement of Constants in the Expression for the Derivative 
all occurrences of $C \$ I$ have been replaced by appropriate constants. The details of this process are shown in Fig. B12.

\section{SIMPLIFICATION}

RPLCNS returns a string DSTR, which constitutes a FORTRAN formula for the derivative of $F C N$ with respect to $X$. Even though segments containing no references to $X$ were not analyzed, this formula contains an enormous number of extraneous operations, such as multiplications by zero and one. SIMP and the routines called by it eliminate these operations.

First, DSTR is represented as a list of sorted triples, as described in Sections II and III. Then triples or groups of triples are dropped to eliminate most of the extra operations. When a segment is dropped, its SC value is eliminated from the production, and all PSI's that refer to that SC must be replaced.

The following rules determine which triples or segments to drop:

1. A triple with DI $=$ ' + ' or ' - ' and PSI representing 0.0 (i.e., of the form C\$I, where CONS $(I)=0.0$ ) is dropped. If the triple forms a segment of length 1 , PSI's that refer to the segment are replaced by the "name" of 0.0 .

2. A segment that contains a triple with $\mathrm{DI}=' *$ ' and PSI representing 0.0 is dropped. References are replaced by the "name" of 0.0 .

3. If a triple has DI $=' * *$ ' and PSI representing 0.0 , it and the part of the segment following it are dropped. If it is the first triple in the segment, PSI references to the segment are replaced by the "name" of 0.0 . If it is not the first triple, the PSI of the triple immediately preceding it is replaced by the name of the constant 1.0 , since $A * * 0.0=1.0$.

4. A triple with DI $=1 /$ ' and PSI $=$ the name of the constant 1.0 is dropped. A triple with DI $=' *$ ' and PSI the name of the constant 1.0 is dropped unless it is immediately followed by a triple in the same segment with $D I=' /$ '. In the latter case, the triples represent the operation 1.0/A, where A may be a variable, a constant, or a formula (given by another segment).

5. A triple with DI $=$ '**' and PSI = the name of the constant 1.0 is dropped. If it is in a segment of length 1 , PSI references to the segment are replaced by the "name" of 1.0 .

6. If two triples in the same segment have PSI's equal to the names of constants, the operation in the second triple is performed on the constants. The second triple is then dropped, the result of the operation is added to the list of constants if it is not already present, and the PSI of the first triple is replaced by the name of the resultant constant.

7. A segment of length 1 is dropped unless its DI is '-'.

The routine SIMP implements rules $1-5$ and calls CKOPN to implement 6 and CKLN to implement 7 . In SIMP, the triples are scanned, starting with 
the last one. Scanning is repeated until a scan occurs in which no triples are dropped. The first segment in the list is never dropped。 Figures B13 and B14 describe SIMP; Fig。 B15 describes CKOPN. CKLN is described by the listing in Appendix $C$ 。

The following "service routines" are also used to implement the above rates:

1. DTRPL drops a single triple, as determined by rule 1, 4, or 7 .

2. DRST implements rule 3 by dropping all of the segment after the occurrence of a ${ }^{*} * 0,0^{*}$ operation. It is also used for rule 5 when the '**1.0' operation is not the first triple in segment.

3. RPLRF replaces PSI references to a dropped segment by the name of the constant that replaces the segment.

4. DSG drops segments containing ' $* 0.0$ ' (rule 2 ), and segments containing ' $* * 1.0$ ' as the first triple (rule 5).

5. MKCONS(NUM) searches the list of constants for an occurrence of the constant NUM。 If there is some constant CONS(I) which is equal to NUM, the routine returns the character string C\$I. If there is no such CONS(I), the number of constants NCONS is increased by 1 and the character string C\$NCONS is returned. The effect of this routine is to avoid creating new names for constants that are equal to already-named constants.

\section{CONCLUSIONS}

The derivative-taker was tested with a number of formulas and was then incorporated into the special-purpose language for least-squares fits. A sample formula and its derivatives are shown in Appendix $\mathrm{E}$. The program finds these three derivatives in a minute and a half, and uses about half of the available fast core. Smaller formulas take less time and less core. Thus in the context of the language, the program provides a saving in user time and effort for a relatively small additional cost in machine time.

The derivative-taker is available only as a part of the language. Because IBM's FORMAC, which has a similar facility, is now available at Argonne, there are no plans for making this derivative-taker available as an independent program. 


\author{
APPENDIX A \\ Special-purpose Language for Least-squares Fits
}

Introduction

The purpose of the language is to allow a user who is unfamiliar with computers to make least-squares fits to a number of different functions. The user must define his symbols, give the function to be fitted, and list data points. The translator for the language will define an appropriate FORTRAN subprogram to be executed as part of a standard fitting procedure, Davidon's variable metric minimization program.

\title{
Description of the Input
}

\section{General Principles}

Input is on cards or card images. Unless otherwise stated, input may appear anywhere on a card.

The equals sign $\Leftrightarrow$ is used as a keyword. Thus, it should not be used except where specifically required.

Names may not begin with the letters I, J, K, L, M, or N, or end with the dollar sign (\$).

The word END, appearing in columns 1-3, indicates the end of a section of data or of a case.

2. Minimal Input

\subsection{Function Definition} routine FCN\$:

The translator uses the following cards to generate a FORTRAN sub-

2.1.1. A title identifying the function. This title must be the first card and is printed every time the program is run.

appear:

The following cards may be in any order, but all must

2.1.2. The symbol PARAMETERS=, followed by a list of parameter names, each having at most six characters. The names must be separated by commas. The list may occupy more than one card, but no name should appear more than once in the list.

2.1.3. The symbol IV=, followed by a list of the names of the independent variables. These names may have at most six characters each and must be separated by commas. The list may appear on more than one card, but no name should appear more than once in the list.

variable.

$$
\text { 2.1.4. The symbol } \mathrm{DV}=\text {, followed by the name of the dependent }
$$


2.1.5. The symbol DATA=, followed by a list of independent- and dependent-variable names in the order in which they appear in the data to be fitted. If weights are given, the word WEIGHT appears in the list. If error estimates are given, the word ERROR appears in the 1ist.

2.1.6. The explicit formula for the dependent variable. If DVNAME represents the name of the dependent variable, this appears as DVNAME = any valid FORTRAN formula. It may occupy more than one card, but if it does, no continuation marks of any kind may appear. The formula may contain the names of the independent variables and parameters. If a formula for the partial derivative of this function with respect to a parameter named PNAME appeared before this formula in the input, DPNAME, denoting this derivative, may also be used.

2.1.7. For each parameter, the partial derivative of the function with respect to that parameter. If $\mathrm{PNAME}$ is the name of the parameter, the statement DPNAME= DERV will call the derivative-taker. If the derivativetaker is not used, this derivative appears as DPNAME= any valid FORTRAN formula, which may contain names of parameters and independent variables. The DVNAME's and the DPNAME's may also be used if the appropriate formulas have already been given. The formula may occupy more than one card, but each derivative should start on a new card. Continuation marks are not permitted.

2.1.8. An end-of-section card, containing the word END in columns 1-3 and blanks in all other columns. This card must follow the functiondefinition cards.

\subsection{Required Data for Cases}

2.2.1. The first card must be a title card to identify the case. It is printed with the output for each case.

2.2.2. For the first case, an estimated value and, possibly, a standard deviation for each parameter. For cases following the first, only those values that differ from the first case need appear. Each parameter estimate must appear on one card.

One of the following forms is used:

2.2.2.1. If no standard deviation is specified, PNAME $=$ value.

In this case, a standard deviation of 0.1 of the value is assumed.

2.2.2.2. PNAME=value; standard deviation.

2.2.2.3. PNAME=value; CONSTANT。

In this form the value is held constant for the duration of the case.

2.2.3. After the estimates for the parameters have been given, an END card (with END in columns 1-3) must appear. 
2.2.4. The observed data to be fitted then follow. For each point, numbers must be in the order given in the statement DATA= (as specified in 2.1.5.). Each number must be separated from other numbers by at least one blank and may not contain embedded blanks.

2.2.5. Two END cards must follow the last data card. If more cases are desired, more sets of cards (starting with the case title) are included.

2.3. Job-control Cards Needed (to run on System/360/50/75 under MVT OS Release 17 with ASP monitor)

The cataloged procedures VMMCLG and VMMLG are listed in Appendix D。 2.3.1. To compile the FORTRAN subroutine FCN\$ and run one or more cases, the following job-control cards are needed:

$$
\begin{aligned}
& / / \text { EXEC VMMCLG } \\
& / / \text { GO.SYSIN DD * } \\
& \text { Data as described above } \\
& / *
\end{aligned}
$$

Punched cards containing the names of the parameters and other information are always produced in this process.

2.3.2. If the function to be fitted is complicated, the default region for the translator may not be large enough. The following job-control cards may be used to avoid this difficulty:

$$
\text { // EXEC VMMCLG, VMMREGN=nnnK, GOREGN=nnnK }
$$$$
/ / \text { GO.SYSIN DD * }
$$

Data as described in 2.1 and 2.2 above

$$
/ *
$$

Here "nnn" is a number not greater than 750. VMMREGN and GOREGN must have the same value.

2.3.3. To compile and run as above and to produce an object deck of the FORTRAN subroutine, the following job-control cards are needed:

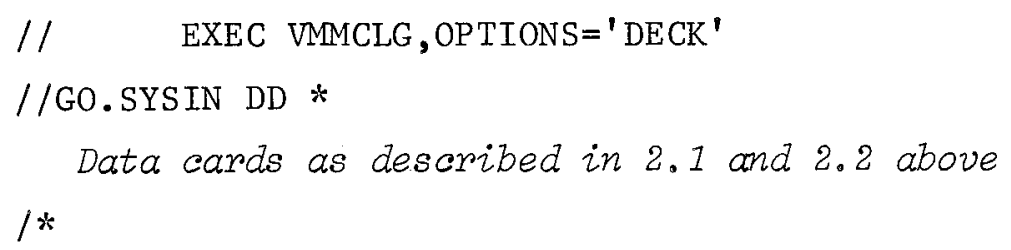

Under Release 17, two sets of punched output are provided by such a run. The first consists of

\subsubsection{Burst card.}


2.3.3.2. Two to five cards always obtained from the special-purpose compiler when a FORTRAN program is generated.

2.3.3.3. Burst card。

The object deck contains

2.3.3.4. Burst card.

2.3.3.5. Object deck for the generated FORTRAN subroutine FCN\$. This part of the punched output contains the characters FCN\$ in columns $73-76$ and a fourdigit sequence number, starting with 0000 , in columns 77-80.

2.3.3.6. Burst card.

Only the object deck is valid input to the linkage editor.

2.3.4. To execute the program using the object deck obtained in 2.3.3.5 the following cards are needed:

$$
\begin{aligned}
& / / \text { EXEC VMMLG } \\
& / / \text { EDT.SYSIN DD * } \\
& \text { Object deck from } 2.3 .3 .5 \text { above } \\
& / * \\
& / / \text { Go.sysin DD * } \\
& \text { Cards obtained in 2.3.3.2. } \\
& \text { Case definition data given under } 2.2 \text {. }
\end{aligned}
$$

\begin{tabular}{|c|c|c|c|}
\hline Parameter & Default Value & Procedure & Meaning \\
\hline VMMREGN & $350 \mathrm{~K}$ & VMMCLG & $\begin{array}{l}\text { Region size for dummy step } \\
\text { preceding the translation } \\
\text { step. Value must be greater } \\
\text { than or equal to GOREGN. }\end{array}$ \\
\hline \multirow[t]{2}{*}{ GOREGN } & $350 \mathrm{~K}$ & VMMCLG & $\begin{array}{l}\text { Region size for translation } \\
\text { step. }\end{array}$ \\
\hline & $260 \mathrm{~K}$ & VMMLG & $\begin{array}{l}\text { Region size for execution of } \\
\text { variable metric minimization } \\
\text { program. }\end{array}$ \\
\hline REGN & $260 \mathrm{~K}$ & VMMCLG & $\begin{array}{l}\text { Region size for execution of } \\
\text { FORTRAN compiler. }\end{array}$ \\
\hline
\end{tabular}

2.3.5. Table A.I. gives a list of the available symbolic parameters in VMMCLG and VMMLG and their default values.

TABLE A.I. Symbolic Parameters and Default Values for VMMCLG and VMMLG 
TABLE A。I. (Contd.)

\begin{tabular}{|c|c|c|c|}
\hline Parameter & Default Value & Procedure & Meaning \\
\hline \multirow[t]{2}{*}{ EDTREGN } & $260 \mathrm{~K}$ & VMMCLG & $\begin{array}{l}\text { Region size for execution of } \\
\text { the linkage editor. }\end{array}$ \\
\hline & $260 \mathrm{~K}$ & VMMLG & Same as for VMMCLG. \\
\hline RUNREGN & $260 \mathrm{~K}$ & VMMCLG & $\begin{array}{l}\text { Region size for execution of } \\
\text { the variable metric minimiza- } \\
\text { tion program. }\end{array}$ \\
\hline \multirow[t]{2}{*}{ EDTOPTS } & 'LIST, MAP' & VMMCLG & Linkage editor options. \\
\hline & 'LIST, MAP' & VMMLG & Linkage editor options. \\
\hline \multirow[t]{2}{*}{ LSIZE } & ' $(232 \mathrm{~K}, 100 \mathrm{~K}) '$ & VMMCLG & $\begin{array}{l}\text { Space available to the link- } \\
\text { age editor. }\end{array}$ \\
\hline & $'(232 \mathrm{~K}, 100 \mathrm{~K}) '$ & VMMLG & Same as in VMMCLG. \\
\hline OPTIONS & $\begin{array}{l}\text { None given; } \\
i_{0} e_{\text {, }} \text {, standard } \\
\text { system defaults }\end{array}$ & VMMCLG & FORTRAN compiler options. \\
\hline
\end{tabular}

3. Sample Case Using Minimal Input

Suppose it is desired to find the values of $a$ and $b$ that give the leastsquares fit of $y=a x+b$ to the following sets of data:

\begin{tabular}{|c|c|c|c|}
\hline Case 1 & $\mathrm{y}$ & $x$ & Error in $y$ \\
\hline & -1.0 & 0.0 & 0.02 \\
\hline & -0.8 & 0.2 & 0.03 \\
\hline & -0.25 & 1.0 & 0.01 \\
\hline & 0.4 & 2.0 & 0.04 \\
\hline & 1.2 & 0.3 & 0.03 \\
\hline & 1.9 & 4.0 & 0.02 \\
\hline & 2.6 & 5.0 & 0.01 \\
\hline Case 2 & $\mathrm{y}$ & $\mathrm{x}$ & Error in $\mathrm{y}$ \\
\hline & -1.0 & 0.0 & 0.01 \\
\hline & -1.4 & 1.0 & 0.01 \\
\hline & -1.8 & 2.0 & 0.02 \\
\hline & -2.2 & 3.0 & 0.03 \\
\hline & -2.7 & 4.0 & 0.06 \\
\hline
\end{tabular}

The entire input might look like this (each line is a card):

$J O B$ card

Accounting card

$1 /$ EXEC VMMCLG

//GO.SYSIN DD *

LINEAR FIT TO SAMPLE DATA 


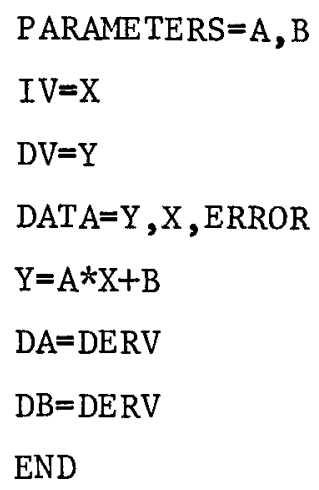

CASE 1

$A=.833$

$B=-1.0$

END

$\begin{array}{lll}-1.0 & 0.0 & 0.02 \\ -0.8 & 0.2 & 0.03 \\ -0.25 & 1.0 & 0.01 \\ 0.4 & 2.0 & 0.04 \\ 1.2 & 0.3 & 0.03 \\ 1.9 & 4.0 & 0.02 \\ 2.6 & 5.0 & 0.01\end{array}$

END

END

CASE 2

$A=-.4$

END

$\begin{array}{lll}-1.0 & 0.0 & 0.01 \\ -1.4 & 1.0 & 0.01 \\ -1.8 & 2.0 & 0.02 \\ -2.2 & 3.0 & 0.03 \\ -2.7 & 4.0 & 0.06\end{array}$

END

END

$/ *$

After an object deck for the FORTRAN subroutine has been obtained, the following input deck is used:

$J O B$ card

Accounting card

$/ / \quad$ EXEC VMMLG

//EDT.SYSIN DD *

object deck as described under 2.3.3.5. 
$1 *$

//GO.SYSIN DD *

Cards obtained in 2.3.3.2.

CASE 1

$A=.833$

$B=-1,0$

END

Data as before, ending with

END

END

$1 *$

4. Expanded Input

The following statements may appear in the function-definition section of the input. Except for the DATA=INSERT option, which replaces the DATA=list statement, these statements appear in addition to the functiondefinition cards described under "2. Minimal Input."

4.1. DATA FORMAT Option

A user may, if he wishes, give his own FORTRAN format for reading the observed data. The statement for specifying the format is

DATA FORMAT = any valid FORTRAN format.

The format may be continued on more than one card. The equals sign is optional here; the compiler supplies enclosing parentheses for the format. This statement causes information for each data point to be read according to the given format in the order specified in the statement DATA=list. This option is extremely slow. If at all possible, the format specification should be omitted or a DATA=INSERT option used (see 4.3 below).

\section{$4.2 \quad$ FORTRAN Inserts}

A user may extend the language by placing FORTRAN statements at six "breakpoints" in the subprogram, For instance, inserts can be used to read extra data, print information about the progress of the fitting procedure, fit a function that cannot be specified in a single statement, or plot results. Also, the code may be made more efficient by defining common subexpressions in inserts so that they are calculated only once.

\subsubsection{The inserts have the following form:}

$\underline{\text { Column }}$

1
Description

An integer from 0 to 5 indicating the placement of the insert ("C" for comment may also be included if it immediately follows a numbered insert)。 
$\frac{\text { Column }}{2-80}$

Description

Valid FORTRAN statement。 To avoid duplicate statement numbers, user's statement numbers should be between 100 and 999 . User's names known to the program are the names of the dependent variable, independent variables, and parameters. D followed by a parameter name is the derivative of the user's function with respect to that parameter. All other names should be defined by the user. No name may end with \$.

When the card image is inserted by the translator, the integer in column 1 is replaced by a blank. The rest of the card image is not changed in any way.

\subsubsection{The six inserts are as follows:}

Insert Leve1

0

1

2

3

\section{Placement and Contents}

These cards are placed between a DIMENSION and a DATA statement, and therefore must contain similar nonexecutable statements.

These cards are placed immediately after the reading of the fitting data and are executed only once for each case. Extra data may be read here. If extra data are present, they must appear immediately before the last END statement. If information about the progress of the fitting procedure is desired, the statement "NSSWI\$=1" may be included as a leve1 1 insert. Then the sum of the squared residuals, the values of the fitting parameters, and the values of the derivatives of the sum with respect to each parameter are printed for each iteration of the Davidon procedure. This printout is explained in Refs。, 2 and 4 。

This set of statements is executed once each time FCN\$ is called. It precedes the loop defining the sum of the squared residuals and its first partial derivatives.

These statements are internal to the loop that defines the sum of the squared residuals. Their exact placement depends partly on the order, relative to the function definition and derivative statements; in which they appear in the input. Thus,

$$
\begin{aligned}
& 3 \mathrm{P}=\operatorname{EXP} \quad(\mathrm{Z} * 5 \circ) \\
& \text { DVNAME }=\mathrm{P}+2 \\
& \mathrm{DZ}=5 。 \mathrm{P}
\end{aligned}
$$

$$
3 \mathrm{Q}=5 .+6 。 * \mathrm{~A}
$$

is compiled as

$$
\begin{aligned}
& \mathrm{P}=\mathrm{EXP} \quad(\mathrm{Z} * 5 \circ) \\
& \mathrm{Y} \$=\mathrm{P}+2 。 \text { (for dependent variable definition) } \\
& \mathrm{GGG}(1)=5 . * \mathrm{P} \text { (if } \mathrm{Z} \text { is the first parameter) } \\
& \mathrm{Q}=5 .+6 . * \mathrm{~A}
\end{aligned}
$$


Insert Leve1

3

(Contd.)

4

5
Placement and Contents

In any case, however, cards for Insert 3 appear before the sum of the squared residuals and the derivatives of the sum are defined. The statements $\mathrm{DVNAME}=$ and $\mathrm{DPNAME}=$ may be omitted from the function definition if the value of the function and its partial derivatives are given with Insert 3 cards。

Inserts are not analyzed by the derivative-taker. Therefore, if it is called, they should be used cautiously. In the example above, for instance, the statement "DZ=DERV" would give the erroneous result "GGG\$(1)=0.0."

These inserts appear after all calculations and printing for a case are completed. The statements are executed once for each case.

If results are to be plotted, calls to plotting subroutines appear as level 4 inserts.

These statements are the last to appear in the generated program (except for RETURN and END and also some formats). They are executed once after all the cases have been completed. If plotting routines have been called, the buffers are cleared with an insert at level 5 .

4.2.3. Inserts of a particular level appear in the code in the same order they appeared in the input stream. For example, suppose the following cards appear in the input:

$\begin{array}{ll}1 & \text { LEVEL } 1, \text { CARD } 1 \\ 2 & \text { LEVEL 2, CARD } 1 \\ 1 & \text { LEVEL } 1, \text { CARD } 2 \\ 3 & \text { LEVEL } 3, \text { CARD } 1 \\ 3 & \text { LEVEL } 3, \text { CARD } 2 \\ 2 & \text { LEVEL 2, CARD } 2\end{array}$

These appear as follows:

Block of code preceding place for Insert 1

LEVEL 1, CARD 1

LEVEL 1, CARD 2

Code between place for Insert 1 and place for Insert 2

LEVEL 2, CARD 1

LEVEL 2, CARD 2

Code between place for Insert 2 and place for Insert 3

LEVEL 3, CARD 1

LEVEL 3, CARD 2

Rest of code 
Insert cards may appear anywhere in the function definition section after the title and before the END card.

4.2.4. Because of the way the job steps are organized and the data processed, the stepname of the job step in which the Davidon procedure is actually executed is different in the procedures VMMCLG and VMMLG. Thus, DD cards that refer to extra data sets used on these inserts will have DDnames qualified by different stepnames in the two procedures. For example, suppose plotting is desired. The deck structures, including a DD statement for a Calcomp tape, are as follows.

\subsubsection{To generate a FORTRAN code and execute:}

$/ *$ SETUP DDNAME $=$ PLOTTAPE , DEVICE $=2400-7, \mathrm{ID}=($, , SAVE , NL $)$

$/ /$ EXEC VMMCLG

$/ /$ GO.SYSIN DD *

Data to generate FORTRAN code and execute

$1 *$

//RUN.PLOTTAPE DD DSNAME $=P L O T 780, D I S P=(N E W, K E E P), \quad C$

$/ / \quad \operatorname{UNIT}=(2400-2,, \mathrm{DEFER}), \mathrm{LABEL}=(, \mathrm{NL})$

$/ *$

generated FORTRAN code:

4.2.4.2. To execute, using an object deck for the

/ *SETUP DDNAME $=$ PLOTTAPE, DEVICE $=2400-7, \mathrm{ID}=($, , SAVE , NL $)$

// EXEC VMMLG

//EDT.SYSIN DD *

object deck

$/ *$

//GO.PLOTTAPE DD DSNAME $=\mathrm{PLOT} 780, \mathrm{DISP}=(\mathrm{NEW}, \mathrm{KEEP}), \mathrm{C}$

// UNIT $=(2400-2$, , DEFER $), \mathrm{LABEL}=(, \mathrm{NL})$

//GO.SYSIN DD *

Data as appropriate for executing the program using an object deck

$1 *$

Thus, for a compilation the stepname is RUN, and cards referring to it follow the data. For execution from an object module, the stepname is GO, and cards referring to it immediately precede the data.

\subsection{DATA=INSERT Option}

A programmer may use Insert 1 cards to write his own READ statements for the observed data by replacing the statement DATA=list with the statement DATA=INSERT. DATA=INSERT causes the translator to omit the usual 
FORTRAN statements for reading the observed data. The parameter estimates and case title are, however, read as usual. The number of data points is set to 1000 and read by the statement "READ(IN\$,1002)ND\$." Thus if the programmer wants to read the number of data points, he must include an appropriate READ statement in the insert. Some variable names that may be useful in programming the appropriate READ statements are
IN\$
Input "tape number"--set to 5.
ND\$
Number of data points--set to 1000 .
YD\$ (I)
Value of the dependent variable for the Ith data point. This array is dimensioned by 1000 .
$\mathrm{XD} \$(\mathrm{~J}, \mathrm{I})$
Value of the $\mathrm{J}^{\text {th }}$ independent variable for the Ith data point. $J$ is determined by the variable's position in the list following $\mathrm{IV}=$. This array is dimensioned $\operatorname{XD} \$(20,1000)$.
$W \$(I)$ Weight of the Ith data point. This array is dimensioned
WS(1000).

When the DATA=INSERT option is used, only one END card follows the data for each case. 
APPENDIX B

Flow Charts for the Derivative-taker

Block Number

1

$2-3$

4

5

6

$7-8$

$10-11$

12

13-14

15
DCL S CHAR (1320)

VAR EXTERNAL;

$\mathrm{S}=\mathrm{STRNG}$;

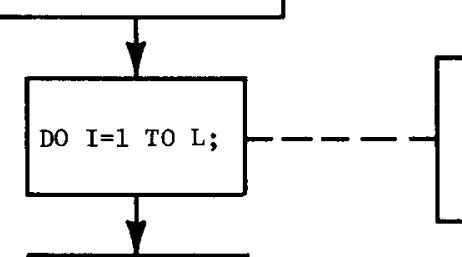

Classify each character

in $S$ as a letter, a digit

or period, or an operator

$\mathrm{CH}=\mathrm{SUBSTR}$

$(S, I, 1)$

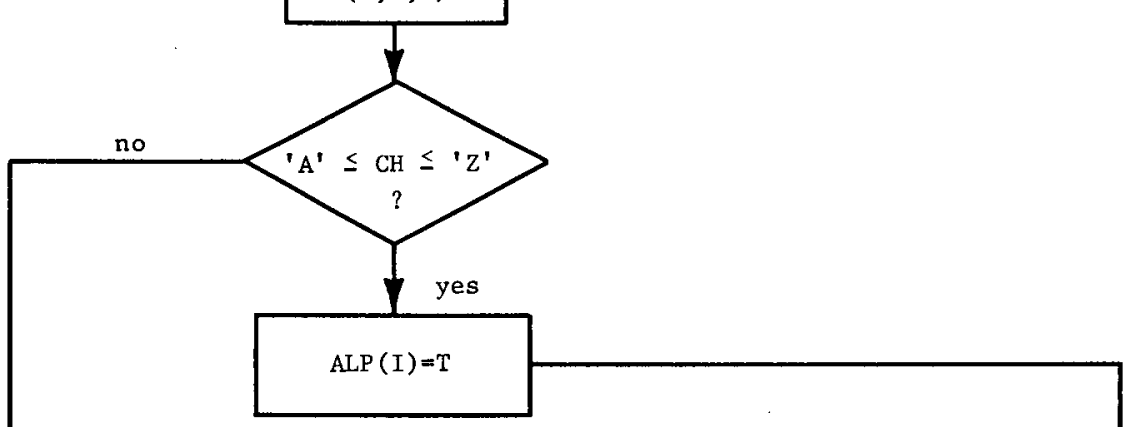

DO $K=1$ TO NOPS

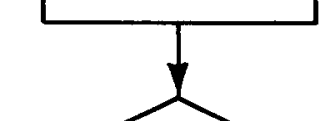

$\mathrm{CH}=\mathrm{OPN}(\mathrm{K})$
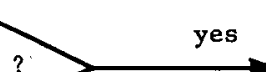

$\operatorname{OPP}(\mathrm{I})=\mathrm{T}$

no

END
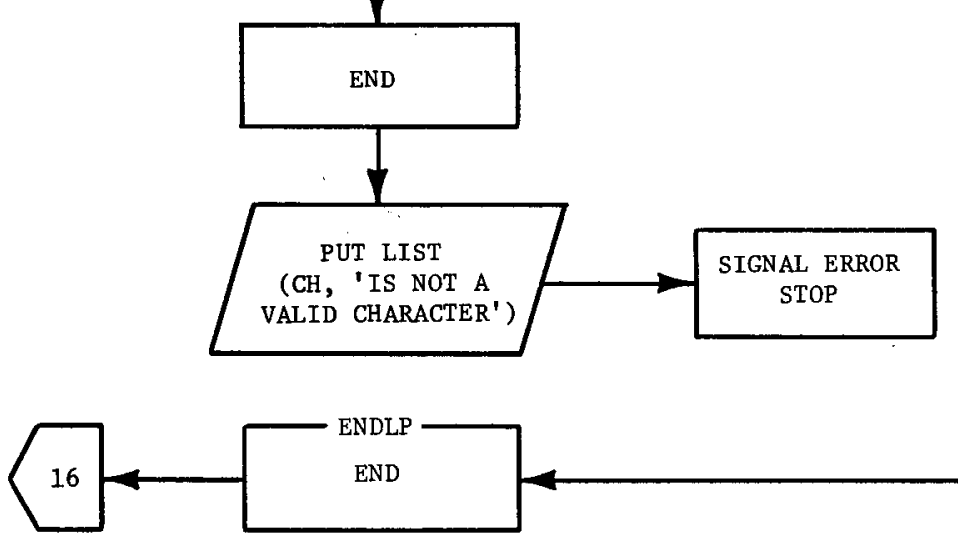

Fig. BI

Chart 1 ANALYS

$\operatorname{NUM}(I)=T$

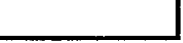


Block Number

$16-17$

18

19

20-21

22

23

$24-25$

26-27

28-29

$30-31$

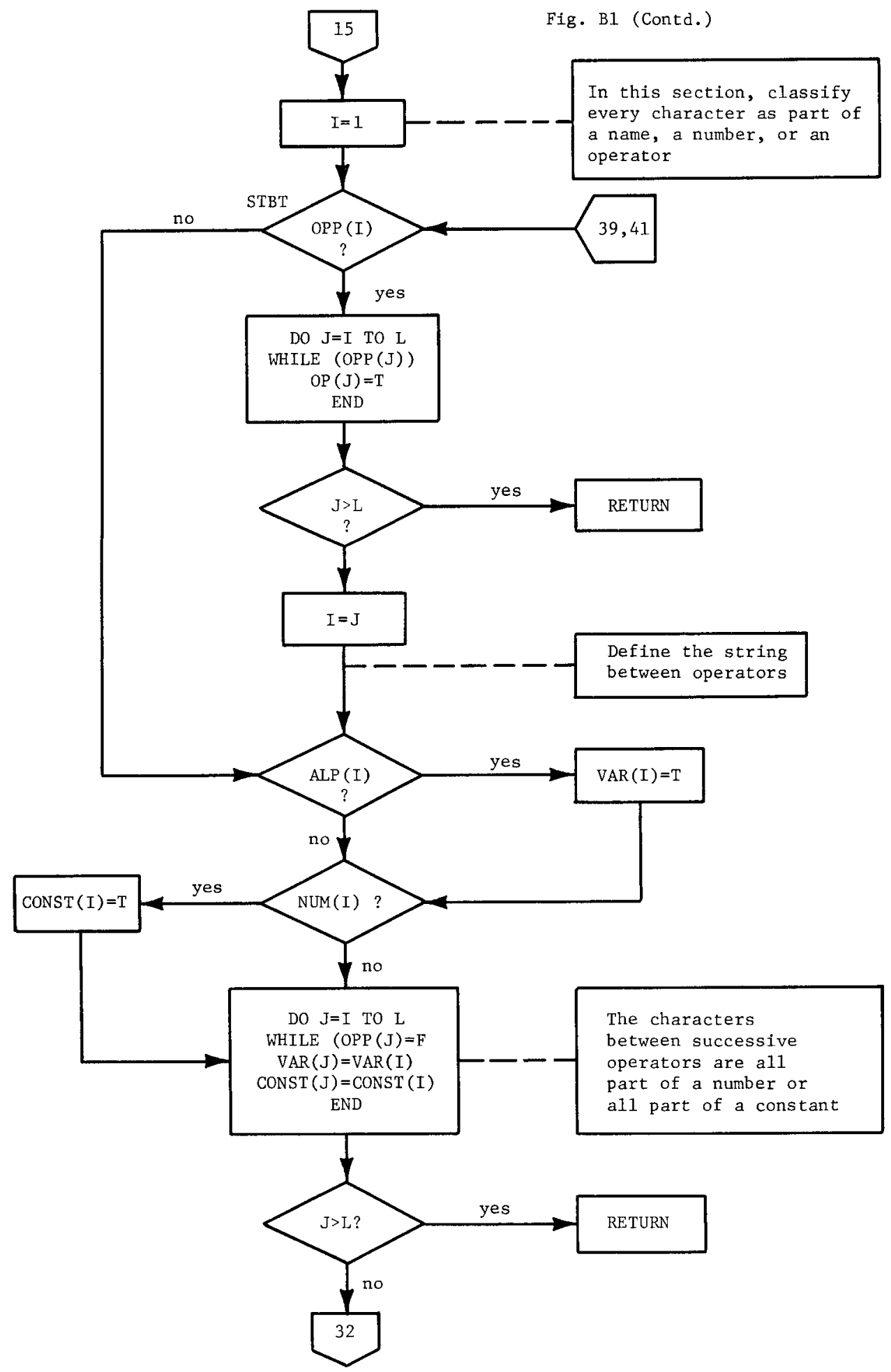


Block Number

Look for

floating

point con-

stants

written like

$5.2 \mathrm{E}+06$

$\operatorname{OPP}(J)=T$ here

34

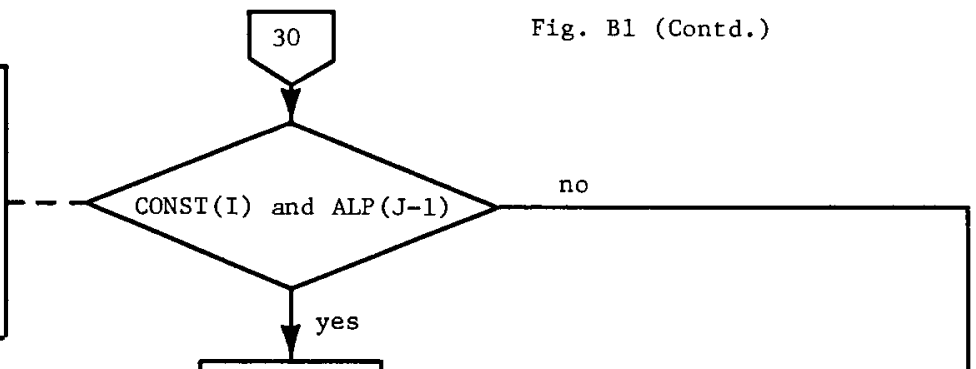

$35-36$

$\mathrm{CH}=$ SUBSTR

$(\mathrm{S}, \mathrm{J}-1,1)$

37

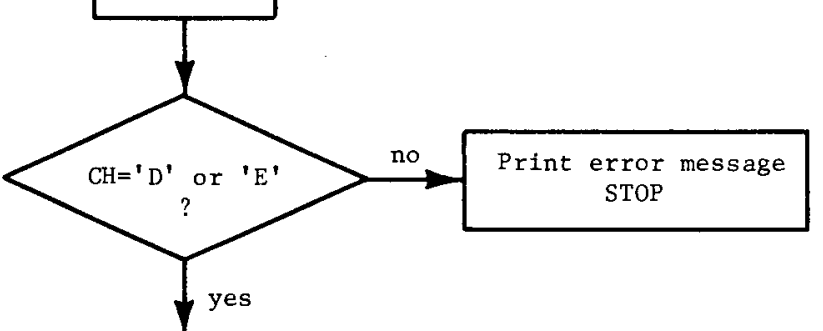

38-39

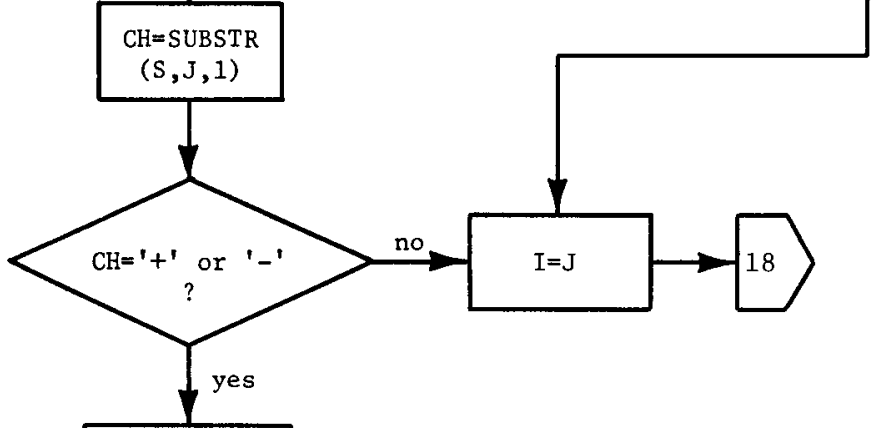

40
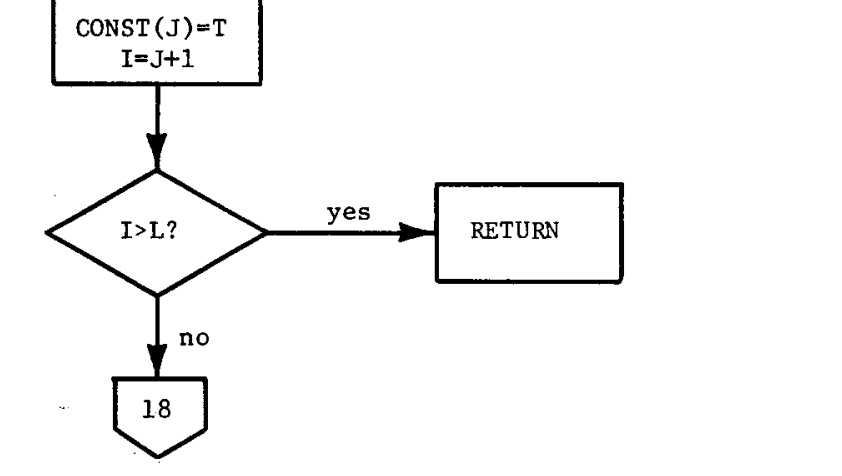

41-42 
Block Number

1

4

5

6

$7-8$

9

$10-11$

12

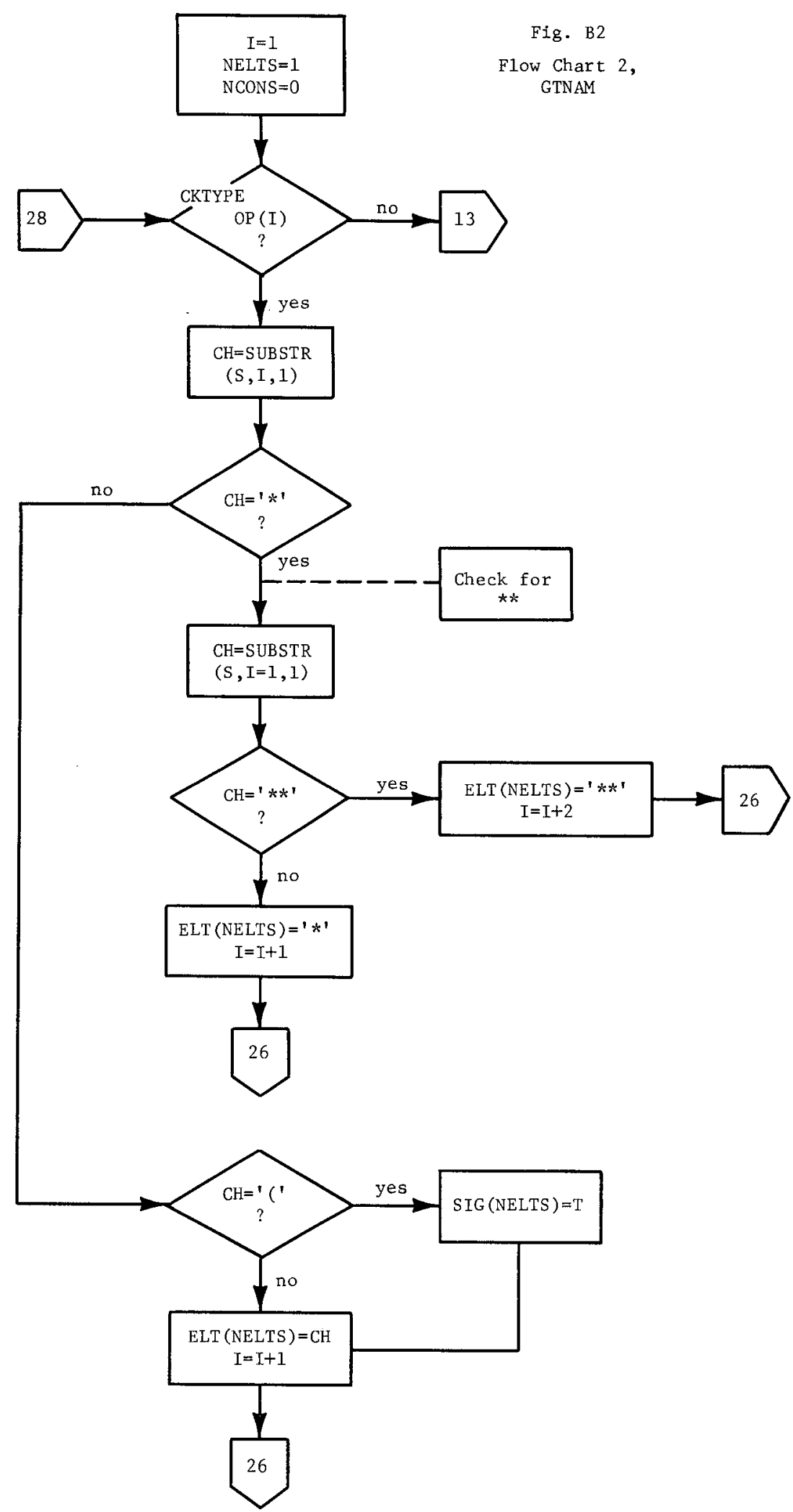


Block Number

13

14

15

$16-17$

18

19

20

$21-22$

23

24

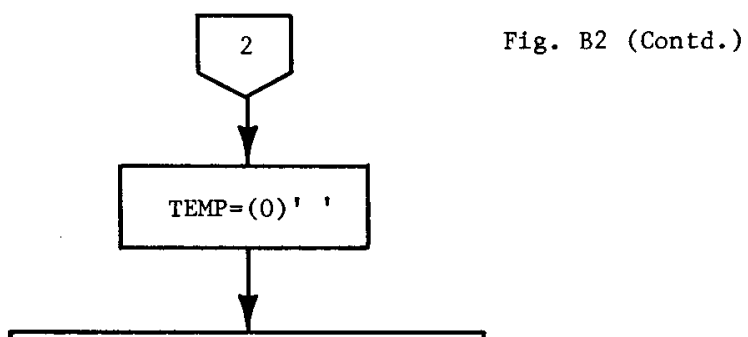

DO $J=1$ TO L WHILE (OP $(J)=F)$

TEMP $=\operatorname{TEMP}|| \operatorname{SUBSTR}(\mathrm{S}, \mathrm{J}, 1)$ END

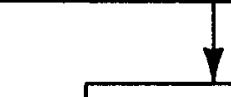

SIG (NELTS) $=\mathrm{T}$

Store the constants

Replace

name in ELT

$\mathrm{NCONS}=0$ ?

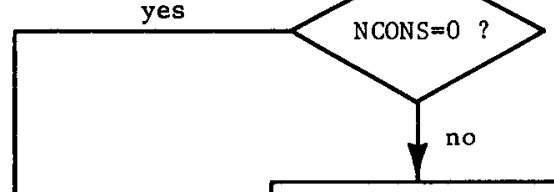

DO $\mathrm{K}=1$ TO NCONS
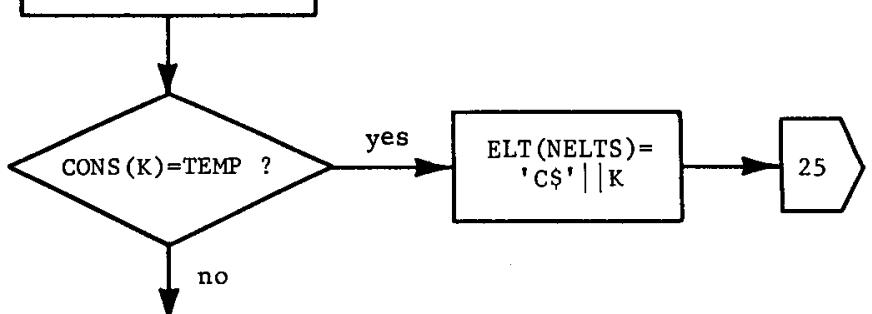

END

$\mathrm{NCONS}=\mathrm{NCONS}+1$

CONS (NCONS) $=$ TEMP ELT (NELTS) =' C\$' $\mid$ NCONS 
Fig. B2 (Contd.)

25

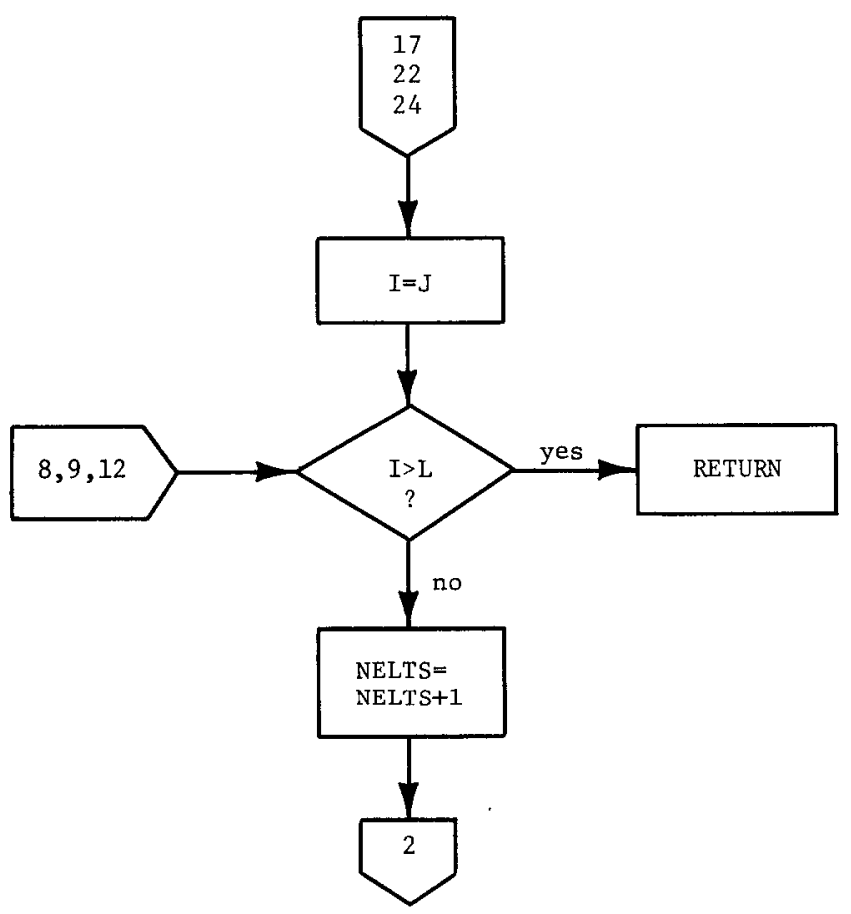


Fig. B3

Flow Chart 3, BACKUS

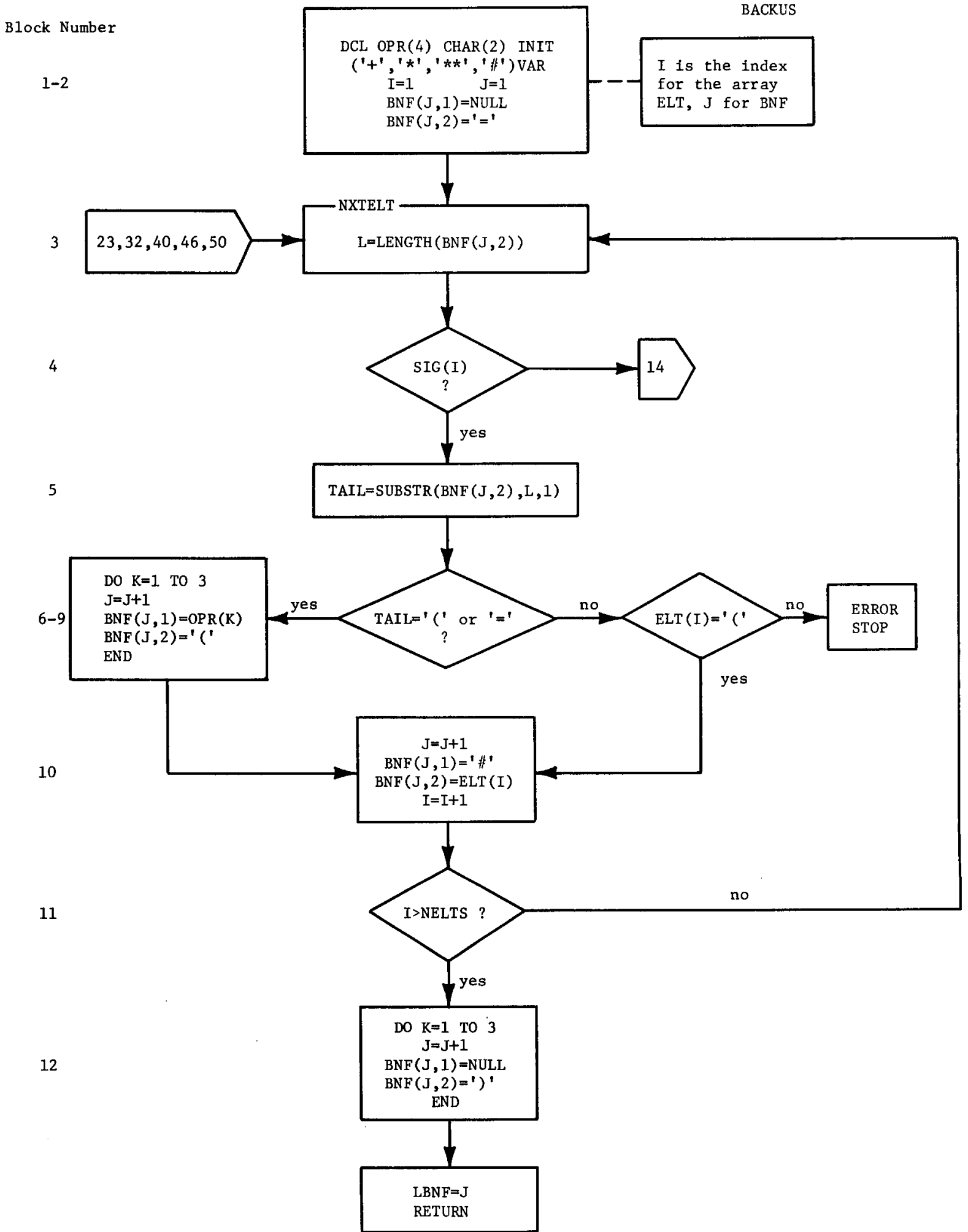


Block Number

14

15-16

17

18-19

20

21

22

23-25

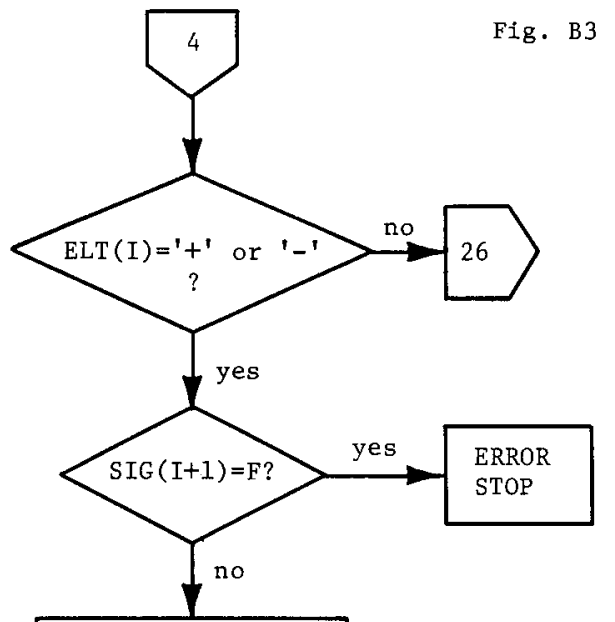

$\mathrm{TAIL}=\mathrm{SUBSTR}$

$(\operatorname{BNF}(J, 2), \mathrm{L}, 1)$

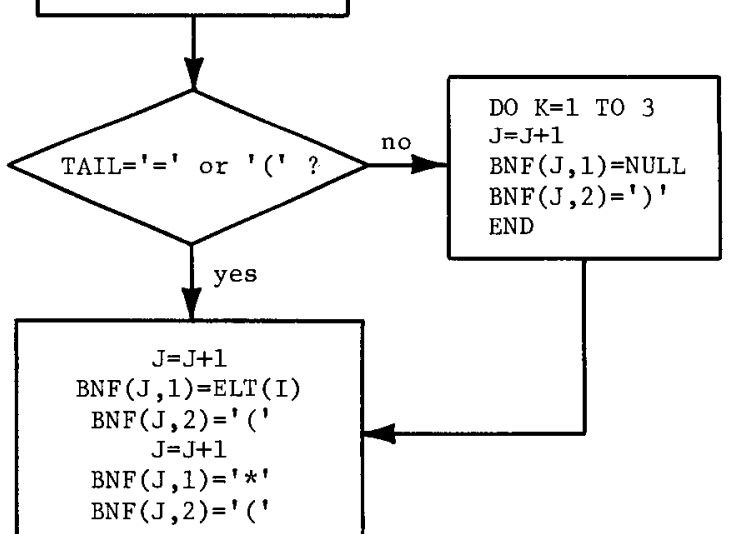

$\operatorname{BNF}(\mathrm{J}, 2)={ }^{\prime}\left({ }^{\prime}\right.$

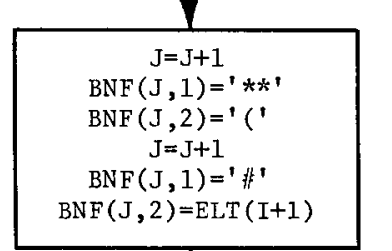

DO $\mathrm{K}=1$ TO 3

$\mathrm{J}=\mathrm{J}+1$

$\operatorname{BNF}(\mathrm{J}, \mathrm{I})=\mathrm{NULL}$

$\left.\operatorname{BNF}(J, 2)=)^{\prime}\right)^{\prime}$

$\mathrm{LBNF}=\mathrm{J}$

RETURN 
Block Number

26

$27-28$

29

30

31

32

33

34

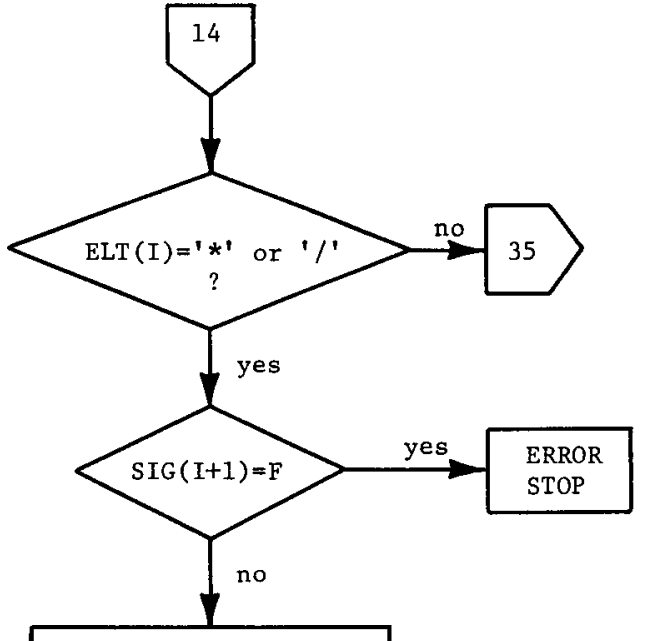

Fig. B3 (Contd.)

$$
\operatorname{BNF}(\mathrm{J}, 1)=\operatorname{NUL}
$$

$\left.\operatorname{BNF}(J, 2)={ }^{\prime}\right)^{\prime}$

$\mathrm{J}=\mathrm{J}+1$

$\operatorname{BNF}(\mathrm{J}, 1)=\mathrm{NULL}$

$\left.\operatorname{BNF}(J, 2)={ }^{\prime}\right)^{\prime}$

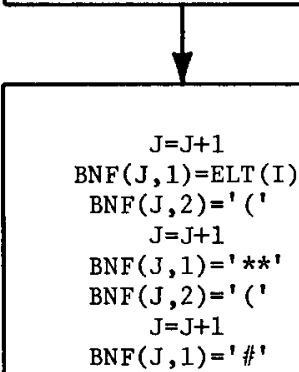

$\operatorname{BNF}(\mathrm{J}, 2)=\operatorname{ELT}(\mathrm{I}+1)$

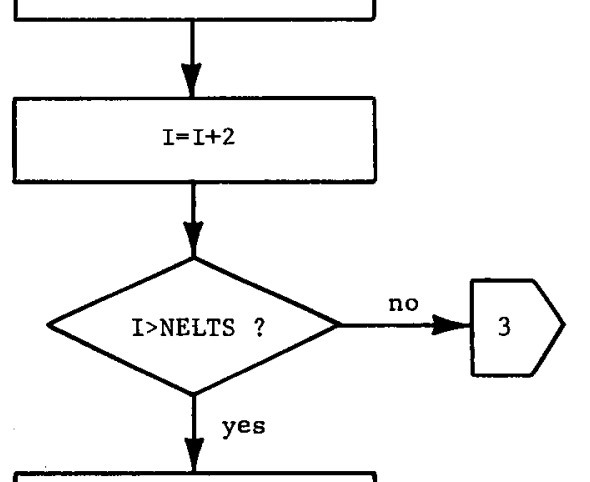

DO $\mathrm{K}=1$ TO 3

$\mathrm{J}=\mathrm{J}+1$

$\operatorname{BNF}(J, 1)=N U L L$

$\left.\operatorname{BNF}(J, 2)={ }^{\prime}\right)$ '

END

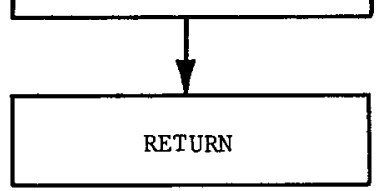




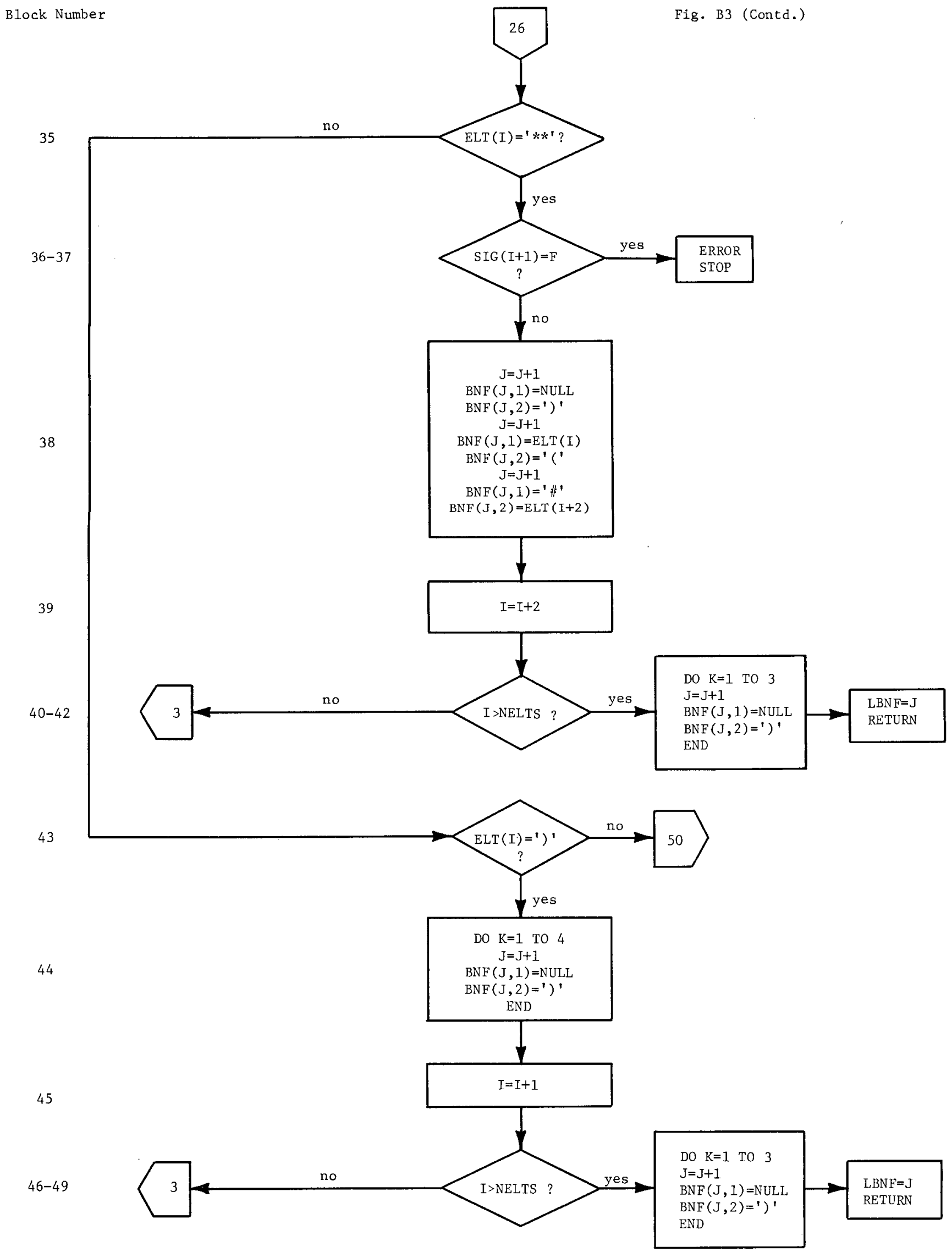


Block Number

$50-51$

52

53

54

55

56

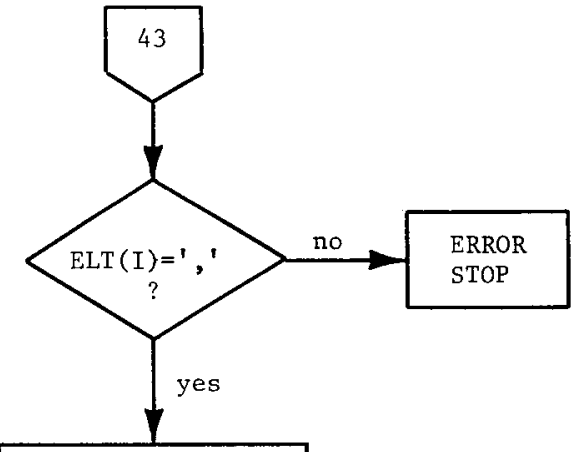

Fig. B3 (Contd.)

DO $\mathrm{K}=1$ TO 4

$\mathrm{J}=\mathrm{J}+1$

$\operatorname{BNF}(J, 1)=\operatorname{NULL}$

$\left.\operatorname{BNF}(J, 2)={ }^{\prime}\right)$ '

END

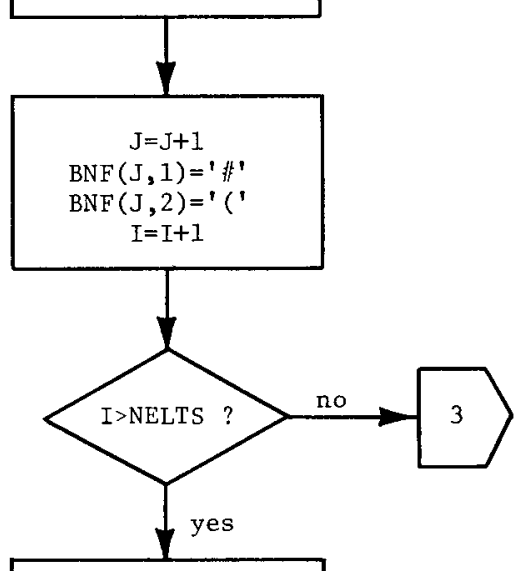

DO $\mathrm{K}=1$ TO 3

$\mathrm{J}=\mathrm{J}+1$

$\operatorname{BNF}(J, 1)=N U L L$

$\operatorname{BNF}(J, 2)=')^{\prime}$

END

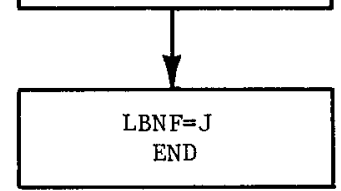


Fig. $B 4$

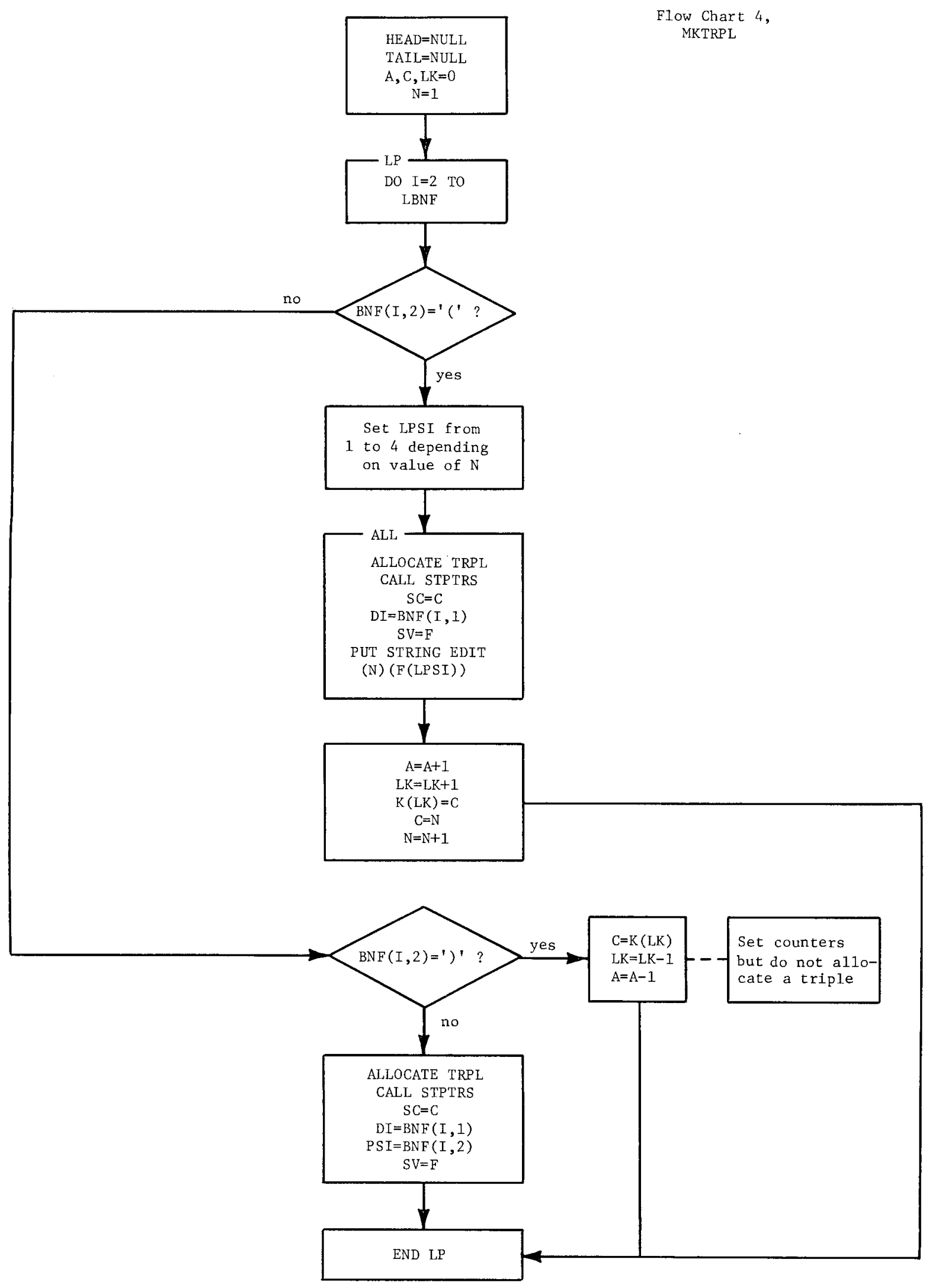


Fig. B5

Flow Chart 5 , STPTRS

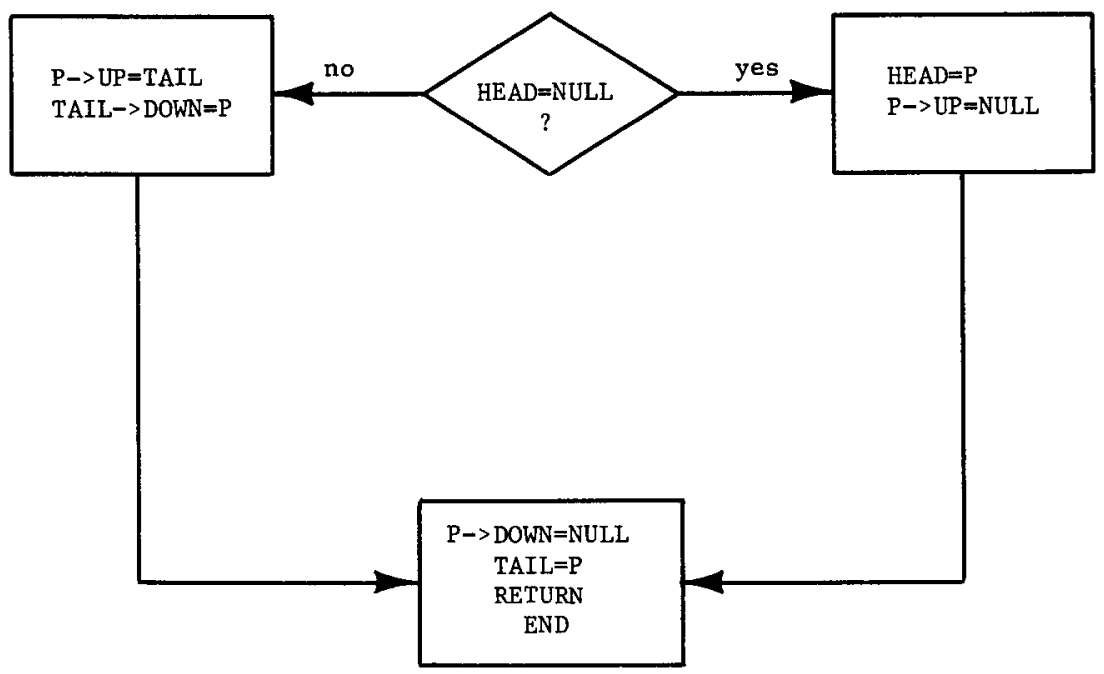




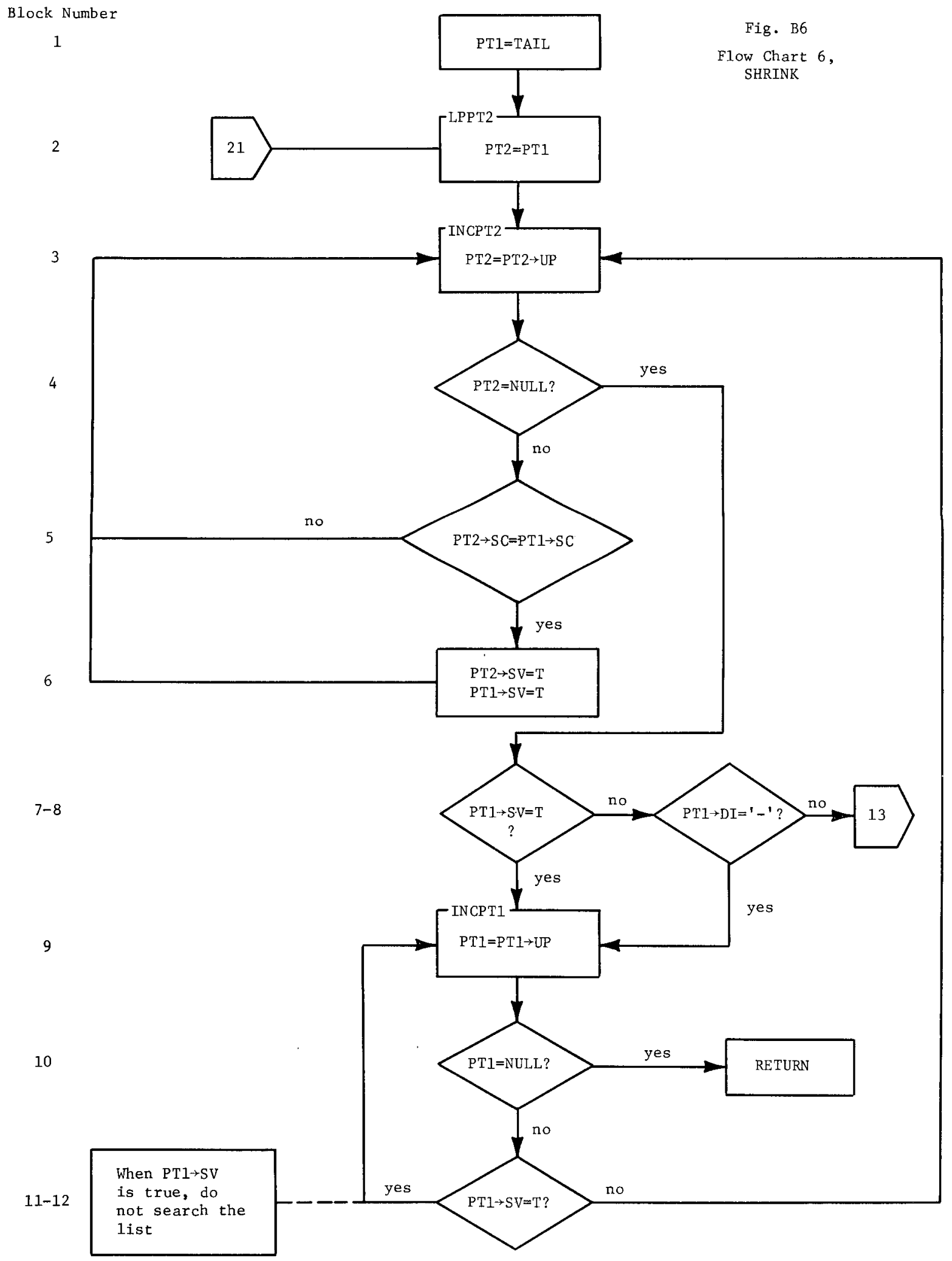


Block Number

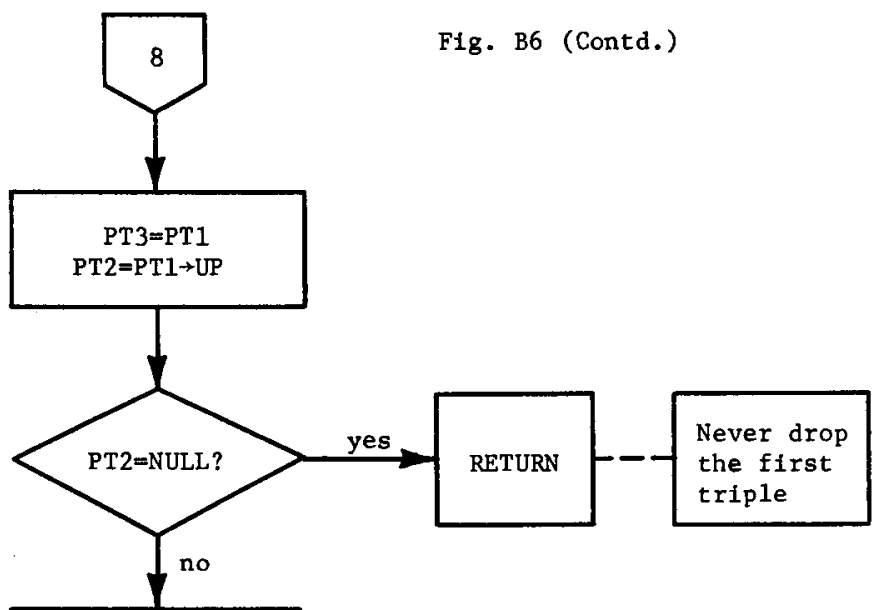

17

$\mathrm{PT} 2 \rightarrow \mathrm{PSI}=\mathrm{PT} 1 \rightarrow \mathrm{PSI}$

PT $4=\mathrm{PT} 1 \rightarrow \mathrm{DOWN}$

$\mathrm{PT} 2 \rightarrow \mathrm{DOWN}=\mathrm{PT} 4$

$18-20$

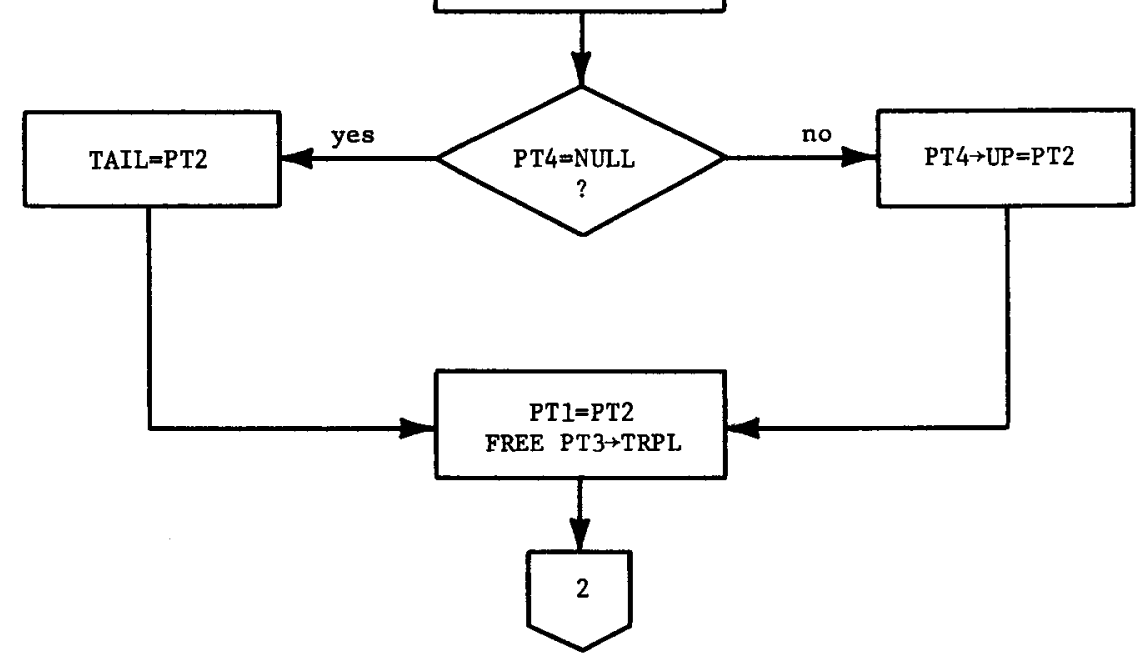

21 


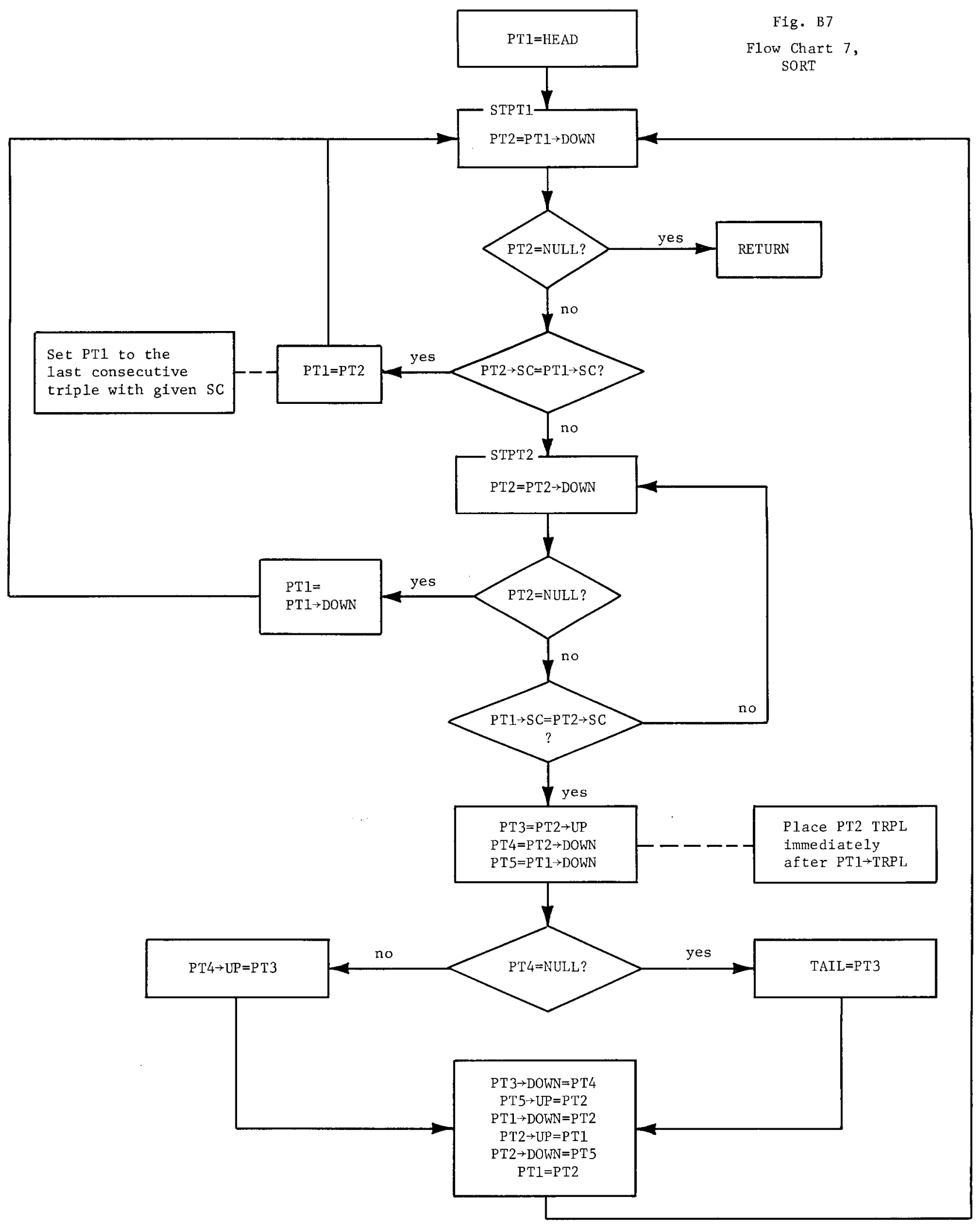




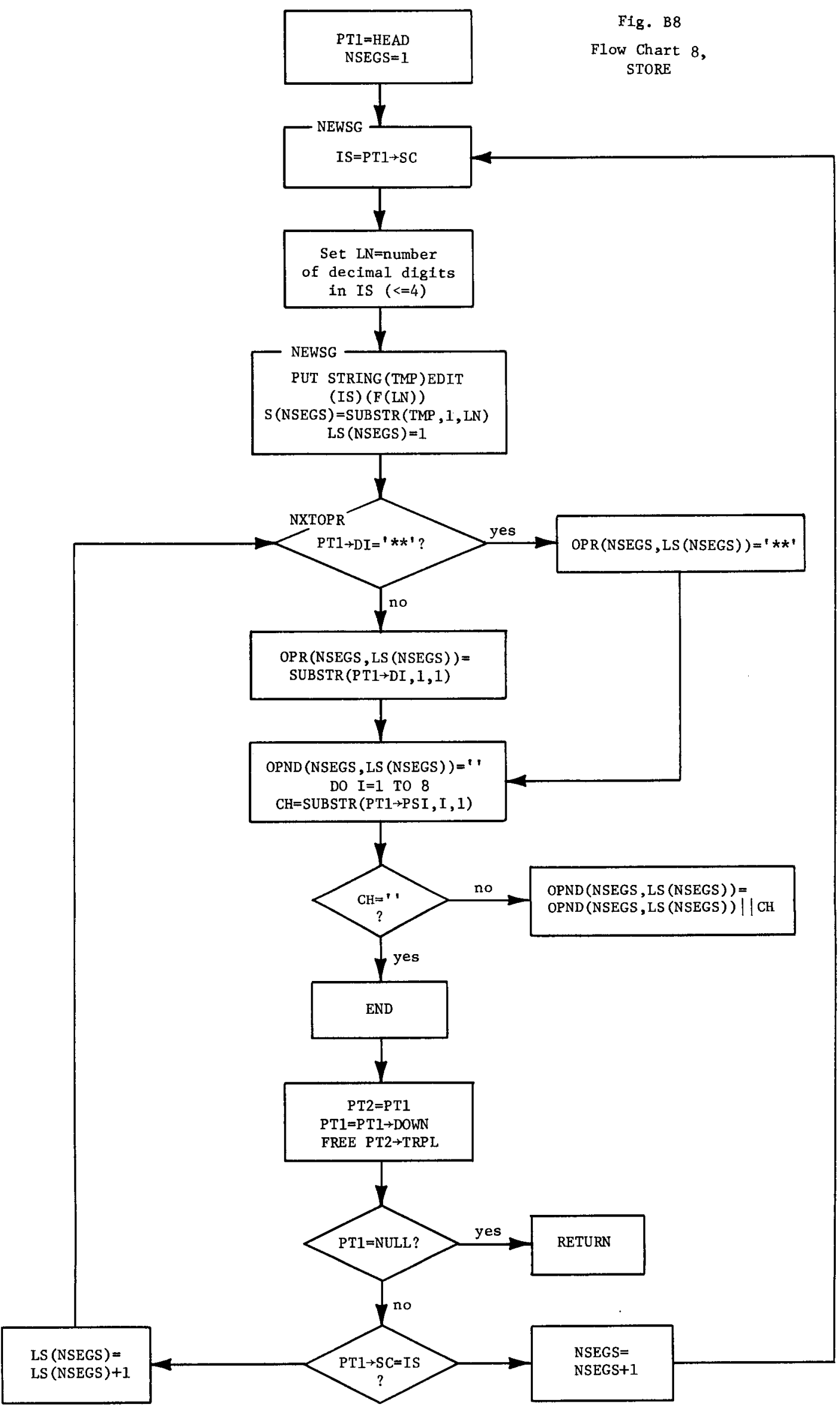




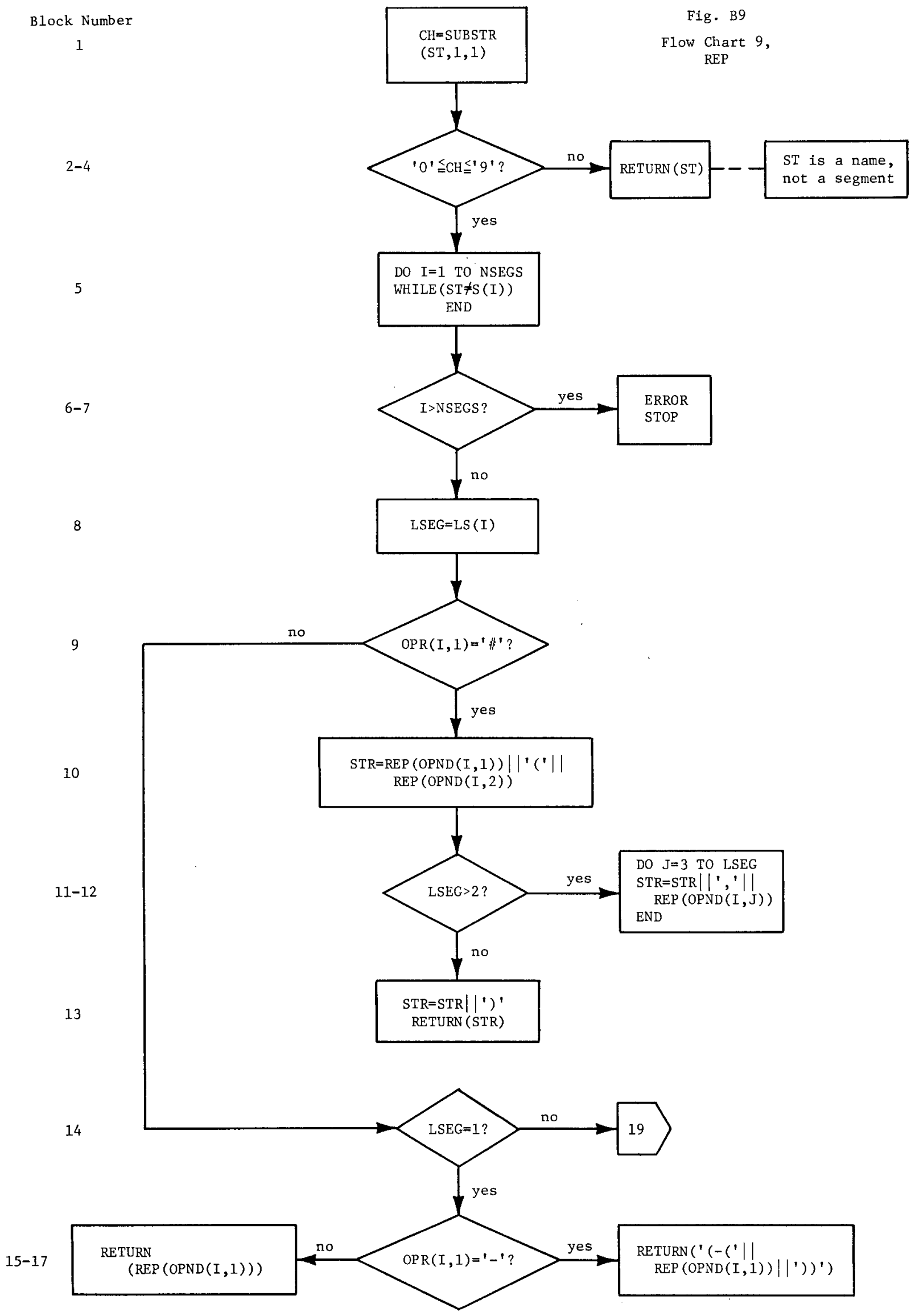


Block Number

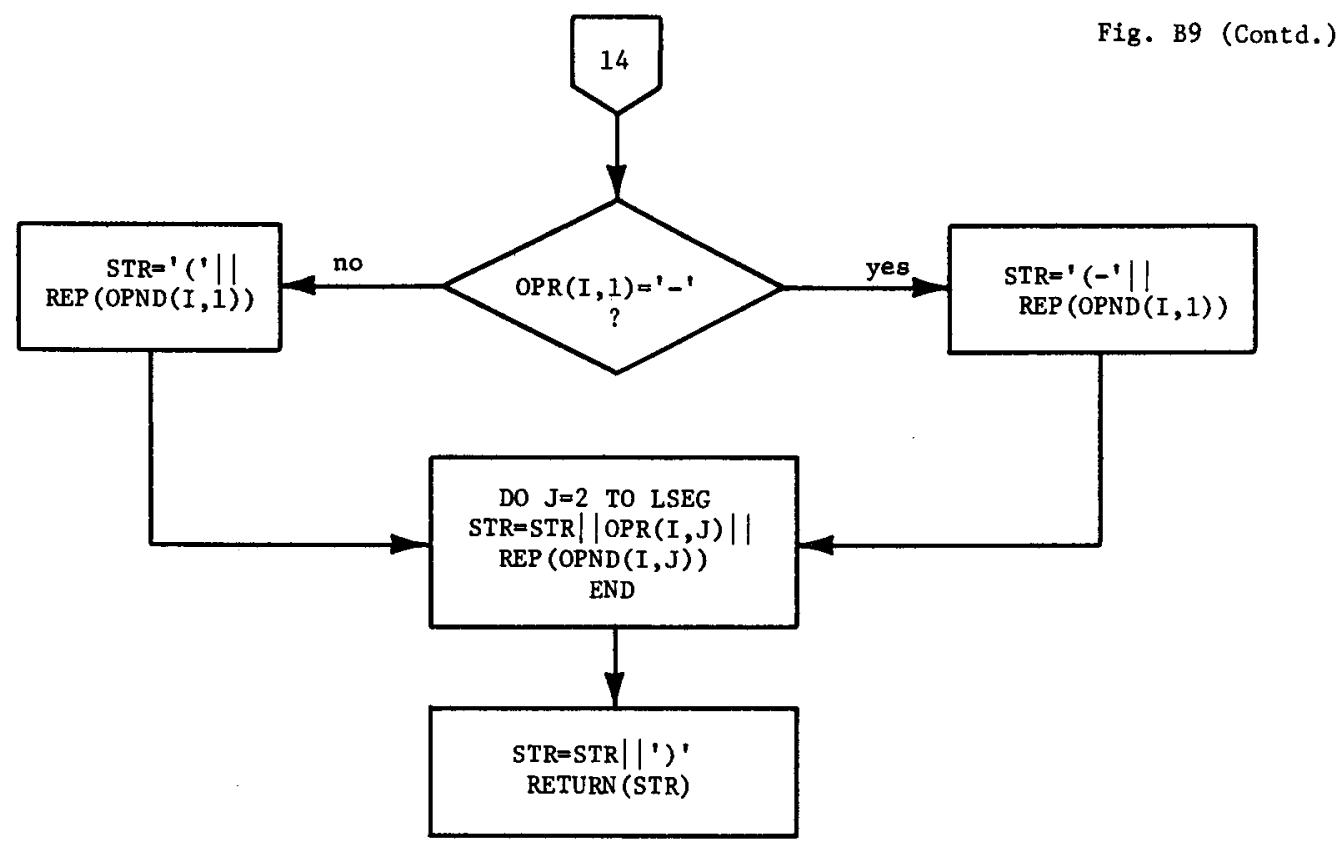




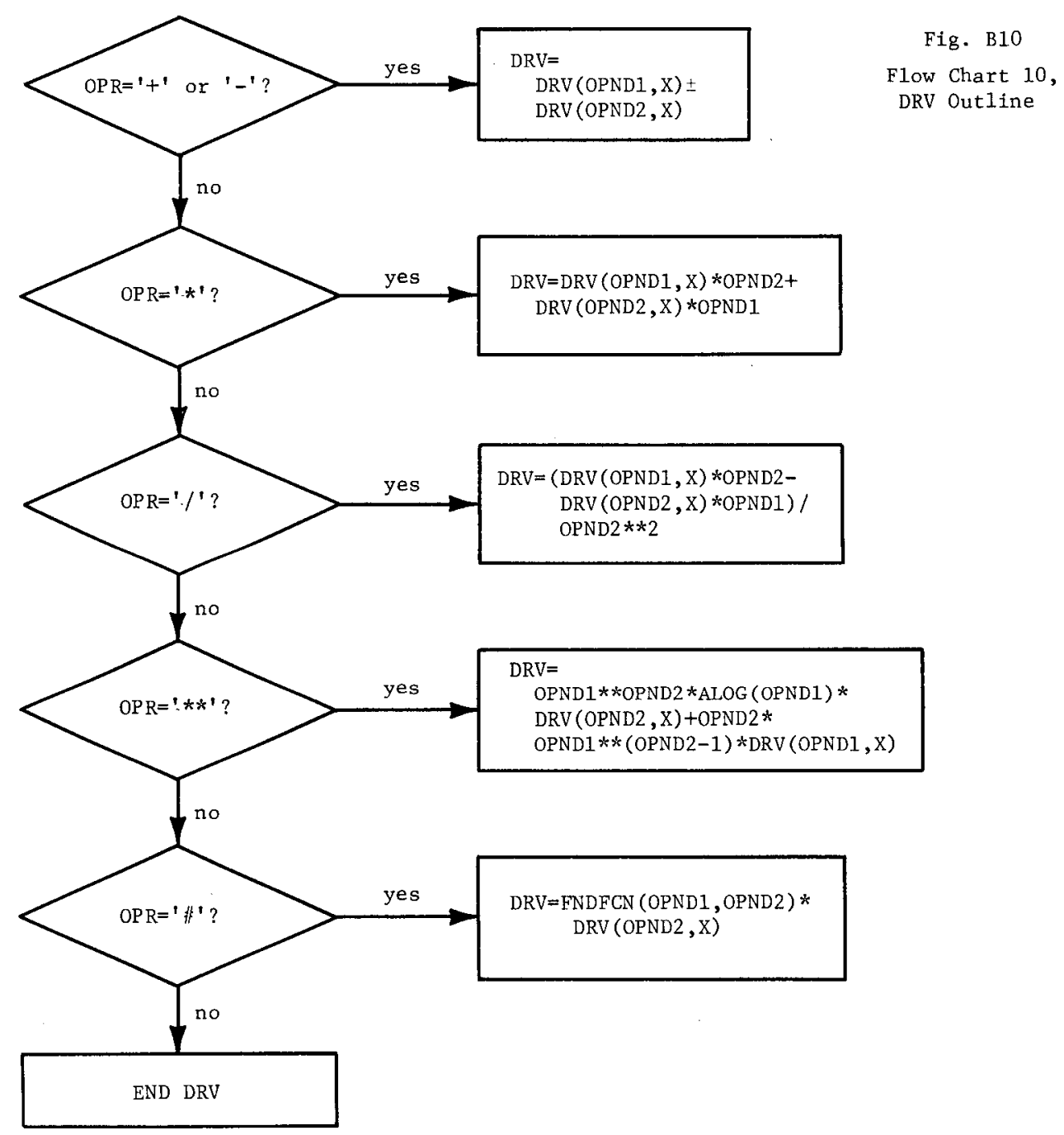




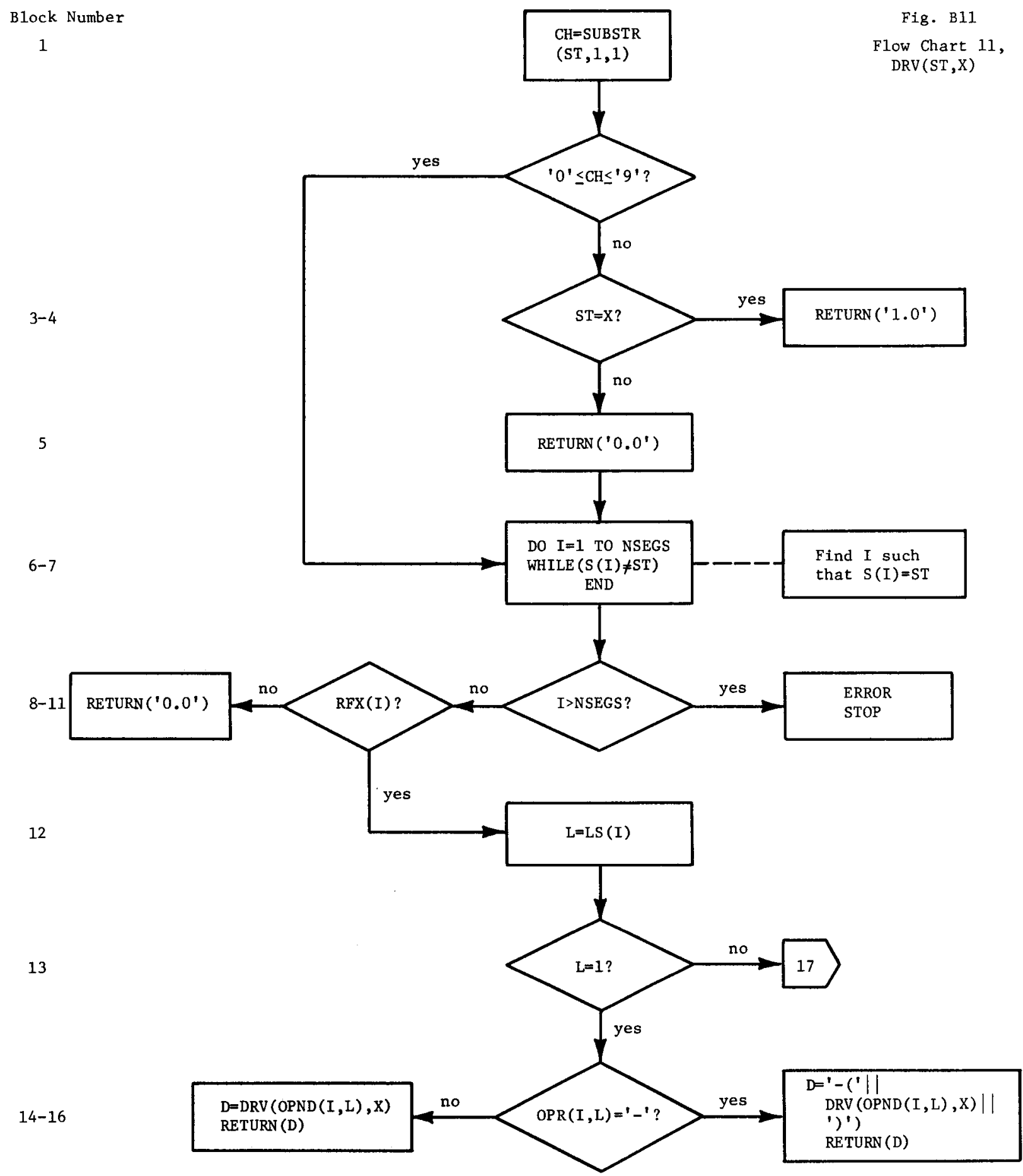




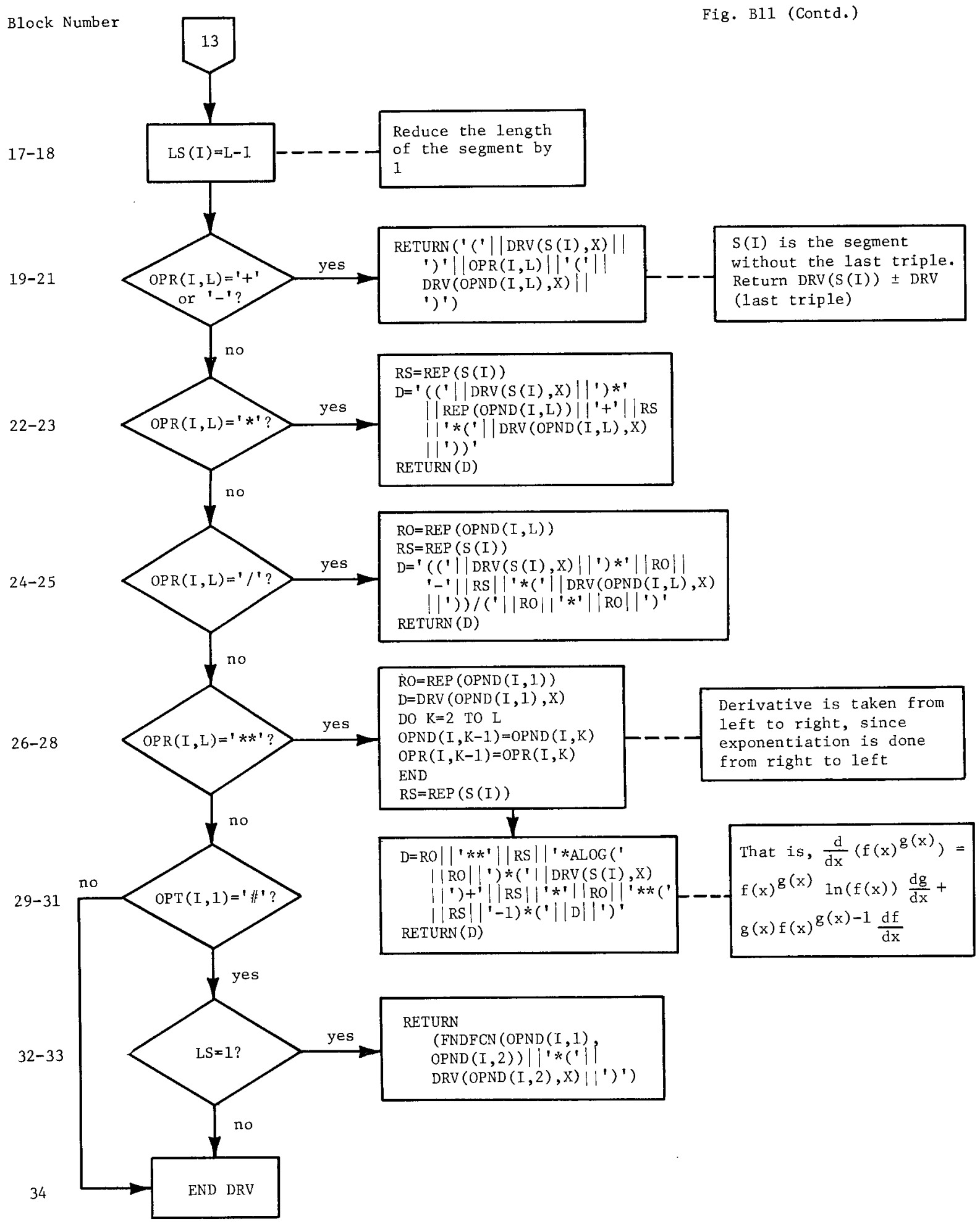


Block Number

16

$17-18$

$19-20$

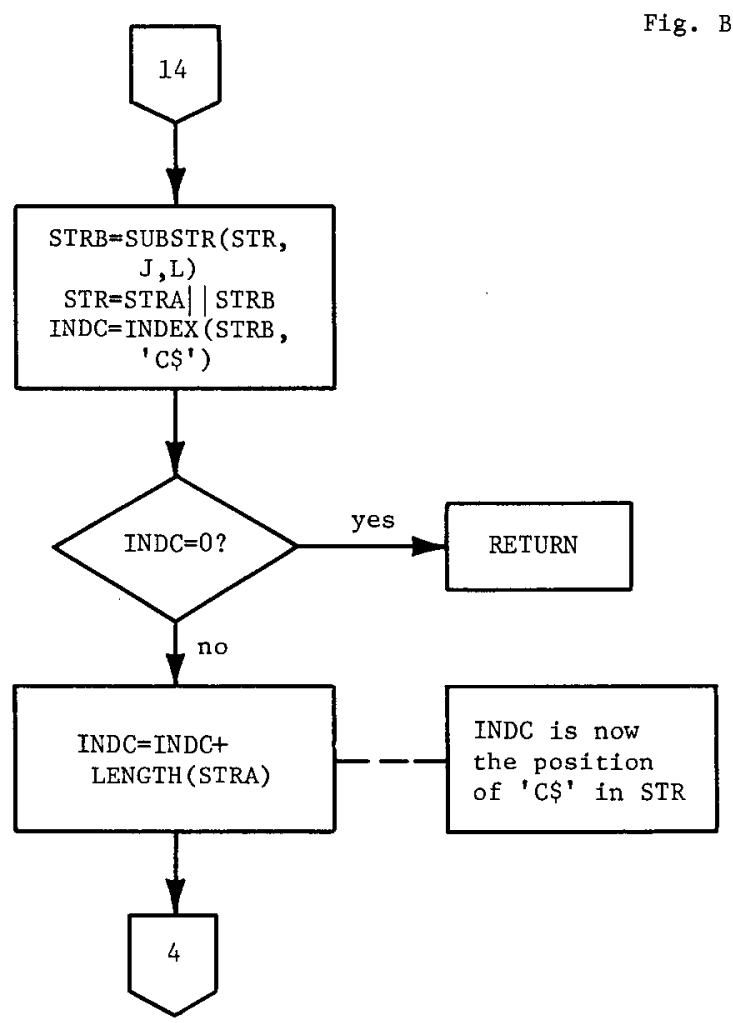




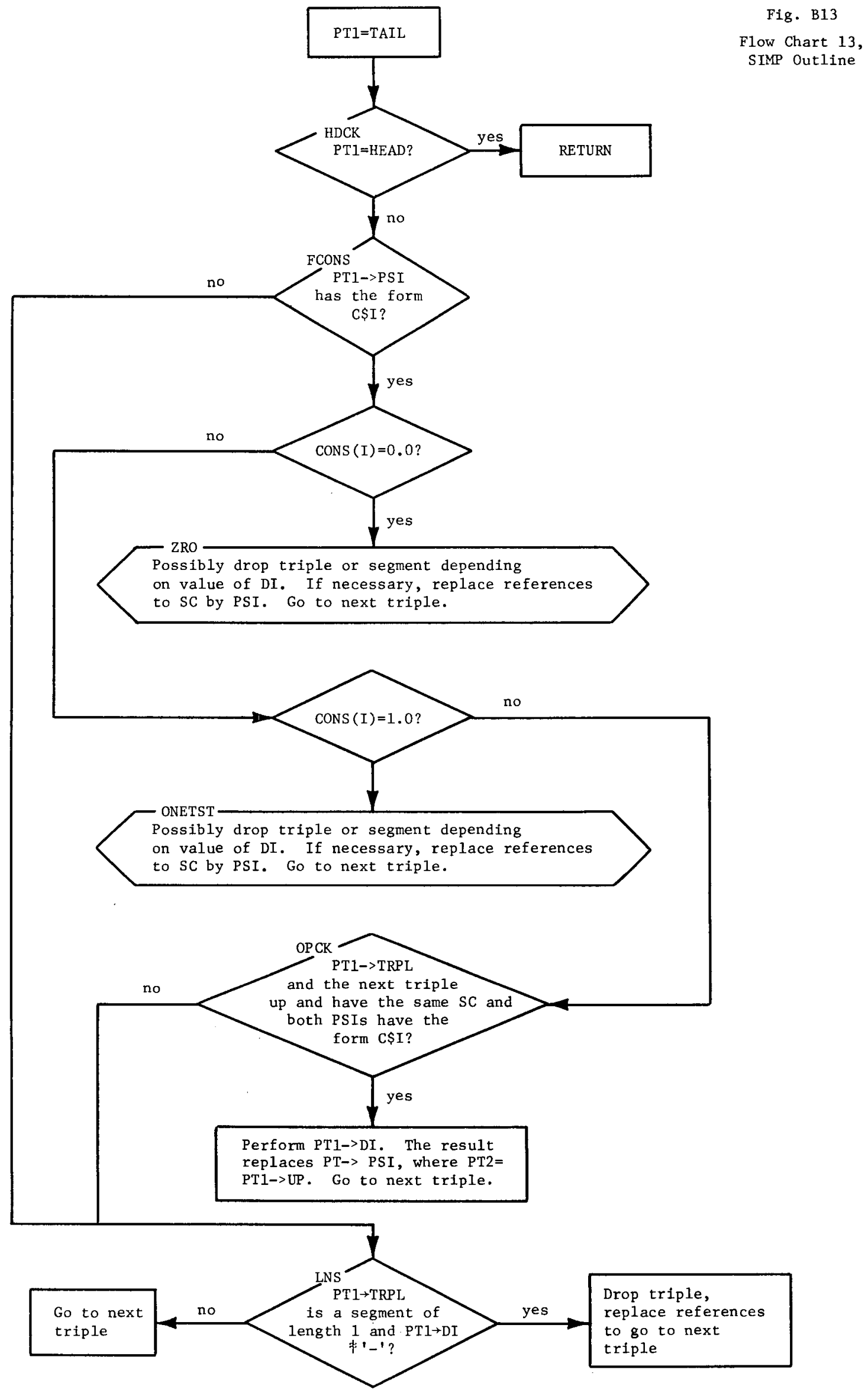




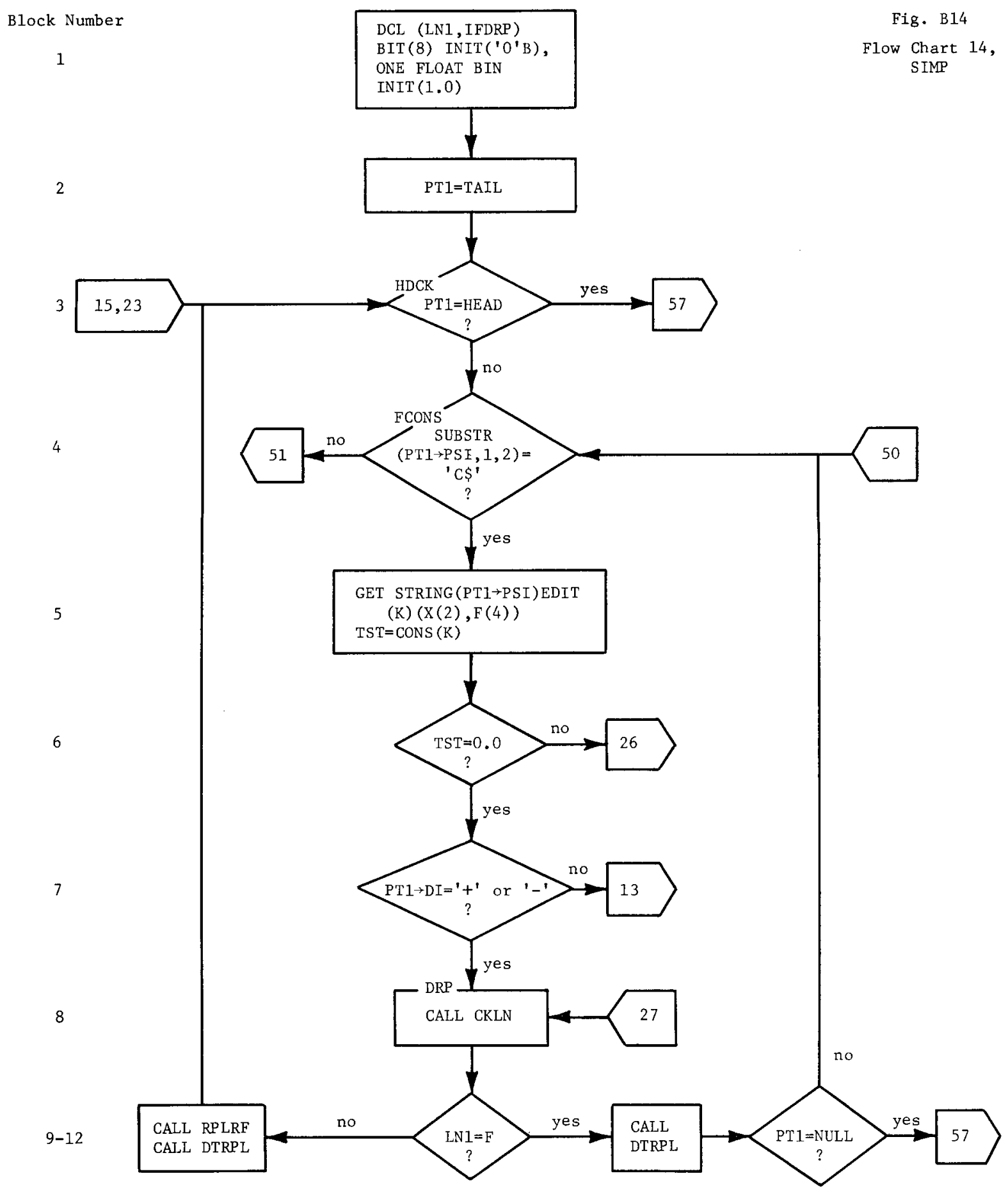




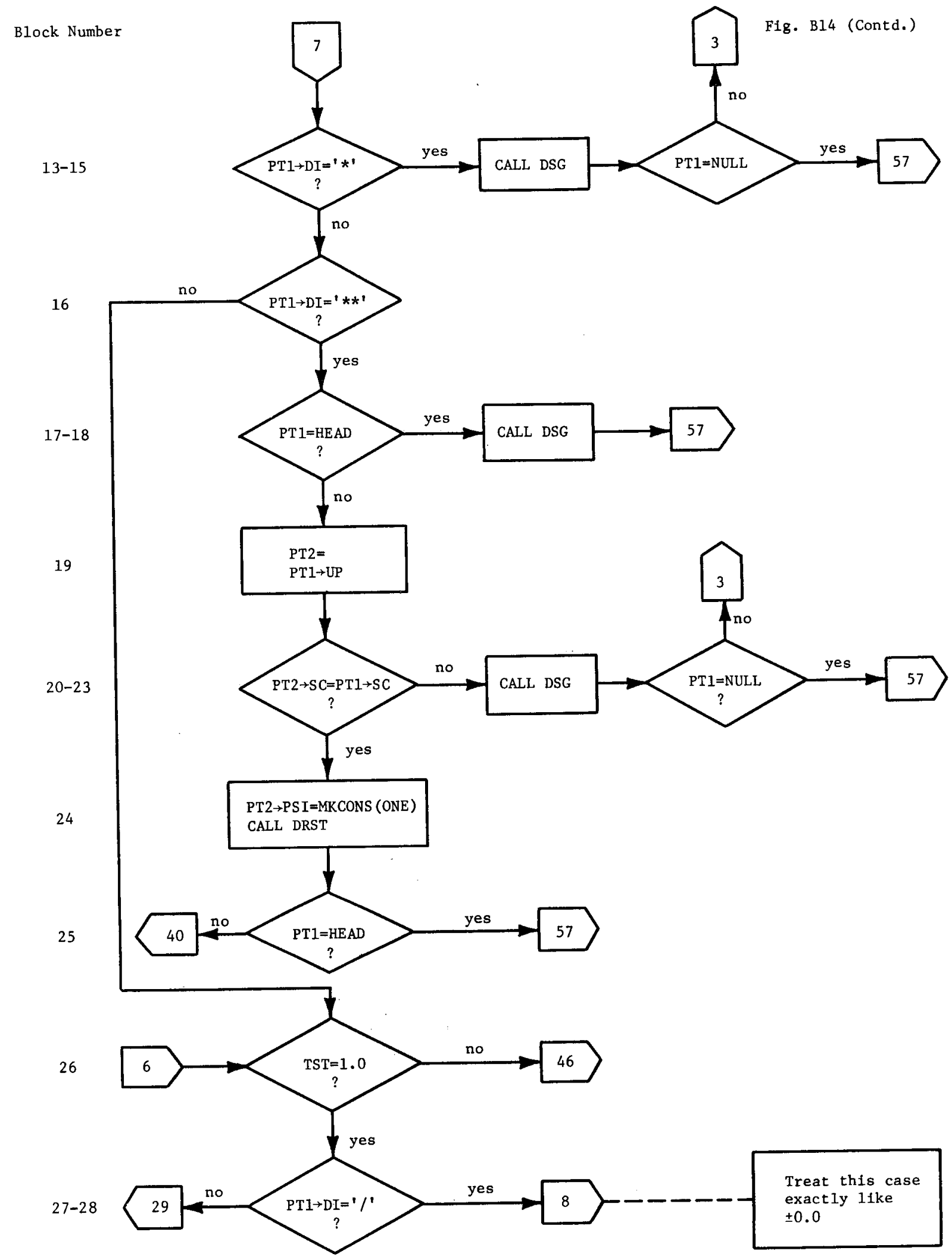




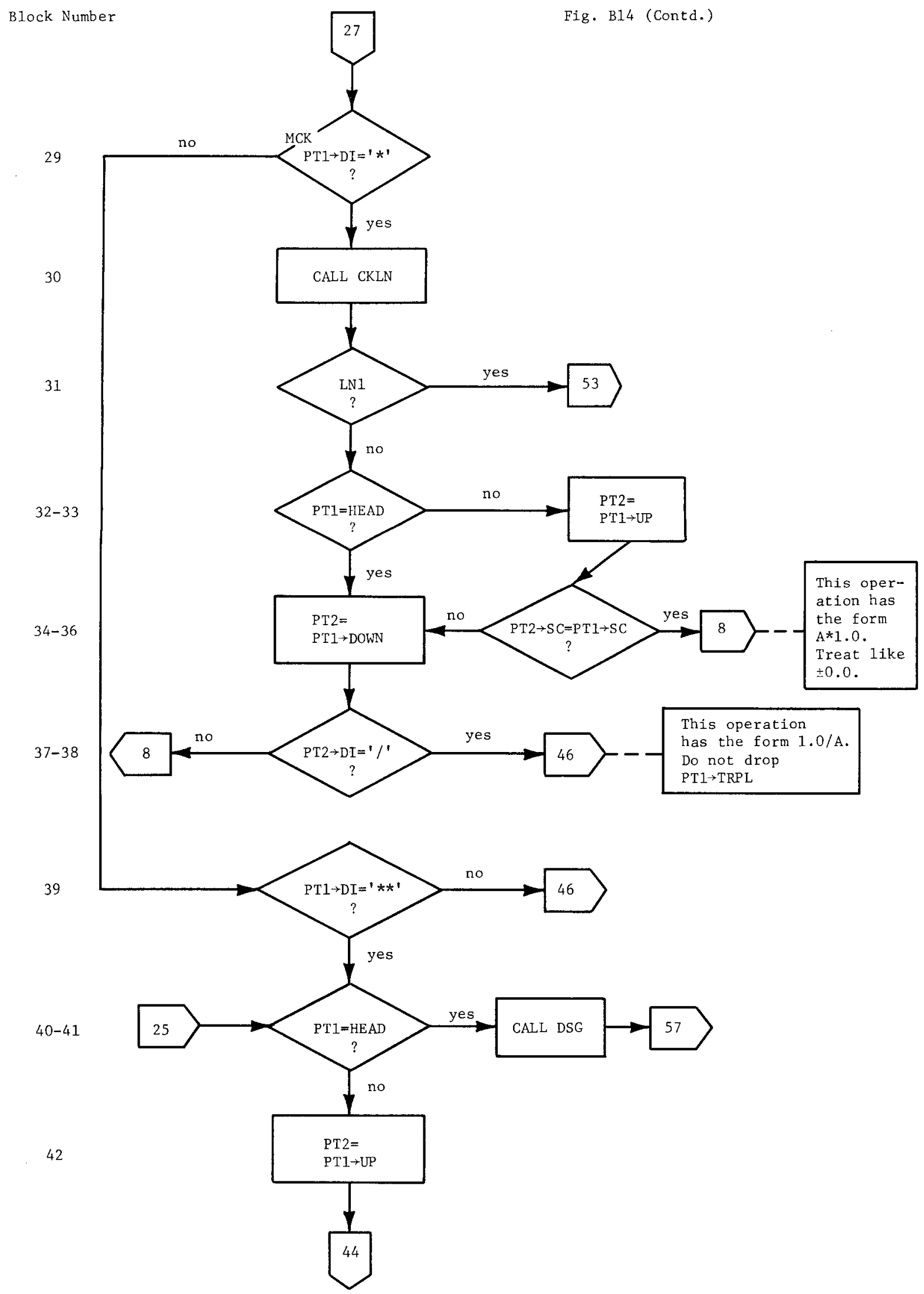



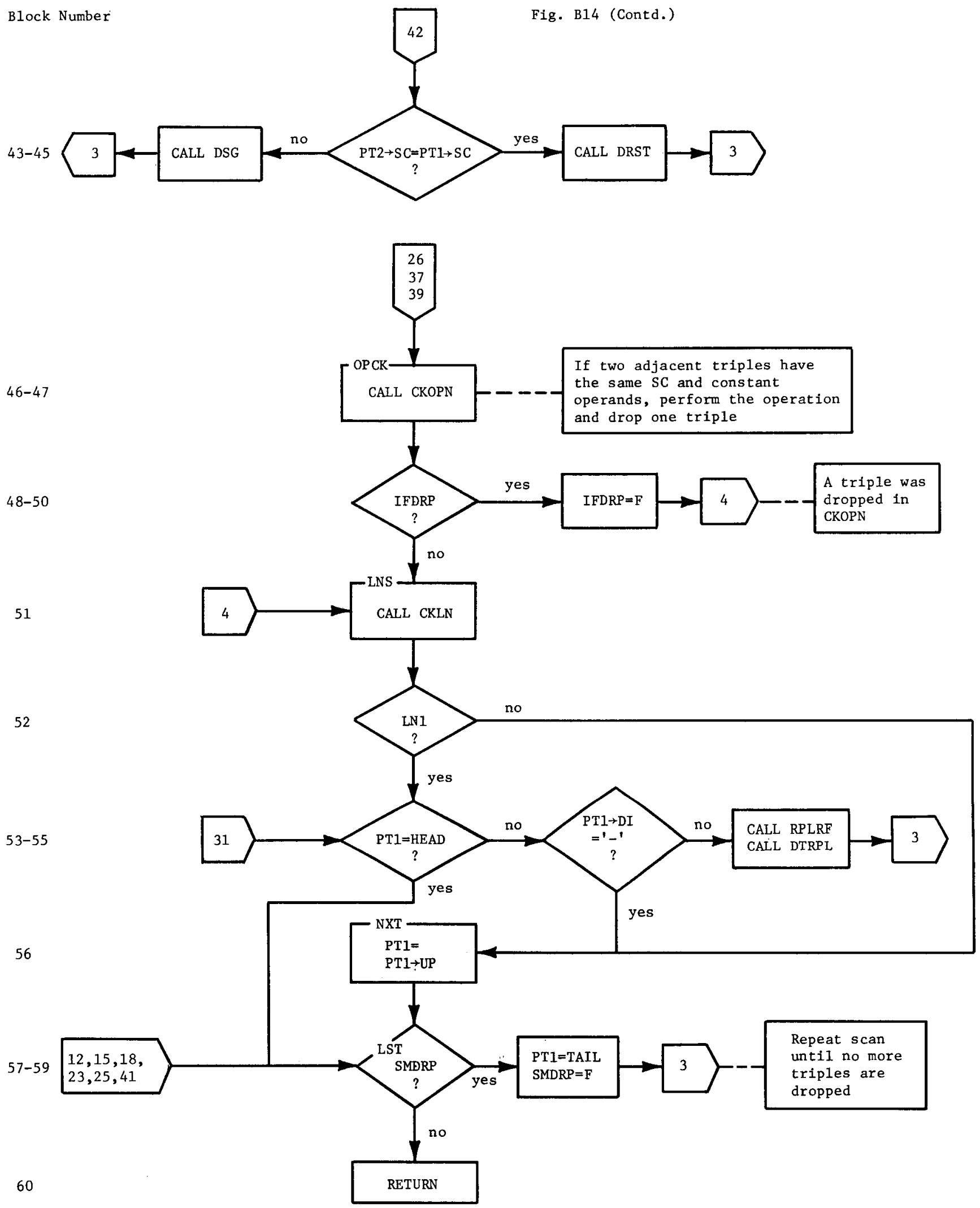


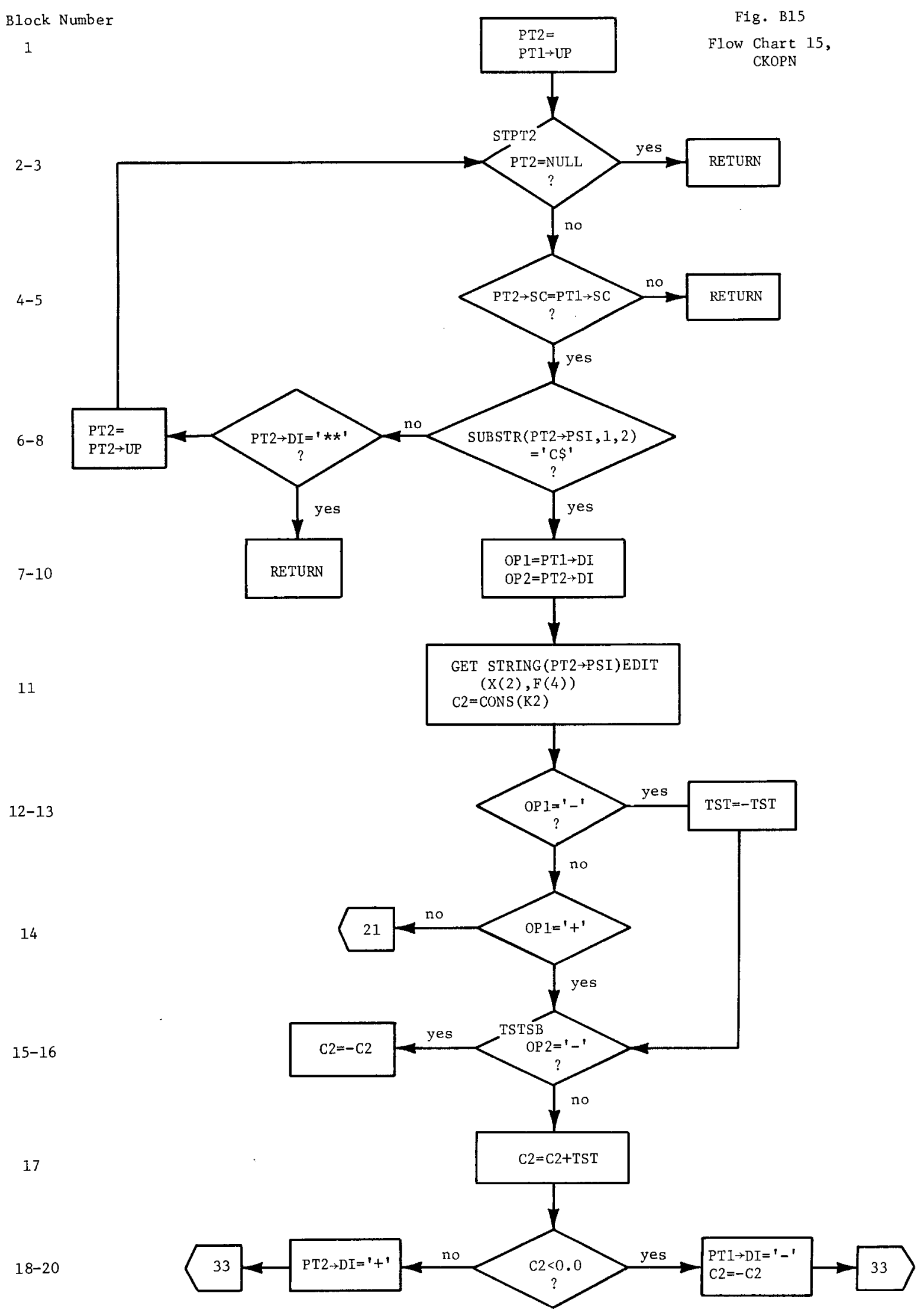




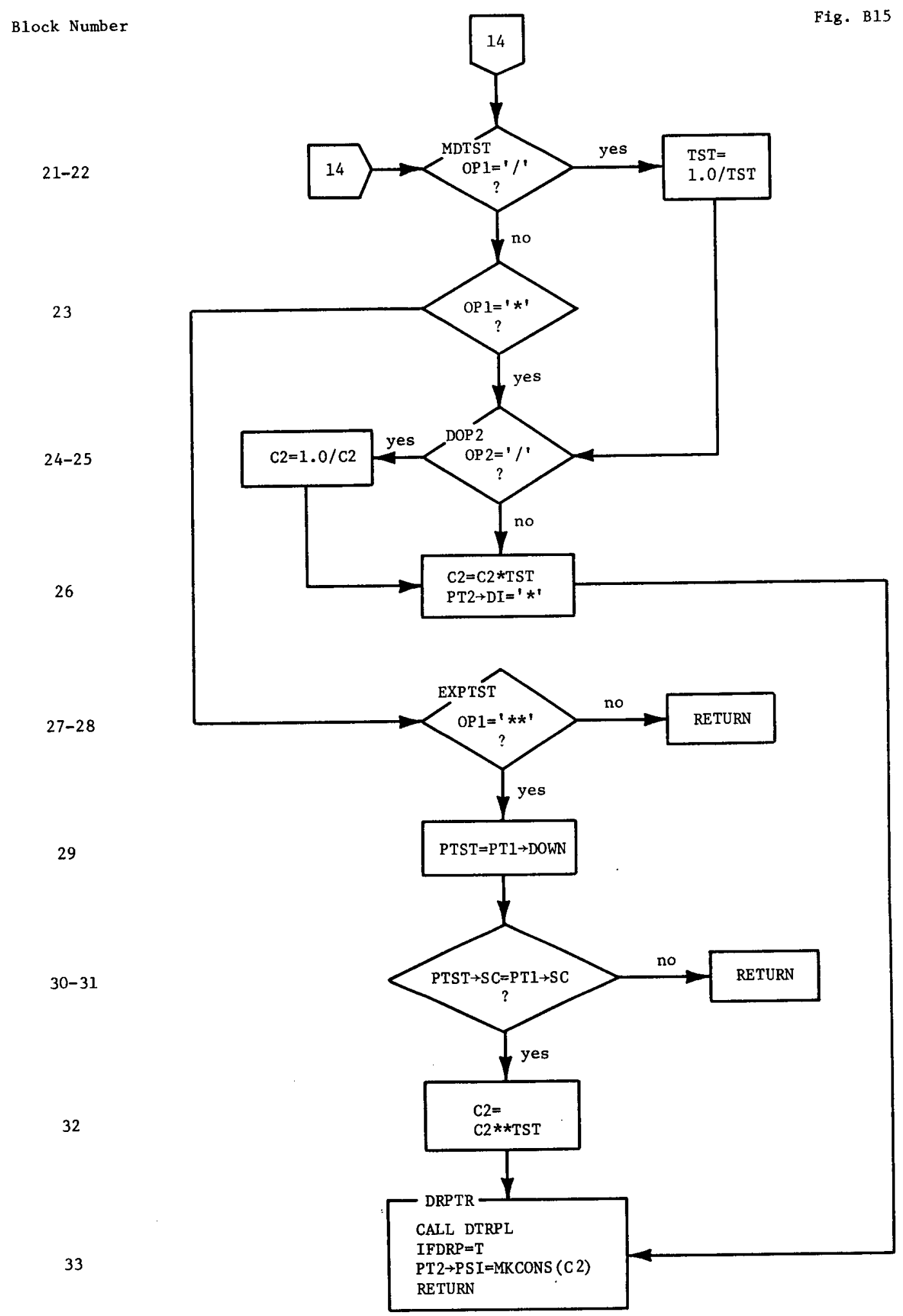


APPENDIX C

Listing of DERV

DERV: PROCIFCN,X) CHAR (1320) VAR;

ON ERROR CALL IHEDUMP;

DCL (FCN,OSTR) CHAR(1320) VAR,X CHAR(6) VAR;

DCL DRV

DCL REP

RETURNS (CHAR (1320) VAR);

DCL FNDFCN RETURNS(CHAR(1320) VAR);

DCL STRNG CHAR(1320) VAR,

CH CHAR (1), IOPP, ALP, NUM, VAR, OP, CONST)

(1320) BIT( 8$)$ CONTROLLED, NOPS FIXED BIN INIT(7),

OPN (7) CHAR(1) INITI $+\cdot, \cdot-1, \cdot * \cdot, \cdot, \cdot, 1,, \cdot 1, \cdot, \cdot 1$, T BIT(8)

INITI'I'B), F BIT(8) INIT $\left(0^{\circ} 0^{\circ} B\right)$, CARD CHAR $(80)$;

DCL 1 TRPL BASED(P),

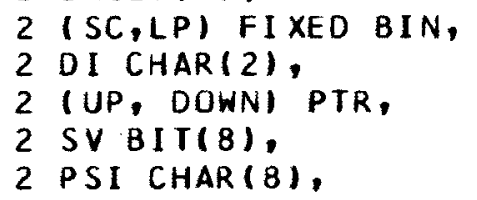

(HEAD, TAIL

I PTR;

DCL PPR PTR,SPR FIXED BIN,DPR CHAR(2),PSIPR CHAR(8) VAR;

DCL (SIG (1320) BIT(8), CONS(1320)CHAR(20) VAR, ELT (1320)

CHAR (6) VAR, CTL, (NELTS, NCONS) FIXED BIN, TEMP CHAR(20) VAR:

DCL BNF $(1320,2)$ CHAR (8) VAR CTL, LBNF FIXED BIN:

DCL (LS(50) FIXED BIN, $(S(50)$, (OPR, OPND) $(50,50)$ )CHAR(6) VAR)

CTL.

INSEGS,NTRPLS

DCL RFX(*) BIT(1) CTL;

IFIXED BIN;

DCL LMAX FIXED BIN;

STRNG $=(0) \cdot$ ';

UO $I=1$ TO LENGTH (FCN);

$C H=S U B S T R(F C N, 1,1)$; IF $C H==$ - THEN STRNG=STRNG $\mid \mathrm{CH}$;

END;

$L=L E N G T H(S T R N G)$;

$M=L+1$;

ALLOCATE OPP(M) BIT(B), ALP(M) BIT(B), NUM(M) BIT (8), VAR (M) BIT(8), OP(M) BIT(8), CONST(M) BIT(8);

ALLOCATE SIG(M) BIT(B) INIT( (M)'O'B),CONSIM) CHAR(20),

ELT(M) CHAR (6);

DO I=I TO $M$;

$\operatorname{ALP}(I), \operatorname{NUM}(I), O P P(I), O P(I), \operatorname{VAR}(I), \operatorname{CONST}(I)=F$; END;

CALL ANALYS;

CALL GTNAM;

ALLOCATE BNF(10*NELTS, 2) CHAR(8);

CALL BACKUS (BNF);

CALL MKTRPL;

CALL SHRINK;

$P P R=H E A D$

NTRPLS $=0$;

CLP: NTRPLS=NTRPLS+1; PPR=PPR->DOWN: IF PPR =NULL THEN GO TO CLP;

CALL SORT;

CALL COUNT;

FREE ELT, SIG, ALP, NUM, OPP, OP, VAR, CONST, BNF;

ALLOCATE LS(NSEGS), S(NSEGS) CHAR(6), OPR(NSEGS,LMAX) CHAR $(6)$, OPND(NSEGS,LMAX) CHAR(6);

CALL STORE; 
CALL CKRF;

DSTR=DRV(S $(1), X)$;

CALL RPLCNS(DSTR);

FREE LS,S, OPR, OPND, CONS;

FREE RFX;

STRNG = DSTR;

$L=L E N G T H(S T R N G)$;

$M=L+1$;

ALLOCATE OPP(M) BIT(8), ALP(M) BIT(8), NUM(M) BIT (8),

VAR (M) BIT(B), OP(M) BIT(8), CONST(M) BIT(8);

ALLOCATE SIG(M) BIT(8) INITI(M)・O'B), CONS(M) CHAR(20),

ELT(M) CHAR (6);

DO $I=1$ TO $M$;

ALP(I),NUM(I),OPP(I), OP(I),VAR(I), CONST(I)=F; END;

CALL ANALYS;

CALL GTNAM;

ALLOCATE BNF(10*NELTS, 2$)$ CHAR (8);

CALL BACKUS(BNF);

CALL MKTRPL;

CALL SHRINK;

$P P R=H E A D$;

NTRPL $S=0$;

CLP2: NTRPLS=NTRPLS+1; PPR=PPR $\rightarrow D O W N ;$ IF PPR $=N U L L$ THEN GO TO CLP2;

CALL SORT:

CALL SIMP;

CALL COUNT;

FREE ELT, SIG, ALP, NUM, OPP, OP, VAR, CONST, BNF;

ALLOCATE LS (NSEGS), S(NSEGS) CHAR(6), OPR(NSEGS,LMAX) CHAR(6). OPND(NSEGS, LMAX) CHAR (6):

CALL STORE;

DSTR=REP(SI 1$)$ );

CALL RPLCNSIDSTRI:

FREE $1 S, S, O P R$, OPND, CONS;

ANALYS :PRUC;

RETURN (DSTR):

DCL S CHAR(1320) VAR EXTERNAL;

I*NOTE IHAT S IS THE INPUT STRING

$S=S T R N G$; HERE*I

DO I $=1$ TO L:

$\mathrm{CH}=\operatorname{SUBSTR}(\mathrm{S}, \mathrm{I}, 1)$;

IF ' $A \cdot \angle C=C H \& C H \quad \angle=Z^{\prime}$ THEN DO;

$A L P(I)=T$;

GO TO ENDLP;

END;

IF $\left.\left(\cdot 0^{\circ}<=C H \& C H<=9\right)^{\circ}\right),(C H=\cdot, \cdot)$ THEN DO;

$\operatorname{NUM}(I)=\mathrm{T}$;

GO TO ENDLP;

END ;

DO $K=1$ TO NOPS;

IF $C H=O P N(K)$ THEN DO;

$\operatorname{OPP}([)=\mathrm{T}$;

GO TO ENOLP;

END:

END;

PUT LIST 1 ' CHARACTER ',CH,' IN POSITION ',I.' OF STRING', $S, '$ IS NOT A VALID FORTRAN CHARACTER'):

SIGNAL ERROR;

STOP ; 


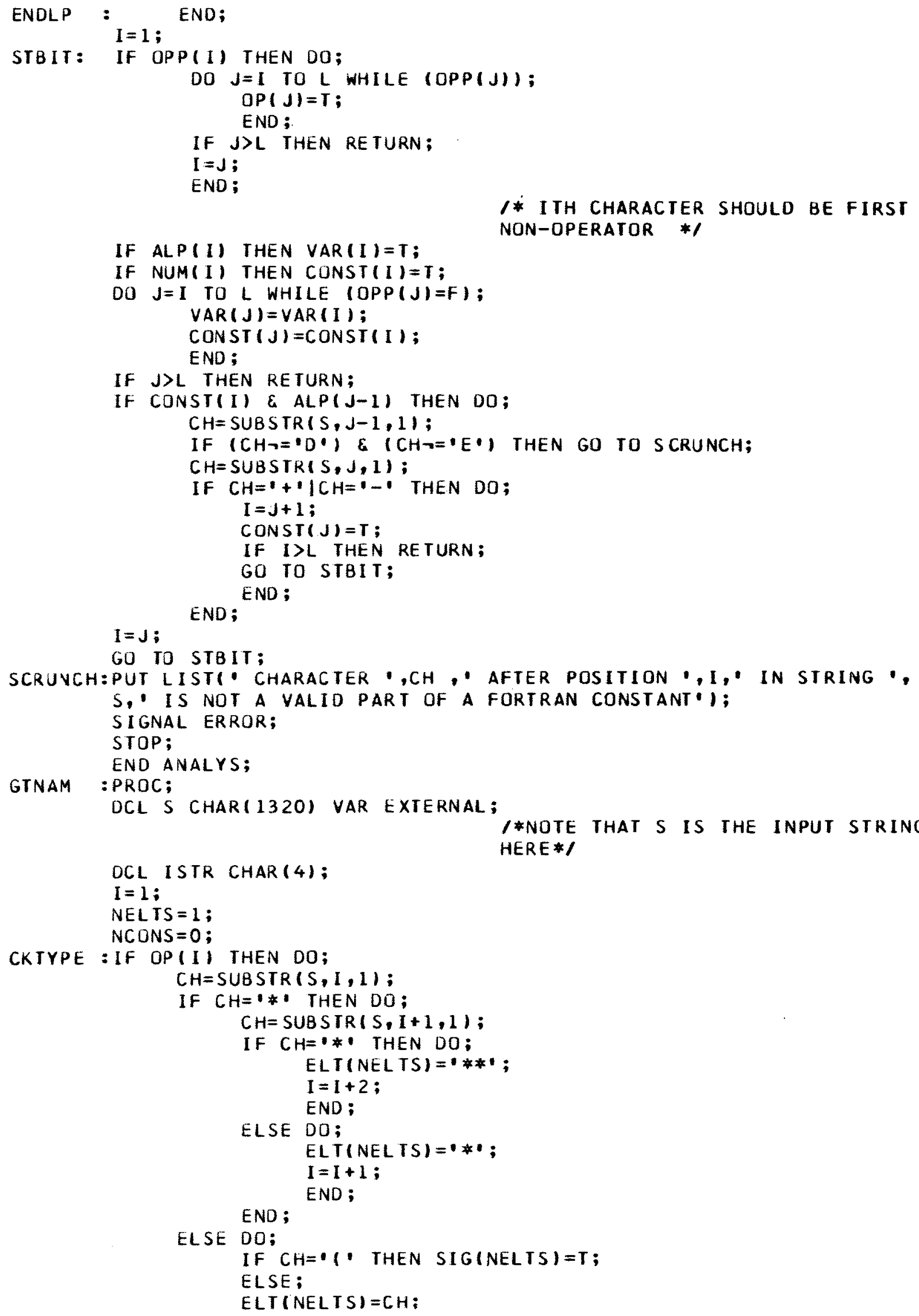




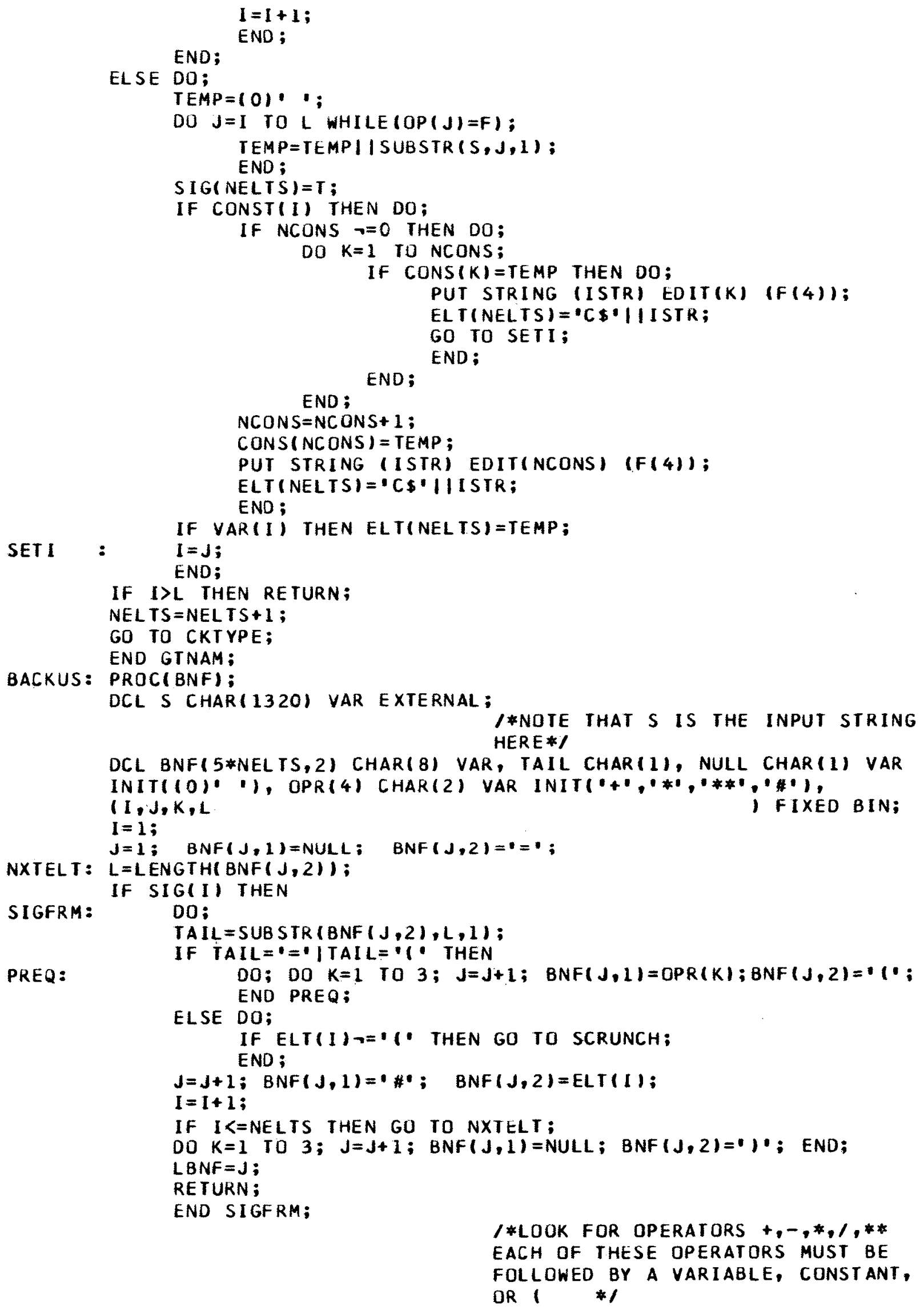

PREQ: DO; DO $K=1$ TO $3 ; J=J+l ; B N F(J, 1)=O P R(K) ; B N F(J, 2)=0(1 ;$ 
PLM: IF ELT(I)="+'|ELT(I)=:-' THEN

DO;

IF SIGII+II=F THEN GO TO SCRUNCH;

TAIL = SUB STR $(B N F(J, 2), L, 1)$;

ADPRN:

IF TAIL $=:=$ ' ETALL $\rightarrow=1$ ' THEN

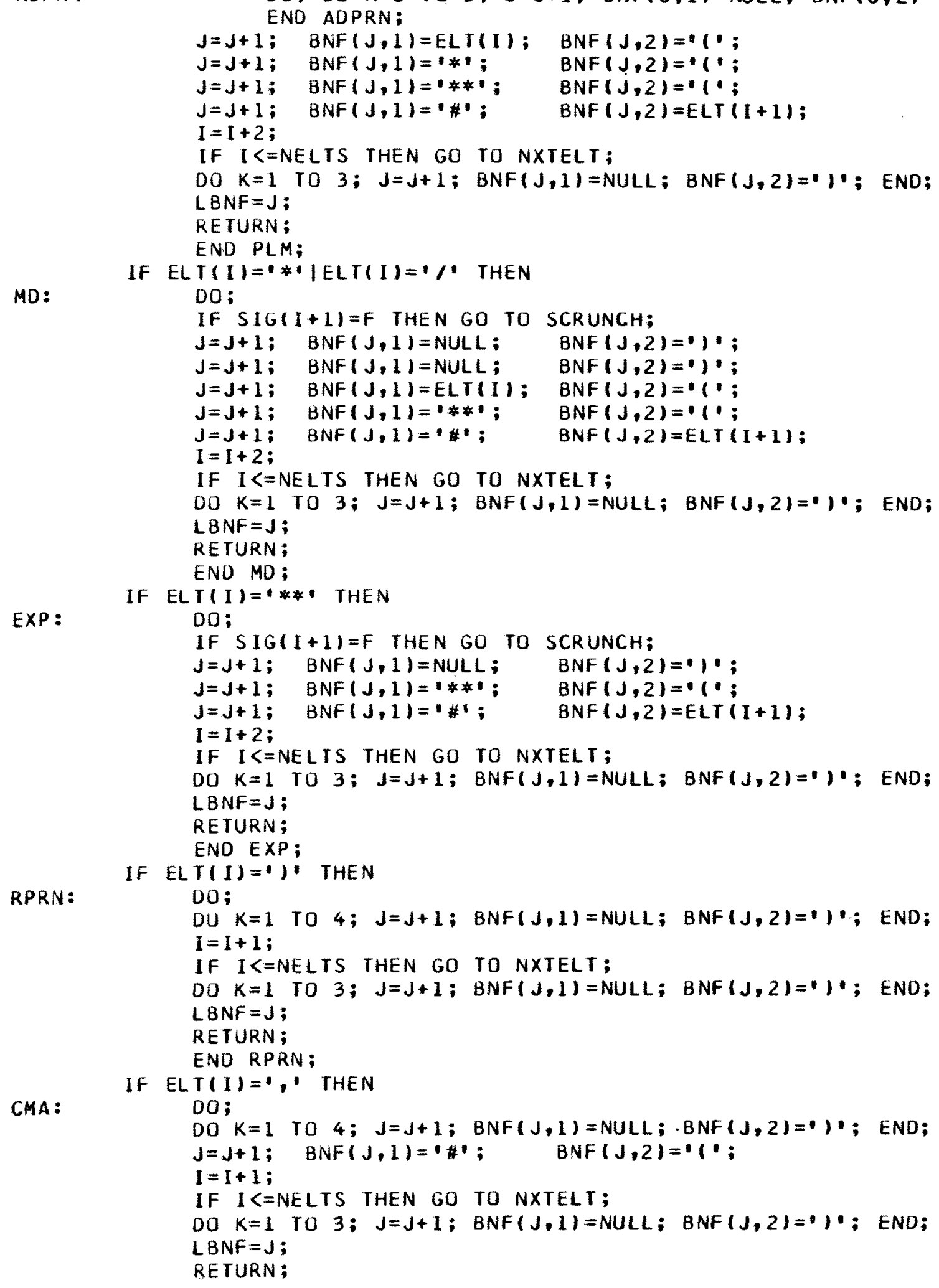

MD:

IF $\operatorname{ELT}(I)=1 * 1 \mid \operatorname{ELT}(I)=1 / 1$ THEN

DO;

CMA : DO;

DO $K=1$ IO $4 ; J=J+1 ; B N F(J, 1)=N U L L ; \cdot B N F(J, 2)=\bullet) \cdot E N D ;$

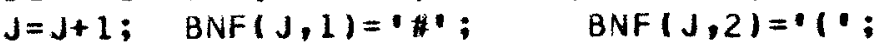




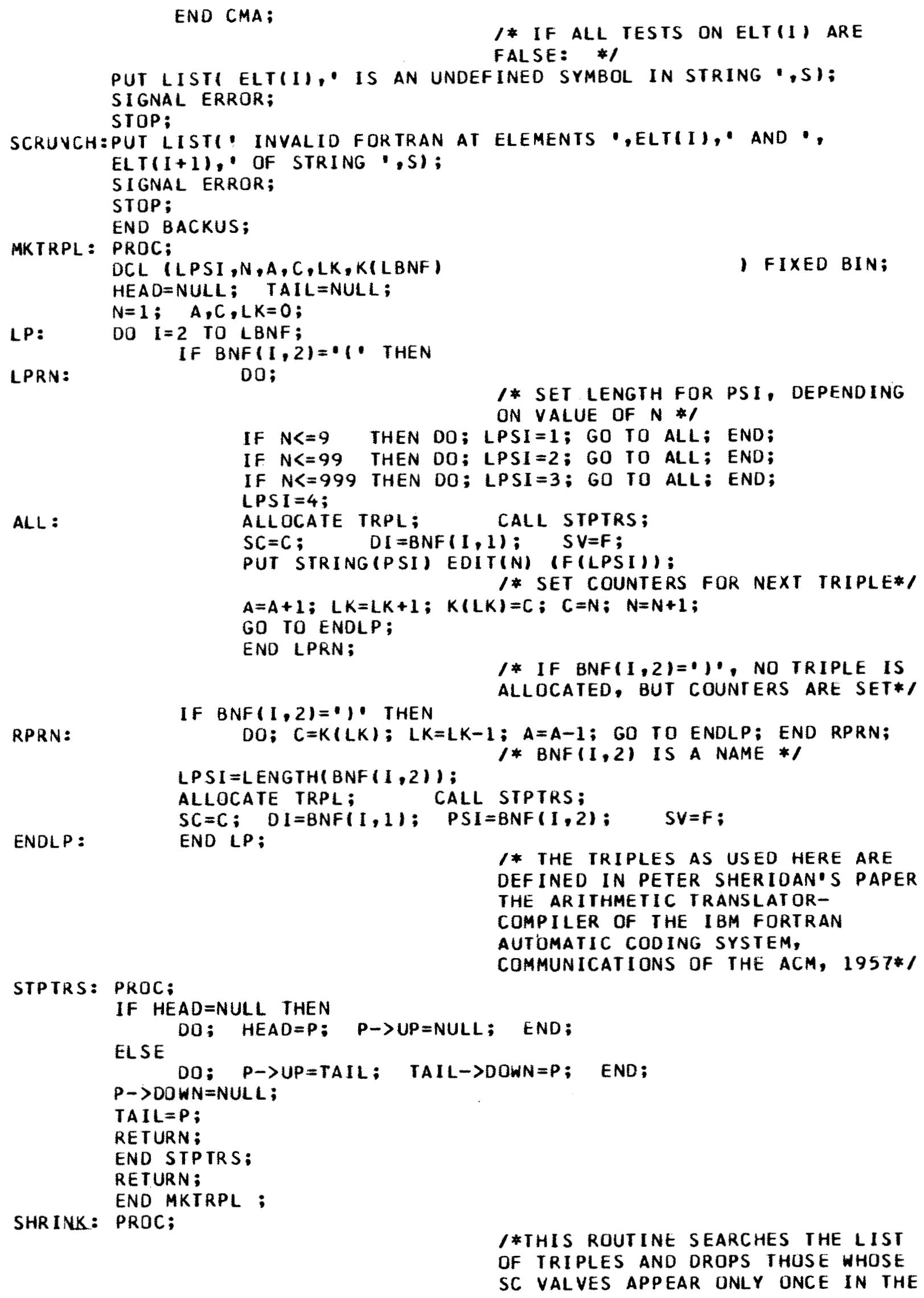

ALL :

ALLOCATE TRPL;

RPRN: 
DCL IPT1,PT2,PI3,PT4) PIR;

LIST IF THEIR OPERAIION IS NOT *I

PTI $=$ TAIL;

LPPT2: PT 2=PT1;

INCPT 2: PT2=PT2->UP;

IF PT2 $=$ NULL THEN

CKSC: $\quad$ DO;

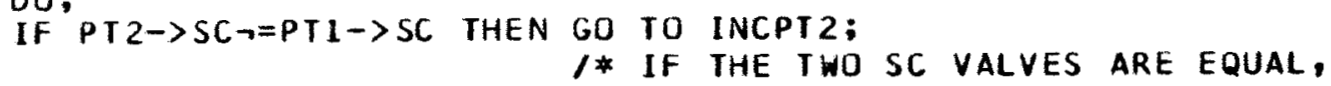

$\begin{array}{ll}\text { NXIPT1: } & \text { DO; } \\ \text { INCPTI: } & \text { PT } 1=P T 1->U P \text {; }\end{array}$

IF PT $1->S V=T$ THEN

IF PTI=NULL THEN RETURN;

IF $P$ T 1 $\rightarrow S V=T$ THEN GO TO INCPTI;

1* IF SV WAS SET TRUE IN AN EARLIER

GO TO LPPT2:

SCAN, OMIT THE SCAN NOW */

END NXTPT1;

IF PT $1->D I=$ - - THEN GO TO INCPT1;

/* DROP THE TRIPLE POINIED TO BY PTI *I

PT3=PT1; PT2=PT1->UP;

IF PT $2=N U L L$ THEN RETURN;

/* DO NOT OROP THE FIRST IRIPLE*/

PI 2->PSI =PTI->PSI ;

$P$ T $4=P$ T $1 \rightarrow D O W N$;

PT 2->DOWN=PT4;

IF PT $4=N U L L$ THEN TAIL=PI2;

ELSE PT 4- $>U P=P T 2$;

PT 1=PT2; FREE PT3->TRPL;

GO TO LPPT2;

SORT: PROC;

END SHRINK;

DCLIPT1, PT2, PI3,PT4, PT5

IPIR;

STPT1: PT2=PT1->DOWN:

IF PT $2=N U L L$ THEN RETURN:

IF PT2->SC=PT1->SC THEN DO; PTL=PT2; GO TO STPI1; END; /*SET PTI TO LAST TRIPLE IN SEGMENT *

STPT2: PT2=PT2->OOWN:

IF PT2=NULL THEN DO; PT1=PT1->DOWN; GO TO STPTI; END;

IF PT $1 \rightarrow S C \rightarrow=P T 2 \rightarrow S C$ THEN GO TO STPT2;

/*FOR EQUAL SCS, REARRANGE THE

LIST SO THAT THE TRIPLE POINIED TD BY PT 2 BECOMES THE NEXT ONE AFTER THE ONE POINTEO TO BY PT $1 * /$

PI3=PT2->UP; PT4=PT2->DOWN: PI5=PT1->DOWN:

IF PT 4=NULL THEN TAIL=PT3; ELSE PT4->UP=PT 3;

PT $2->D O W N=P T 5 ; \quad P T 5->U P=P T 2$;

PT3->DOWN=PI4; PI1->DOWN=PT2; PI2->UP=PII; PT1=PI2;

GO TO STPTI;

END SORT;

STORE: PROC;

PROC; $D$ DCL IPT 1, PT 2,PT3

$(I S, I, L N$

TMP CHAR(6),

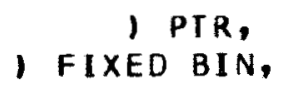




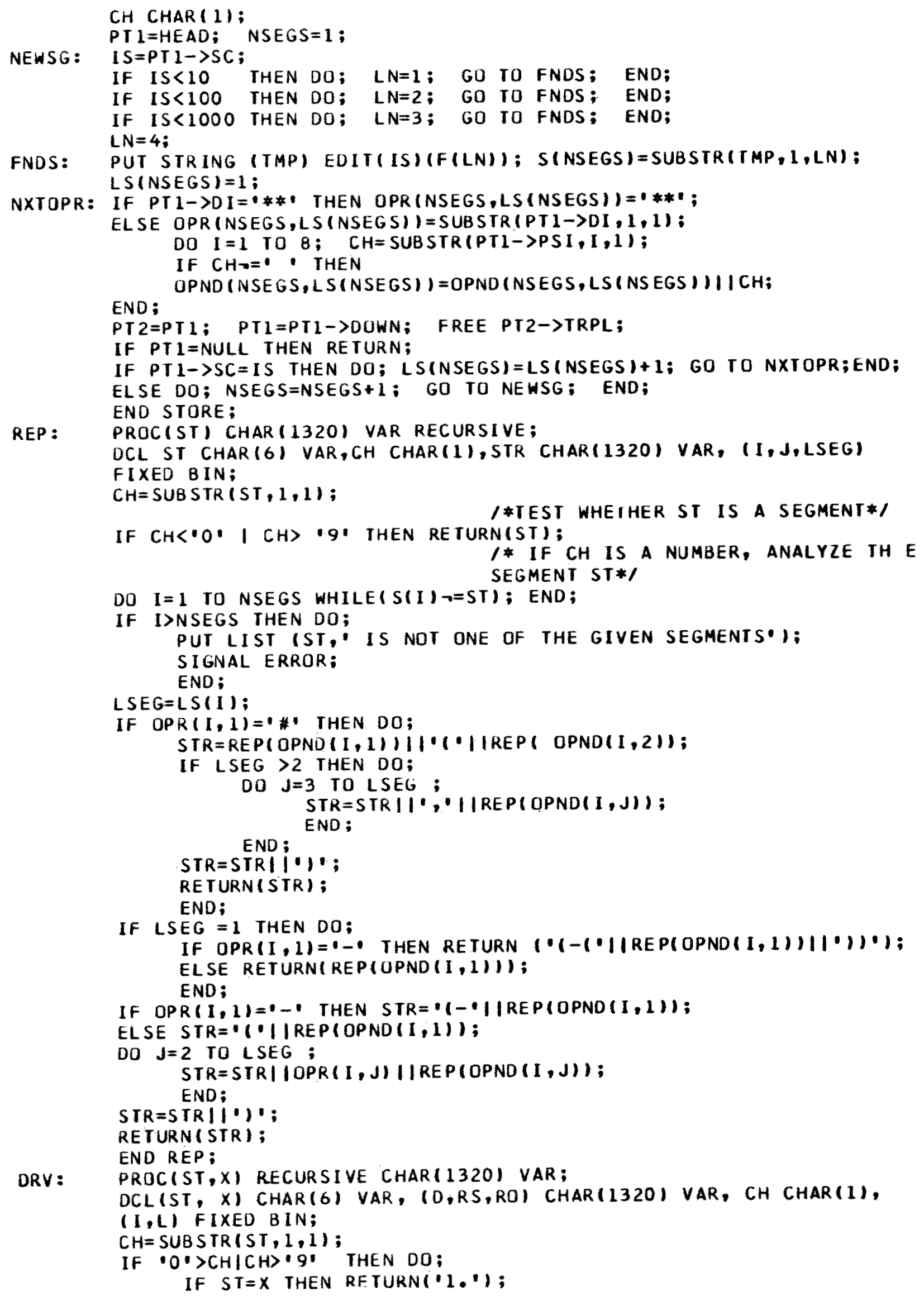




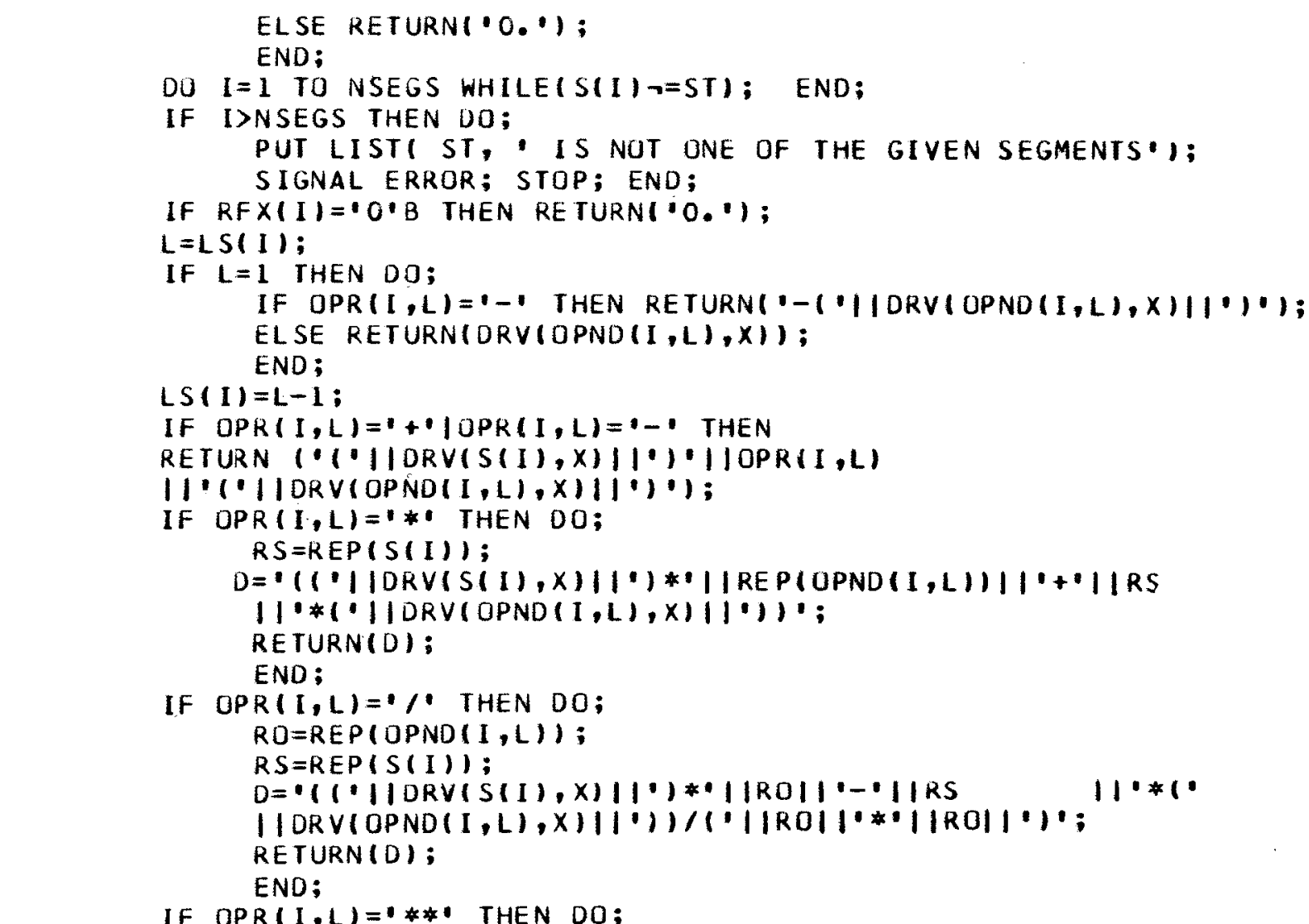

IF $\operatorname{OPR}(I, L)=+* \mathbb{U}^{\prime}$ THEN DO;

$R O=R E P(O P N D(1,1)) ; D=D R V(O P N D(1,1), X)$;

/*NOTE THE REVERSE ORDER, SINCE * IS DONE FROM RIGHT TO LEFT*I DO $K=2$ TO L; $\operatorname{OPND}(I, K-1)=\operatorname{OPND}(I, K) ; \operatorname{OPR}(1, K-1)=O P R(I, K) ; \quad E N D ;$ $R S=R E P(S(I))$;

$D=R O||$ *** ||RS||'*ALOG $(\cdot|| R O|| \cdot \mid *(\cdot|| O R V(S(I), X) \mid 1 \cdot)+\cdot$

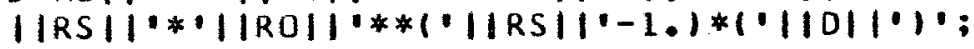

RETURN(D); END;

$\begin{array}{cc}\text { FUNC: } & \text { OPR }(I, 1)=0 \text { \# THEN } \\ & \text { DO; } \\ & \text { IF } L S(I)=1 \text { THEN }\end{array}$ IF LS(I) $=1$ THEN
RETURN(IFNDFCN(OPND(I, 1$)$, OPND $(1,2)) 11 \cdot *(\cdot 1 \mid \operatorname{DRV}(\operatorname{OPND}(1,2), x)$ (I) 1 ); END FUNC:

END DRV;

FNOFCN: PROC(LF,Z) CHAR(1320) VAR;

DCL (LF,Z) CHAR( 6 ) VAR;

I*THIS IS A LIST UF DERIVATIVES OF FORTRAN LIBRARY FUNCTIONS \#/

IF LF= 'EXP' IHEN RETURNI 'EXPI || REP(Z) $|1| 1)$;

IF LF='SIN' THEN RETURNI'COSI'IIREP(Z)|l' $1 \cdot 1$;

IF LF $=$ 'COS' THEN RETURNI'1-SIN('IIREP(Z)।1'11');

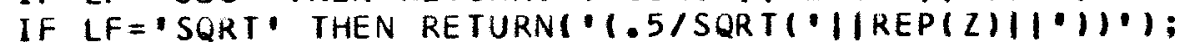

IF LF = 'TAN' THEN RETURNI'(1.0/COS('||REP(Z)||')**2)');

IF LF = 'COTAN' THEN RETURNI' $(-1.0 /$ SIN $(|| \operatorname{REP}(2) \mid 1 \cdot) * 2) \cdot 1$;

IF LF= 'ALOG' THEN RETURN $(1.01 \cdot|| R E P(Z 1) 1 \cdot 1)$;

IF $L F=$ 'ALOG 10 ' THEN RETURN(' $\left.(0.4342945 / 1 \mid \text { REP }(Z) \mid 1)^{\prime}\right) \cdot 1$;

IF LF ='ARSIN' THEN RETURNI'(1.0/SQRT(1.0-'||REP(Z)||'**2))!);

IF LF ='ARCOS' THEN RETURN('1-1.0/SQRT(1.0-'|IREP(Z) $11 \cdot * * 2)) \cdot 1$;

IF LF ='ATAN' THEN RETURN( $(1.0 /(1.0+\cdot|| \operatorname{REP}(Z) \mid 1 \cdot * 2)) \cdot 1$; 
IF LF='TANH' THEN RETURN('(1.0/COSHI'||REP(Z)|1')**2)!1;

IF LF='SINH' THEN RETURN('COSH('||REP(2) 11 !) 1 ;

IF LF='COSH' IHEN REIURN('SINH(')|REP(Z) 11,1$)$;

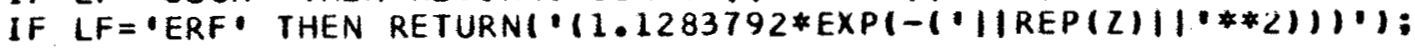

IF LF $=$ 'ERFC' THEN

RETURNI'(-1.1283792*EXP(-1:||REP(Z)|1**21))!;

PUT LIST ILF,' IS AN UNDEFINED FUNCTION $1 ;$ S SIGNAL ERROR; END FNDFCN;

RPLCNS: PROC(STR);

DCL (STR,STRA,STRB) CHAR(1320) VAR,DGT CHAR (8) VAR,CH CHAR(1),

I INDC, INDST, I, J,LN,L

INDC=INDEX(STR, 'C $\$$ '); IF INOC=0 THEN RETURN;

FNDDGT: $I N D S T=I N D C+2 ; \quad D G T=(O) ; ' ; \quad L N=L E N G T H(S T R)$; DO J=INDST TO LN; CH=SUBSTR(STR,J,I);

IF $0^{\circ} \angle=C H \& C H \angle=9^{\circ}$ THEN DO; DGT=DGT $\| C H ; G O$ IO ELP;END; IF $\mathrm{CH}==$ ' THEN GO TO FNDI;

ELP: $\quad$ END;

FNDI: $\quad$ DGT $=$ ' $\|D G T\| \cdot$;

GET STRING (DGT) LISTII):

STRA = SUBSTR ISTR, I, INDC-I IIICONS I I );

$L=L N-J+1$;

IF $L<=0$ THEN DO; STR=STRA; RETURN; END;

$S T R B=S U B S T R(S T R, J, L) ; \quad S T R=S T R A|| S T R B$;

INDC=INDEX(STRB, 'C\$'); IF INDC=O THEN RETURN;

INDC = INDC +LENGTH $(S T R A)$;

GO TO FNODGT;

END RPLCNS;

SIMP: PROC;

DCL $\left(P Y_{1}, P T 2\right.$

IPTR,

(K

IFIXED BIN,

I SMDRP,

LNI, IFDRPIBIT(8) INIT( $\left.0^{\circ} B\right)$, (TST, ONE INIT(1.0)) FLOAT BIN,

MKCONS RETURNS(CHAR $(8))$;

PT $1=$ TAIL:

HDCK: IF PTL=HEAD THEN GO TO LST;

1*DO NOT DROP AN INITIAL SEGMENT OF LENGTH ONE

FCONS: IF SUBSTR(PT1-PPSI,1,2) $\rightarrow={ }^{\circ} C{ }^{\circ}$ THEN GO TO LNS; I \#FIND SUBSCRIPT IN CONS \#/

1 *CONVERT TO FLUAT BIN

GET STRING(PT1-PPSI) EDIT(K) $(X(2), F(4))$; TST=CONS $(K)$; IF TST $=0.0$ THEN

ZRO: DO;

IF $P T 1->0 I=+^{+} \mid P T 1->0 I={ }^{\prime} \cdot$ THEN

PLM:

DO;

DRP:

CALL CKLN; IF LNI =F THEN

DO;CALL DTRPL; IF PTI=NULL THEN GO TO LST; /*IF THE SEGMENT IS NOT OF LENGTH 1. THE INITIAL TRIPLE MAY BE

GO TO FCONS; END; DROPPED FROM THIS SEGMENT */

IF PT $1=H E A D$ THEN GO TO LST;

/ *HERE THE LENGTH IS 1 */

CALL RPLRF; CALL DIRPL; GO TO HDCK;

END PLM;

IF PII->OI=** THEN

DO;CALL DSG;IF PT $1=N U L L$ THEN GO TO LST;

GO TO HOCK; END;

EXP:

IF $P I 1->D I=* * * 0$ THEN

DO; IF PIL=HEAD THEN DO; CALL DSG; GO TO LST;END;

PI2=PT1->UP: IF PT2 $>S C=P T 1->S C$ THEN 


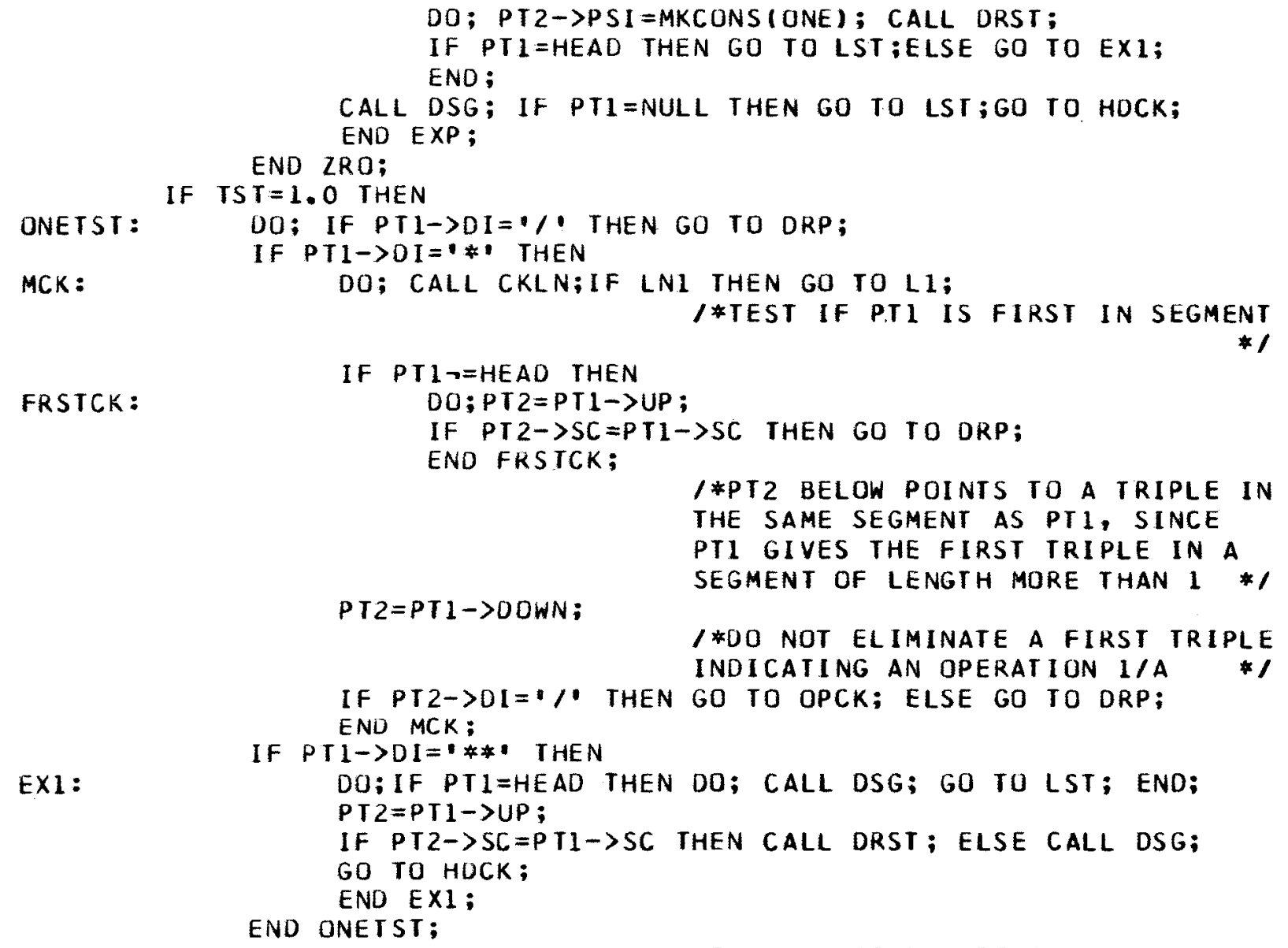

ONETST:

MCK :

FRSTCK :

EX1:

$$
\text { END ONETST; }
$$


PTU->DOWN=PTD; PTI=PTU; RETURN;

END OTRPL;

DRST: PROC:

I*THIS ROUTINE FREES IRIPLES FROM

PTI DOWN TO THE NEXI SEGMENT*/

DCL (PT 2,PDRP, PKP

IPTR,

SCTST FIXED BIN;

SMDRP $=T$;

PKP $=P T 1 \rightarrow$ I ; SCTST=PT1 $>S C ; P D R P=P T 1$;

FRTR: $\quad$ PT $2=P D R P \rightarrow>D O W N$; FREE PORP->TRPL;

IF PT2=NULL THEN

DO; TAIL =PKP; PKP $\rightarrow D O W N=P T 2 ;$ PT $1=P K P ;$ RETURN; END;

IF PT 2->SC=SCTST THEN DO; PDRP=PT2; GO TO FRTR; END;

$P T 2->U P=P K P$;

/ *RESET POINTERS

IF PKP=NULL THEN HEAD=PI2; ELSE PKP->DOWN=PT2;

PT I =PKP;

RETURN;

END DRST;

DSG: PROC:

DCL (PT2,PKP) PTR,SCTST FIXED BIN;

$S C T S T=P T 1 \rightarrow S C$; $P K P=P T 1$;

SPKP: $\quad$ PKP $=$ PKP $\rightarrow \triangle U$;

1*IF THIS IS THE FIRST SEGMENT,

IF PKP $=$ NULL THEN

KEEP THE FIRST IRIPLE *I

DO; HEAD->PSI =PI I PPSI ;

CALL CKLN; IF LNI THEN DO; PTI=NULL; RETURN; END;

PT $1=H E A D->D O W N$; GO TO DRPSG; END;

IF PKP- $>S C=S C T S T$ THEN GO TO SPKP:

PT $2=P K P->D O W N ;$ PT2->PSI=PI1 $>$ PSI; PTI=PT2; CALL RPLRF;

DRPSG: CALL DRST;

RETURN:

END DSG;

RPLRF: PROC;

OCL PI2 PTR, (NSG, SCTST) FIXED BIN,CH CHAR (1);

I*REPLACE REFERENCES TO A SEGMENT PT1 $\rightarrow$ SC BY PT 1->PSI

*I

PT2=PT1 $\rightarrow$ UP; SCTST=PT1 $>S C$;

CKPSI: CH=SUBSTR(PI2->PSI,1,1); IF $10 .<=C H E C H \angle=19$, THEN

DO: GET STRINGIPI2->PSI) LISTINSG);

IF NSG $=S C$ TST THEN PT2->PSI=PT1->PSI;

END;

PT2=PT2->UP; IF PT2 $=$ NULL THEN GU TO CKPSI;

RETURN;

END RPLRF;

CKLN: PROC;

$\operatorname{LN} 1=\mathrm{T}$;

IF PTI=TAIL IHEN GO TO CKUP;

PT $2=P$ T 1->DOWN:

IF PT 2->SC $=P T 1->S C$ THEN DO; LN1=F; RETURN; END;

CKUP: IF PT $1=$ HEAD THEN RETURN;

$P T 2=P T 1->U P$; IF PI2->SC=PT1->SC THEN LNI=F;

RETURN; END CKLN;

CKOPN: PROC;

DCL (OP 1,OP 2$)$ CHAR (2), (C2 FLOAT, K2 FIXEO) BIN, PTST PIR;

PT $2=P$ T 1->UP;

STPT2: IF PT 2=NULL THEN RETURN;

IF $P$ T 2->SC $\rightarrow=P T 1->S C$ THEN RE TURN;

IF SUBSTR(PT2->PS1,1,2) = CC\$ THEN

DO; IF PT2->DI=?**! THEN RETURN; 
/*NOTE * IS NOT COMMUTATIVE *I END;

ELSE DO; PT2=PT2->UP; GO TO STPT2; END;

$O P 1=P T 1 \rightarrow D I ; O P 2=P T 2->D I ;$

GET STRING(PT2->PSI) EDII(K2) $(\times(2), F(4)) ; C 2=C O N S(K 2)$;

I*IF ADDITION OR SUBTRACTION OF CONSTANTS IS INOICATED, PERFORM

THE OPERATION

IF $O P 1=--$. THEN DO; TST=-TST; GO TO TSTSB; END;

IF $O P 1 \rightarrow=++\cdot$ THEN GO TO MDTST;

TSTSB: IF OP $2=\cdot-1$ THEN C2 $=-C 2$;

$\mathrm{C} 2=\mathrm{C} 2+\mathrm{TST}$;

IF $C 2<0.0$ THEN DO; PT2->DI='-';C2=-C2;END; ELSE PT2->DI='+';

GO TO DRPTR;

/ IF * OR / is. INDICATED,

PERFORM THE OPERATION

MOTST: IF OP I= / THEN DO; TST=1.0/TST; GO TO DOP2; END;

IF OP $1 \neg=* *$ THEN GO TO EXPTST;

DOP 2: IF OP $2=1 /$ THEN C $2=1.0 / \mathrm{C} 2$;

C $2=C 2 * T S T ; P T 2->D I=* * \cdot$; GO TO DRPTR;

EXPTST: IF OP $1 \neg=\cdot * *$ ' THEN RETURN;

PIST $=$ PT $1->D O W N$;

* if the LAST operation in a SEGMENT IS CONSTANT \# CONSTANT, PERFORM IT

IF PIST $\rightarrow S C=P I 1->S C$ THEN RETURN;

$C 2=C 2 *$ TST;

DRPTR: CALL DTRPL; IFDRP $=\mathrm{T}$;

PI 2->PSI $=$ MKCONS $(C 2)$;

I*REPLACE PT2 $\rightarrow$ PSI by NEW VALUE* I

RETURN;

END CKOPN;

END SIMP;

COUNT: PROC;

DCL ILSS, SCTST) FIXED BIN, PII PTR;

PT $1=H E A D$; NSEGS $=1$; LMAX $=0$;

NWSG: $\quad$ LSS $=1$; SCTST=PT1 $>S C$;

NWPT: $\quad$ PT $1=P T_{1} \rightarrow>$ DOWN; IF PT $1=$ NULL THEN RETURN;

If $P T 1->S C=S C$ TST THEN DO; LSS $=L S S+1 ; G O$ TO NWPI; END;

NSEGS=NSEGS+1; IF LSS $>$ LMAX THEN LMAX=LSS ; GO TO NWSG;

CKRF: PROC;

END COUNT;

ALLOCATE RFX(NSEGS) BIT(1); RFX $=0.0 \cdot B$;

DO $I=N S E G S$ TO 1 BY -1 ;

DO $J=1$ TO LS(I); $/$ EXAMINE OPERANDS IN THE ITH SEGMENT

IF OPND $(I, J)=X$ THEN DO;RFX(I) $=: 1$ 'B;GO TO NXII;END;

$C H=S U B S T R(O P N D(I, J), 1,1)$;

IF $\cdot \mathrm{O}^{\circ}<=\mathrm{CH} \& \mathrm{CH}<=99$ ' THEN

$/$ SEE IF THE SEGMENT OPND $(I, J)$

REFERS TO $X$

DO;DO $K=1$ TO NSEGS WHILEIOPNDII,J) $=S(K))$; END;

IF RFX(K) THEN DO;RFX(1)=11.B;GO TO NXTI;END;

END;

END;

NXTI:

END;

RETURN;

END CKRF;

END DERV; 


\section{APPENDIX D}

Listings of Cataloged Procedures VMMCLG and VMMLG

VMMC LG

I PROC VMMREGN=350K, GOREGN=350K, EDTOPTS $=$ 'LIST, MAP', EDTREGN=260K, I/ RUNREGN=260K, REGN=260K, OPTI ONS =, LSI ZE = $1232 \mathrm{~K}, 100 \mathrm{~K})$ " / V VMMTR EXEC PGM=IEFBR 14, REGION=EVMMREGN

/ /PRGG DD DSNAME $=C 145 . B 12533 . T 7120$. SYSLMOD (VMMTR), DISP $=S H R$

$/ / G O$ EXEC PGM =*.VMMTR.PRGG,REGION= EGOREGN

//SYSPRINT DD UNIT=(CTC, DEFER), DCB=(RECFM=FBA,LRECL $=133, B L K S 12 E=798)$

$/ /$ SYSPNCH DD UNI $T=(C T C$, DEFER $), D C B=(R E C F M=F, B L K S I Z E=80)$

$/ / R D F$ ILE DD DSNAME $=C 145 . B 12533 . T 7120$. SOURCEISKFCNI, OISP = SHR

$/ / C D F I L E$ DD DSNAME = EGPDAT,DISP = (NEH,PASS, DELETE),

I/ SPACE $=(C Y L,(1,1), R L S E)$,

$1 / U N I T=2314, D C B=(R E C F M=F B, L R E C L=80, B L K S I Z E=7200)$

//PROG DD DSNAME $=\varepsilon \& F O R T, D I S P=(N E W, P A S S, D E L E T E), S P A C E=(C Y L,(1,1), R L S E)$,

$1 /$ UN I T $=$ (DISK, SEP =CDFI LEI, DCB =*. CDF ILE

//FTH EXEC PGM=FORTRANH, REGION=EREGN,PARM=' \&OPTIONS , COND $=(5, L T, G O)$

/ / SYSPUNCH DD UN I $T=(C T C$, ,DEFER $), O C B=(R E C F M=F B, L R E C L=80, B L K S I Z E=80)$

//SYSPRINT DD UNIT=(ITC, DEFER),DCB=(RECFM=FBA, LRECL $=133, B L K S I Z E=798)$

$1 / S Y S L I N$ DD DSNAME $=E E S Y S L I N, D C B=(R E C F M=F B, L R E C L=80, B L K S 12 E=3200)$,

$1 /$ DI $S P=(N E W, P A S S, D E L E T E), S P A C E=(3200,(4), 10), R L S E)$, UNIT $=2314$

//SYSUT 1 DD DSN $=E E S Y S U T 1, S P A C E=(C Y L,(1,1)), U N I T=(D I S K, S E P=S Y S P R I N T)$

/ /SYSIN DO DSNAME = EGFORT, DISP=(OLD, DELETE, DELETE)

$1 /$

DD DDNAME =CARDS

//EDT EXEC PGM $=L I N K E D I T, C O N D=(5, L T, F T H)$,

$1 / \quad P A R M=$ ' EEDTOPTS, SI ZE = ELSIZE', REGION=EEDTREGN

$/ / S Y S P R I N T$ DD UNIT $=(C T C$, DEFER $), D C B=(R E C F M=F B A, L R E C L=121, B L K S I Z E=726)$

//SYSLIN DD DSNAME =*.FTH.SYSLIN,DISP= (OLD,DELETE)

$/ 1$ DD DSNAME $=C 145 . B 12533 . T 7120 . E D T$, OISP $=$ SHR

$1 /$ DD DDNAME=SYSIN

$/ / S Y S L I B$ DD DSNAME $=S Y S I . A M D L I B, D I S P=S H R$

$1 /$ DD DSNAME $=S Y S 1 . F O R T L I B, D I S P=S H R$

//SYSUT 1 DD SPACE $=(3072,(20,10)$, RL SE $)$, UNI $T=D I S K, D C B=B L K S I 2 E=6144$

$/ /$ SYSLMOD DD UNIT =DISK, SPACE $=(3072,(50,10,1), R L S E), D I S P=(, P A S S)$,

$1 / \quad$ DSNAME $=\varepsilon \varepsilon G(D V D N)$

$/ / L I B$ DD DSNAME $=C 145 . B 12533 . T 7120 . S Y S L M O D, D I S P=S H R$

I/RUN EXEC PGM=*.EDT.SYSLMOD,COND $=(15, L T, F T H),(5, L T, E D T))$, $1 /$ REGION= GRUNREGN

$/ / C D F I L E$ DD DSNAME $=8$ EDATA, DI SP $=($, , DELETE $)$, UNIT $=2314$,

$1 / \quad S P A C E=(C Y L,(1,1), R L S E), D C B=(R E C F M=F B, L R E C L=3), B L K S I Z E=7200)$

//FTO6F001 DO UNI $T=(C T C,, D E F E R), D C B=(R E C F M=F B A, L R E C L=133, B L K S I 2 E=798)$

$/ / F T O 7 F O O 1$ DD UNI $T=(C T C, D E F E R), D C B=(R E C F M=F, B L K S I Z E=80)$

$/ / S Y S P R I N T$ DD UNIT $=(C T C$, , DEFER), DC $B=(R E C F M=F B A, L R E C L=133, B L K S I Z E=798)$

$/ / F T 05 F 001$ DD DSNAME =*.CDFILE, VOLUME =REF=* . CDFILE,

/ $/$. DISP $=$ (OLD,DELETE, DELETE)

/ /TEMP DD DSNAME $=\varepsilon E T D A T$, OI $S P=($, , DELETE $), U N I T=(2314, S E P=(D F I L E)$,

11 SPACE $=(C Y L,(1,1), D C B=*$. CDFILE

$/ / X T F I L E$ DD DSNAME $=\varepsilon \& X D A T, D I S P=($, DELETE $)$, UNIT $=(2314, S E P=C D F I L E)$,

$11 \quad S P A C E=(C Y L,(1,1), R L S E), D C B=(R E C F M=F, B L K S I Z E=80)$

$/ / F T O I F O O I$ DD DSNAME =*. XTFILE, VDLUME =REF =*.XTFILE,

/ $/$ DISP $=($ OLD, DELETE, DELETE)

$/ / S T O R$ DD DSNAME $=\& \& S D A T, D I S P=($, , DELETE, UNIT $=2314$,

$11 \quad$ SPACE $=(C Y L,(1,1)), D C B=*$.CDFILE

$/ /$ SYSIN DD DSNAME $=$ E EPDAT, DI SP $=($ OLD, DELETE, DELETE),

$1 /$ VOLUME $=$ REF $=*$.GO.CDFILE

$11 *$ If TROUBLE,SEE M. GABRIEL, 221-B227

100000010

00000020

00000030

00000040

00000050

00000060

00000070

00000080

00000090

C00000100

00000110

00000120

00000130

00000140

00000150

00000160

00000170

00000180

00000190

00000200

00000210

C00000220

00000230

00000240

00000250

00000260

00000270

00000280

00000290

00000300

000000310

00000320

00000330

C00000340

00000350

00000360

00000370

00000380

00000390

00000400

00000410

00000420

00000430

00000440

00000450

00000460

00000470

00000480

C00000490

00000500

00000510

00000520

00000530 
VMMLG

/ PROC EDTOPTS $=$ 'LIST,MAP', EDTREGN $=260 \mathrm{~K}, \mathrm{LSI} Z \mathrm{ZE}={ }^{\circ}(232 \mathrm{~K}, 100 \mathrm{~K})^{\prime}$

$1 /$ GOREGN=26OK

$/ / E O T$ EXEC PGM=LINKEDIT,PARM='EEDTOPTS,SIZE=\&LSIZE', REGION=EEDTREGN

$/ / L$ IB DD DSNAME $=C 145 . B 12533 . T 7120$. SYSLMOD, DI SP $=S H R$

/ /SYSPRINT DD UNI $T=(C T C,, D E F E R), D C B=(L R E C L=121, B L K S I Z E=1573)$

/ /SYSUT 1 DO SPACE $=(3072,(20,10)$, RLSE $)$, UNIT $=$ DI SK, DCB $=B L K S I 2 E=6144$

I/SYSLIB DD DSNAME = SYSI. AMDLIB,DISP $=$ SHR

$1 /$ DD DSNAME $=$ SYS I.FORTLI B, DI SP $=$ SHR

//SYSLMOD DD UNIT $=D I S K, S P A C E=(3072,(50,50,1), R L S E), D I S P=(M O D, P A S S)$,

$1 / \quad D S N A M E=\varepsilon \& G(G), D C B=B L K S I Z E=6144$

//SYSLIN DD DSNAME $=C 145 . B 12533 . T 7120 . E D T, D I S P=S H R$

$1 /$ DD DDNAME $=$ SYSIN

/ /GO EXEC PGM=*.EDT . SYSLMOD, COND $=(5, L T, E D T), R E G I O N=E G O R E G N$

/ /FT06F001 DD UNI $T=(C T C$, ,DEFER $), D C B=(R E C F M=F B M, L R E C L=133, B L K S 12 E=1596)$ //FT07F001 DD UNIT $=(C T C$, ,DEFER)

$/ / C D F I L E$ DO DSN $=6 E D A T A, U N I T=D I S K, S P A C E=(C Y L,(1,1), R L S E)$,

$1 / \quad D C B=(R E C F M=F B, L R E C L=80, B L K S I Z E=7200), D I S P=($, DELETE

$/ /$ TEMP DD DSN $=\varepsilon \varepsilon T D A T, U N I T=(2314, S E P=C D F I L E), S P A C E=(C Y L,(1,1)$,

$1 / \quad D I S P=1,, D E L E T E), D C B=*$, CDFILE

$/ / X T F I L E$ DD $D S N=\varepsilon E X D A T, U N I T=(2314, S E P=C D F I L E), S P A C E=(C Y L,(1,1), R L S E)$,

11 $D I S P=(, D E(E T E), D C B=(R E C F M=F, B L K S I Z E=80)$

/ /STOR DD DSNAME $=\& E S D A T, D I S P=($, ,DELETE $)$, UNI $T=2314$,

II SPACE $=1 C Y L,(1,1)), D C B=*$. CDFILE

//FTOSF001 DO DSN=*.CDFILE, VOL =REF =*.CDFILE, DISP=(OLD, DELETE, DELETE)

$/ / F T O I F O O 1$ DO OSN $=*$. XTFILE, VOL $=R E F=*$. XTFILE, DISP $=(O L D, D E L E T E, D E L E T E)$

/ /SYSPRINT DD UN I $T=(C T C,, D E F E R), D C B=(R E C F M=F B M, L R E C L=121, B L K S I 2 E=1573)$

11* IF TROUBLE,SEE M. GABRIEL, 221-B227

000000010

00000020

00000030

00000040

00000050

00000060

00000070

00000080

C00000090

00000100

00000110

00000120

00000130

00000140

00000150

500000160

00000170

C00000180

00000190

C00000200

00000210

$\mathrm{C} 00000220$

00000230

00000240

00000250

00000260

00000270 
APPENDIX E

Sample Function and Its Derivatives

FUNCTION IS

$A 1 * \operatorname{EXP}(||-B|+X| / C 1) * * 2 \mid+$

$A 2 * \operatorname{EXP}(1(-B 2+X) / C 2) * * 2)+$

$A 3 * \operatorname{EXP}(\mid(-B 3+X \mid / C 3) * 2)+$

A4*EXP $((1-B 4+X) / C 4) * 2)+$

$A 5 * \operatorname{EXP}(|(\mid-B 5+X) / C 5| * * 2)+$

$A 6 * \operatorname{EXP}((1-B 6+X) / C 6) * * 2) *$

$A 7 * \operatorname{EXP}((1-B 7+X) / C 7) * 2)+$

$A B * \operatorname{EXP}((1-B 8+X) / C 8) * * 2)+$

$A 9 * \operatorname{EXP}((1-89+X) / C 9) * * 2)+$

$A 10 * \operatorname{EXP}((1-B 10+X) / C 10) * * 2)$

DER IVATIVE OF FUNETION WITH RESPECT TO AL IS EXP $(((1-B)+X) / C(1) * 2))$

DER IVATIVE DF FUNETION WITH RESPECT TO BI IS

$(A 1 *(\operatorname{EXP}(()(-B 1+X) / C 1) * 2)) *(2 *(1-B 1+X) / C 1) *((1-(1)) * C 1) /.(C 1 * C 1))))$

DERIVATIVE OF FUNCTION WITH RESPECT TO CI IS

$(A) *(\operatorname{EXP}(()(-B)+X) / C 1) * 2)) *(2 *((-B)+X) / C 1) *((-()-B 1+X))) /(C 1 * C 1))))$ 


\section{ACKNOWLEDGMENT}

I wish to thank J. R. Gabriel for suggesting the use of Sheridan's methods for syntax analysis.

\section{REFERENCES}

1. Gabriel, Marian, Special-purpose Language for Least Squares Fits, ANL-7495 (Sept 1968).

2. Davidon, William C., Variable Metric Method for Minimization, ANL-5990 (Rev. 2) (Feb 1966).

3. Sheridan, Peter B., The Arithmetic Translator-Compiler of the IBM FORTRAN Automatic Coding System, Comm. ACM. 2 (Feb 1959), pp. 9-21.

4. Garbow, Burton S., Variable Metric Minimization, Argonne National Laboratory, Applied Mathematics Division Internal Report Program Z013 (unpublished), August 9, 1965. 